\title{
Fund Concessional Financial Support For Low-Income Countries-Responding To The Pandemic
}




\section{INTERNATIONAL MONETARY FUND}

\section{IMF POLICY PAPER}

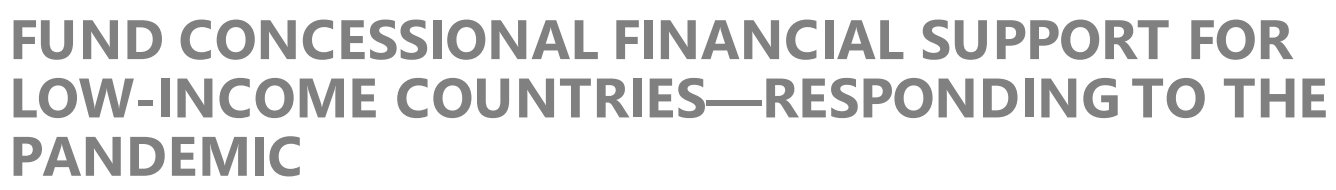

IMF staff regularly produces papers proposing new IMF policies, exploring options for reform, or reviewing existing IMF policies and operations. The following documents have been released and are included in this package:

- A Press Release summarizing the views of the Executive Board as expressed during its July 14, 2021 consideration of the staff report.

- The Staff Report, prepared by IMF staff and completed on June 30, 2021 for the Executive Board's consideration on July 14, 2021.

- A Staff Supplement 1: Supplementary Information on the Proposed Subsidy Reserve Account and Deposit and Investment Account.

- A Staff Supplement 2: Supplementary Information and Proposed Decisions

- A Staff Supplement 3: Additional Background Information

The IMF's transparency policy allows for the deletion of market-sensitive information and premature disclosure of the authorities' policy intentions in published staff reports and other documents.

Electronic copies of IMF Policy Papers

are available to the public from

http://www.imf.org/external/pp/ppindex.aspx

International Monetary Fund

Washington, D.C.

(C) 2021 International Monetary Fund

CInternational Monetary Fund. Not for Redistribution 


\title{
The IMF Approves Policy Reforms and Funding Package to Better Support the Recovery of Low Income Countries From the Pandemic
}

\author{
FOR IMMEDIATE RELEASE
}

- The reforms approved by the IMF's Executive Board seek to ensure that the Fund can flexibly support Low Income Countries (LICs') financing needs during the pandemic and the recovery while continuing to provide concessional loans at zero interest rates.

- The centerpiece of the approved policy reforms is a 45 percent increase in the normal limits on access to concessional financing, coupled with the elimination of hard limits on access for the poorest countries. These higher access limits will facilitate the provision of more concessional support to LICs with strong policies and large balance of payments needs.

- The Executive Board also approved a two-stage-funding strategy to cover the cost of pandemic-related concessional lending and support the sustainability of the Poverty Reduction and Growth Trust (PRGT). The first stage of the strategy aims to secure SDR 2.8 billion in subsidy resources (to support zero interest rates), and an additional SDR 12.6 billion in loan resources which could be facilitated by the "channeling" of SDRs.

\section{Washington, DC - July 22, 2021}

The Executive Board of the International Monetary Fund (IMF) approved on July 14, 2021 a set of reforms to the Fund's concessional lending facilities to better support Low Income Countries' (LICs) during the pandemic and the recovery. The Executive Board also approved an associated funding strategy to support the long-term sustainability of the Poverty Reduction and Growth Trust (PRGT). These reforms are set to ensure that the Fund has the capacity to respond flexibly to LICs' needs over the medium term while continuing to provide concessional loans at zero interest rates.

Fund lending to LICs increased dramatically in 2020 — an eightfold increase from average lending levels in 2017-2019 - and is projected to continue at elevated levels for several years, as LICs seek financial assistance to help them respond to and recover from the pandemic. The bulk of future financial assistance is expected to be provided through multi-year lending arrangements - a shift from 2020 , when most assistance was provided through the Fund's emergency financing facilities.

The centerpiece of the ap proved policy reforms is a 45 percent increase in the normal limits on access to concessional financing, coupled with the elimination of limits on access to the poorest countries provided their economic programs meet the requirements for obtaining above-normal access. These higher access limits will allow provision of more concessional support to countries with large balance of payments needs that are implementing strong economic programs to restore inclusive growth, while maintaining sustainable debt positions.

To support concessional financing to LICs through the PRGT, grant resources are needed to cover the costs associated with providing zero-interest lending. In 2019, the PRGT was assessed to have sufficient resources to finance interest subsidies on the Fund's concessional 
lending on a self-sustaining basis over the long term. However, the volume of pandemic-linked lending - already provided or expected to be provided in the next few years - far exceeds what had been anticipated or previously recorded, creating a sizable shortfall in the necessary resources.

The first stage of a two-stage funding strategy to strengthen PRGT finances wo uld seek to raise SDR 2.8 billion in subsidy resources (to support zero interest rates), relying on a combination of Fund internal resources and voluntary contributions raised from the Fund's economically stronger members. A further SDR 12.6 billion in PRGT loan resources would also need to be mobilized, which could be facilitated by the "channeling" of existing and new SDRs. The second stage, set for 2024-25, would seek a lasting solution to the financing of the Fund concessional lending model, informed by an updated assessment of likely demand for Fund financing from LICs.

\section{Executive Board Assessment ${ }^{1}$}

Executive Directors supported the proposed package of reforms to the concessional financing facilities and the associated two-stage funding strategy to ensure sustainability of concessional lending.

Directors agreed that low-income countries (LICs) have been particularly hard hit by the COVID-19 pandemic and would face significant challenges in achieving sustainable inclusive growth in the coming years. They noted that the Fund has responded quickly to provide financial support to LICs at an unprecedented scale, and, looking ahead, should continue supporting countries that are implementing strong economic programs aimed at recovering from the pandemic and raising living standards.

Directors were in broad agreement that the proposed reform package would better position the Fund to respond to the needs of LICs. They supported the proposed increases in limits on normal access to resources of the Poverty Reduction and Growth Trust (PRGT) and the removal of the limits on exceptional access for the poorest countries. Some Directors, however, expressed concern about entirely removing the hard caps on PRGT exceptional access for poorer LICs. Some Directors suggested that the new access limits should include a sunset clause set to coincide with the time of the next full review of concessional facilities.

Directors generally agreed that higher access limits would provide the Fund with the flexibility to increase concessional financial support for countries with strong reform programs.

However, they emphasized that access levels in individual Fund-supported programs should continue to be based on a case-by-case assessment applying the established access criteria, including balance of payments needs, strength of economic program, and capacity to repay the Fund. In this context, most Directors underscored the importance of maintaining the Fund's established role in catalyzing financing from other sources, while noting that the Fund must respond to its membership's needs in line with its mandate, particularly during crisis times. They supported the proposed simplification of access norms, while emphasizing that norms are neither a floor nor a ceiling on access levels in individual program cases.

With many LICs facing substantial debt vulnerabilities, Directors agreed that program design needs to pay close attention to the expected evolution of debt burdens and the risk of

\footnotetext{
${ }^{1}$ At the conclusion of the discussion, the Managing Director, as Chairman of the Board, summarizes the views of Executive Directors, and this summary is transmitted to the country's authorities. An explanation of any qualifiers used in summings up can be found here: http://www.IMF.org/external/np/sec/misc/qualifiers.htm.
} 
countries falling into debt distress. Higher levels of lending would mean higher credit risk to the Fund and a corresponding need for more in-depth analysis of capacity to repay the Fund. Directors supported the proposal to give enhanced attention to debt dynamics and capacity to repay in staff analysis and in program documents, along the lines discussed in Annex VI of the Board paper. In this regard, Directors emphasized the importance of taking into account country-specific circumstances and called for the Fund to support capacity development in debt management.

Directors supported the staff proposal to closely align the PRGT exceptional access criteria with the requirements of the Policy Safeguards on High Combined Credit, while retaining the current feature that only poorer LICs are eligible for exceptional access to the PRGT.

However, a number of Directors expressed concern about removing the requirement in the PRGT exceptional access framework that programs with countries at high risk of (or in) debt distress should be linked with debt restructuring. Directors ag reed to extend further the temporary increases to the access thresholds that trigger the procedural safeguards for high access in the PRGT until the next comprehensive review of facilities for LICs.

Directors supported the proposals to adjust the framework for determining when LICs are required to blend concessional (PRGT) and non-concessional General Resources Account (GRA) resources. They welcomed the proposed adjustment of the income threshold to limit the impact of transient income changes on a country's blend status and agreed with the proposals to simplify the role of debt vulnerabilities in determining blend status.

Many Directors supported further exploration of the option to allow all PRGT-eligible countries to meet their financing needs through PRGT facilities along with the introduction of a dual interest rate mechanism in the PRGT. They noted that this could provide benefits to LICs now required to blend while modestly reducing the cost of subsidizing PRGT lending. Some Directors did not see merit in implementing such a proposal, given the stresses it would place on reserve coverage. In general, Directors agreed that the approach would be viable only if resources were made available to ensure sufficient lend ing resources and an acceptable level of reserve coverage for the higher levels of PRGT lending that would occur.

Directors endorsed the proposed two-stage funding strategy for the PRGT, entailing a medium-term fund-raising effort to cover the PRGT resource gap created by the pandemic, followed by examination of the appropriate long-term PRGT lending envelope, the associated PRGT funding requirements, and how these needs could be met as part of the next comprehensive review of concessional facilities in 2024/25.

Directors supported the fundraising targets for the first stage of the strategy-a further SDR 12.6 billion in PRGT loan resources and SDR 2.8 billion in new subsidy resources. They broadly supported an increase in the PRGT cumulative borrowing limit to SDR 68 billion to allow mobilization of these loan resources. Directors agreed that the subsidy resources should be generated by i) suspension of PRGT reimbursement to the GRA for administrative expenses through FY2026 and ii) mobilizing SDR 2.3 billion via a broad burden-shared bilateral fundraising campaign. Some Directors stressed that the Fund's own effort, including exploring further use of internal resources, will be essential for asking member countries for bilateral contributions. Directors welcomed the range of options available to donors to provide support, with flexibility in terms of both timing and the mechanisms for providing subsidy contributions. To this end, they supported the creation of two new PRGT accounts-a "Subsidy Reserve Account" (SRA) and a "Deposit and Investment Account" (DIA)—to facilitate 
member contributions for the purpose of PRGT subsidization, with the SRA having a secondary purpose as a supplementary reserve account, boosting the reserve coverage ratio.

Directors noted that the PRGT interest rate mechanism, adopted in 2009 and modified in 2019 , has worked broadly as intended. Going forward, they agreed that interest rates on all loans provided through the PRGT facilities will remain at zero until the next review of the interest rate structure, to occur by end-July 2023.

Directors commended the exceptional response by donors to financing requests from the Fund during the past 18 months. They recognized that the support now being requested is substantial, even if spread over several years, but underscored that the PRGT has played a vital role in the response to the pandemic and, if adequately supported, would continue to provide essential support to LICs during the recovery and beyond. Many Directors recommended an early exploration of all financing options, including mobilizing internal Fund resources and exploring gold sales ahead of the second stage. However, a few Directors did not support proposals for gold sales or a gold pledge, noting the complexity and length of time required to complete the process as well as possible impacts on the strength of the Fund's balance sheet.

Given the substantial uncertainties around potential demand for concessional resources and the timing and scale of donor contributions, Directors underscored the need to closely monitor the evolution of PRGT finances and supported the staff p roposal for annual reviews of the adequacy of PRGT resources. A few Directors emphasized that frequent reviews would be important to enable the Board to conduct adequate oversight and take contingency measures, including possible adjustments to lending policies, if needed. A number of Directors also called for an update to the Board on the fund-raising status after this year's Annual Meetings. Directors looked forward to the first annual review of PRGT finances before the 2022 Spring Meetings. 


\section{INTERNATIONAL MONETARY FUND}

June 30, 2021

\section{FUND CONCESSIONAL FINANCIAL SUPPORT FOR LOW} INCOME COUNTRIES-RESPONDING TO THE PANDEMIC

\section{EXECUTIVE SUMMARY}

The COVID pandemic has had a severe impact on low-income countries (LICs), with many experiencing significant declines in per capita income that threaten the development gains made over the preceding decade. With very low vaccination rates, the strength of any economic rebound is hostage to the evolution of the pandemic and the delivery of vaccines, with staff projections indicating that LICs will fall behind other countries without a broad-based international effort to support them.

The Fund stepped up quickly to provide exceptional levels of financial assistance to LIC members following the onset of the pandemic. New lending to LICs during 2020 amounted to SDR 9.3 billion-an eightfold increase from annual lending in 201719-with the bulk of this disbursed during April-July 2020. In all, 53 of 69 eligible LICs received financial support in 2020, with 29 of these benefiting from SDR 520 million to date in grant-based debt service relief from the Catastrophe Containment and Relief Trust (CCRT) to free up resources for urgent spending needs. This response was made possible by generous support from IMF member countries, who provided new loan resources for the Poverty Reduction and Growth Trust (PRGT) and grants to the CCRT.

Looking ahead, LIC financing needs are expected to remain high in the next few years. Having delivered a rapid initial response to the pandemic through fastdisbursing emergency financing, the Fund must now help countries achieve a sustained and inclusive recovery with financing provided through the Fund's multi-year lending arrangements. To identify how best this might be done, staff have undertaken a wideranging assessment of the Fund's instruments for providing financial support to LICs, drawing on a series of informal consultations with the Executive Board. Staff have also examined how best to rebuild the financial position of the PRGT, which has been significantly weakened by the dramatic surge in concessional lending since March 2020. This will require seeking support from the Fund's better-off member countries.

This paper proposes a package of policy reforms and a funding strategy to ensure that the Fund has the capacity to respond flexibly to LICs' needs during the pandemic and recovery. The key policy reforms proposed include:

- raising the normal annual/cumulative limits on access to PRGT resources to 145/435 percent of quota, the same thresholds for normal access in the GRA;

- eliminating the hard limits on exceptional access (EA) to PRGT resources for 
the poorest LICs, enabling them to obtain all financing on concessional terms if the EA criteria are met;

- changes to the framework for blending concessional and non-concessional resources to make it more robust and less complex;

- stronger safeguards to address concerns regarding debt sustainability and capacity to repay the Fund; and

- retaining zero interest rates on PRGT loans, consistent with the established rules for setting these interest rates.

Other lending policy issues, including potential targeted support to meet external financing needs for vaccination programs, the lending toolkit for fragile/conflict-affected states (FCS), and the potential role of new trusts to support resilience-building and climate-related objectives in the context of voluntary SDR channeling, are being taken forward in separate work-streams.

The proposed increase in access limits would provide the Fund with additional flexibility to support countries with strong economic programs on concessional terms. The Fund's framework for managing the credit risk linked to higher lending levels contains mitigating safeguards, with program design and debt sustainability assessments playing key roles. Given rising debt vulnerabilities in many LICS, new financing requests would require deeper staff analysis of public debt composition and dynamics, including the significance of non-restructurable debt (such as IMF credit), to better flesh out risks to the borrowing country's debt position and identify measures to tackle these risks.

Based on the policy proposals in this paper, staff projects total PRGT lending to reach around SDR 21 billion during the pandemic and its immediate aftermath (2020-24), more than four times the historical average on an annualized basis. This projection is subject to significant uncertainty around economic developments and demand over the coming years. New Fund lending will cover a significant share of the financing needs of those LICs that request financial assistance, while the general SDR allocation will directly support all LICs.

\begin{abstract}
Staff proposes a two-stage funding strategy to finance the exceptionally high levels of pandemic-related concessional lending while preserving the long-term sustainability of the PRGT's endowment-based financing model. The aim in the first stage would be to mobilize: (i) a further SDR 12.6 billion in PRGT loan resources, and (ii) SDR 2.8 billion in new subsidy resources (which allows lending at zero interest rates), financed by a combination of internal resources and a broad burden-shared bilateral fundraising effort. To provide donors with flexibility, various options for providing subsidy resources are available, with support to be pledged upfront and disbursed over time. Two new PRGT accounts would be established to allow contributions in the form of (i) investments to generate earnings for the benefit of the PRGT's subsidy accounts and (ii) subsidy grants that have the dual purpose of enhancing reserve coverage. This fund-raising effort would cover the PRGT resource gap created by the pandemic while preserving a basic self-sustained subsidization capacity for post-crisis concessional lending. The adequacy of PRGT resources would be closely monitored through annual reviews, with corrective actions to be taken if significant shortfalls emerge.
\end{abstract}




\section{A decision on the appropriate longer-term PRGT envelope would be taken up at the second} stage of the funding strategy, as part of the next full review of concessional financing and policies in 2024/25. The need to make further use of IMF internal resources would be carefully considered at that time, especially if the Board were to favor a significantly larger PRGT lending envelope and associated endowment. Channeling of SDRs would facilitate the mobilization of additional PRGT loan resources, which could range from SDR 24-34 billion for the remainder of this decade (202129), and potentially significantly more if further reforms to blending rules were to be implemented. 
Approved By

Ceyla Pazarbasioglu, Bernard Lauwers, and Rhoda Weeks-Brown
Prepared by the Strategy, Policy and Review Department, Finance Department, and Legal Department. The team was led by Sean Nolan, Christian Mumssen, and Bernhard Steinki, and comprised Wes McGrew, Diva Singh, Majdi Debbich, Souvik Gupta, Kyungsuk Lee, Giulio Lisi, Tomohide Mineyama, Anne Paret Onorato, and Kiichi Tokuoka (SPR); Charleen Gust, Linda Kaltani, Wasima Rahman-Garrett, Vidhya Rustaman, Izabela Rutkowska, and Nelson Sobrinho (FIN); Gabriela Rosenberg, Chanda Delong, Kyung Kwak, Hoang Pham, Gustavo Pinto, and Jonathan Swanepoel (LEG). Chiara Castrovillari, Catherine Koh, and Yudong Rao (SPR) provided research assistance and Merceditas San Pedro-Pribram and Phyo Zin (SPR) and Vera Lochan (FIN) provided administrative support.

\section{CONTENTS}

ACRONYMS AND ABBREVIATIONS

I. INTRODUCTION

II. IMF LENDING TO LICS: RECENT EXPERIENCE

III. MODIFYING PRGT FACILITIES AND LENDING SAFEGUARDS

IV. LENDING SCENARIOS AND FINANCING NEEDS

V. FUNDING STRATEGY

VI. PRGT INTEREST RATE REVIEW

VII. DEBT RELIEF FINANCING

VIII. ENTERPRISE RISKS

\section{BOXES}

1. PRGT Access Limits_Staff Proposals________ 16

2. PRGT Facilities Framework: High Access Procedures _____ 19

3. Financing Implications of Alternative Loan Terms for Presumed Blenders_____ $\underline{39}$

\section{FIGURES}

1. Fund Financing to LICS, 2013-2020_____ 11

2. Level of Financing Disbursed: January 2020-May 2021_________ 11

3. Access Level, and Implications for PRGT Resources and Fund Credit Exposure____ 27

4. PRGT Reserve Coverage Ratio Under Illustrative Scenarios, 2017-34______ 34 


\section{TABLES}

1. Proposed Burden Sharing for SDR 2.3 Billion in New PRGT Subsidy Resources

2. Subsidy Value of a SDR 1 Billion 10-Year Contribution to the PRGT Under Alternative

Methods

3. Projections Under Illustrative Demand Scenarios, 2020-34

\section{ANNEXES}

I. PRGT Facilities-Selected Features

II. The PRGT Exceptional Access Criteria and Policy Safeguards for High Combined Credit

Exposures

III. Blending Policies and Eligibility for Exceptional Access: Current and Proposed

49

IV. Evolution of PRGT Access Limits

$\underline{55}$

V. A Dual Interest Rate Mechanism in the PRGT

VI. Analysis of Debt Sustainability and Capacity to Repay DRAFT

$\underline{61}$

VII. Methodology for Estimating PRGT Resource Needs

65

VIII. The PRGT Financing Model

67

IX. PRGT Loan Resource Mobilization

69

X. PRGT Subsidy Resources and Reserve Account

$\underline{70}$

XI. PRGT Investment Strategy and Options for Contributors

$\underline{75}$

XII. PRGT-Review of Interest Rate Structure

$\underline{77}$

XIII. CCRT Grant Mobilization

81

References

$\underline{82}$ 


\section{Acronyms and Abbreviations}

\begin{tabular}{|c|c|}
\hline BIS & Bank for International Settlements \\
\hline BOP & Balance of Payments \\
\hline CCRT & Catastrophe Containment and Relief Trust \\
\hline DIA & Deposit and Investment Account \\
\hline DLP & Debit Limits Policy \\
\hline DSA & Debt Sustainability Analysis \\
\hline DSF & Debt Sustainability Framework \\
\hline EA & Exceptional Access \\
\hline EAAL & Exceptional Annual Access Limit \\
\hline ECAL & Exceptional Cumulative Access Limit \\
\hline ECF & Extended Credit Facility \\
\hline $\mathrm{EF}$ & Emergency Financing \\
\hline EM & Emerging Market \\
\hline ESAF & Enhanced Structural Adjustment Facility \\
\hline FCS & Fragile/Conflict-Affected States \\
\hline FTP & Financial Transaction Plan \\
\hline GE & Grant Element \\
\hline GNI & Gross National Income \\
\hline GRA & General Resources Account \\
\hline HAP & High Access Procedures \\
\hline HIPC & Heavily Indebted Poor Countries \\
\hline IDA & International Development Association \\
\hline IIRs & Intermediate Interest Rate Countries \\
\hline LICs & Low-Income Countries \\
\hline LND & Large Natural Disaster \\
\hline NAAL & Normal Annual Access Limit \\
\hline NCAL & Normal Cumulative Access Limit \\
\hline NPV & Net Present Value \\
\hline ODA & Official Development Assistance \\
\hline PB & Presumed Blender \\
\hline $\mathrm{PCl}$ & Policy Coordination Instrument \\
\hline PPG & Public and Publicly-Guaranteed \\
\hline PRGS & Poverty Reduction and Growth Strategy \\
\hline PRGT & Poverty Reduction and Growth Trust \\
\hline PS-HCC & Policy Safeguards for High Combined Credit Exposure \\
\hline RA & Reserve Account \\
\hline RCF & Rapid Credit Facility \\
\hline RFI & Rapid Financing Instrument \\
\hline SCF & Standby Credit Facility \\
\hline SDA & Special Disbursement Account \\
\hline
\end{tabular}

CInternational Monetary Fund. Not for Redistribution 


$\begin{array}{ll}\text { SDGs } & \text { Sustainable Development Goals } \\ \text { SDR } & \text { Special Drawing Rights } \\ \text { SDRi } & \text { SDR interest rate } \\ \text { SMP } & \text { Staff-Monitored Program } \\ \text { SRA } & \text { Subsidy Reserve Account } \\ \text { UCT } & \text { Upper Credit Tranche } \\ \text { VTAs } & \text { Voluntary Trading Arrangements }\end{array}$




\section{INTRODUCTION}

1. The IMF's current framework for providing financial support to Low-Income Countries (LICs) came into effect in January 2010. ${ }^{1}$ Access to the Fund's concessional facilities, financed via the Poverty Reduction and Growth Trust (PRGT), is available to countries that are assessed to be PRGT-eligible by the Fund's Executive Board. ${ }^{2}$ Modifications to several aspects of the framework (such as limits on access) were made at various points between 2013 and 2020, but the basic structure of the framework has remained substantially unchanged over time.

\section{A comprehensive review of the PRGT's lending framework and its financial} underpinning was completed in May 2019. At that time, the Board approved a one-third increase in the overall limits on access (expressed as a share of quota) to PRGT resources and a similar increase in the limits on access to the Fund's emergency financing (EF) instruments. ${ }^{3}$ Other reforms introduced included changes to the blending rules, increases in the maximum length of ECF (Extended Credit Facility) and SCF (Standby-Credit Facility) lending arrangements, and targeted increases in access to financing under EF instruments to accommodate the special circumstances of fragile/conflict-affected states (FCS) and countries vulnerable to large natural disasters. Staff assessed that the reform package would be generally consistent with the self-sustained PRGT financing framework, with risks evenly balanced over the coming decade. Staff noted that the evolution of lending capacity would need to be monitored carefully, and policies reviewed periodically to ensure that lending capacity remained in line with the PRGT's base envelope for annual lending of SDR 11/4 billion on average on a long-term self-sustained basis.

\section{The COVID pandemic has hit LICs hard, with many experiencing significant declines in} per capita income that will be not be speedily reversed. The scope for providing policy support for economic recovery was tightly constrained in most LICs by limited fiscal space and binding financing constraints, exacerbated in several cases by high pre-crisis debt levels. With very low vaccination rates, the outlook for recovery is subject to significant downside risks, with staff projections pointing to a significant divergence in economic performance between LICs and higher

\footnotetext{
${ }^{1}$ The current framework comprises three concessional lending facilities under the PRGT—the Extended Credit Facility (ECF), which provides medium-term support to LICs with protracted balance of payments problems; the Standby Credit Facility (SCF) to help members deal with short-term balance of payment needs; and the Rapid Credit Facility (RCF) to provide rapid financing with limited conditionality to help members deal with urgent balance of payment needs-and one non-financial instrument, the Policy Support Instrument (PSI). In addition, PRGT-eligible members have access to the General Resources Account, as well as to the non-financial Policy Coordination Instrument (PCI).

2 The terms "low income countries" and "PRGT-eligible countries" are used interchangeably throughout this paper. For a full discussion of the determinants of PRGT eligibility, see "Review of Eligibility to Use the Fund's Facilities for Concessional Financing, 2020," IMF Policy Paper 20/016 (IMF, 2020b).

3 The Fund's emergency financing instruments include the RCF, available only to LICs, and the Rapid Financing Instrument (RFI), available to all IMF member countries.
} 
income countries, with the former falling behind unless there is a broad-based international effort to accelerate recovery and boost development efforts over the next 3-4 years. ${ }^{4}$

\section{The Fund responded to the pandemic with a series of temporary increases to access} limits that facilitated an unprecedented surge in IMF emergency lending to both LICs and emerging market economies (EMs). PRGT disbursements to LICs during 2020 amounted to SDR 6.8 billion-compared with an annual average of less than SDR 1 billion during 2017-2019—while total new lending to LICs, including non-concessional loans from the Fund's General Resources Account (GRA) as part of blended financing, reached SDR 9.3 billion. ${ }^{5}$ In all, 53 of 69 PRGT-eligible countries received financial assistance from the Fund in 2020, including via debt service relief from the Catastrophe Containment and Relief Trust (CCRT). This surge in financial support helped LICs cope with the initial shock of the pandemic and ensuing slowdown in global economic activity.

\section{Looking ahead, most LICs face severe economic challenges and balance of payments} (BoP) needs as they seek to recover from the pandemic shock and resume progress towards their development objectives. The majority are expected to seek multiyear program support with substantial financial assistance from the Fund to help tackle their BoP difficulties. This will come on top of significant levels of pre-existing debt to the Fund, incurred either in tackling economic difficulties prior to the pandemic or as an emergency response to the pandemic. ${ }^{6}$ This is a very different environment from the circumstances prevailing prior to the pandemic, calling for adjustments to the lending policy framework to allow the Fund respond to the exceptional needs of its poorest members with customized economic programs and financial support.

\section{The Fund's concessional financing through the PRGT is designed to be self-sustaining,} with an endowment that generates sufficient investment returns to subsidize lending at zero or near-zero interest rates. ${ }^{7}$ While the PRGT was assessed to be adequately financed to meet LICs' future borrowing needs prior to the pandemic, the large surge in lending levels since the onset of the pandemic and the expectation of continued high lending levels in the near term means the PRGT is now significantly underfunded. The endowment will thus need a substantial injection of fresh funds if it is to sustain reasonable levels of lending to LICs over the medium-to-longer term (see Section IV for a detailed analysis).

\section{This paper lays out a package of policy reforms and a funding strategy to ensure that} the Fund has the capacity to respond to LICs' exceptional needs during the pandemic and

\footnotetext{
4 See "Macroeconomic Developments and Prospects in Low-Income Countries, 2021," IMF Policy Paper 21/020 (IMF, 2021c) for discussion of the economic impact of the pandemic and projections of LICs' likely financing needs for 2021-25.

${ }^{5}$ LICs at relatively high levels of income per capita are required to blend concessional loans from the PRGT with nonconcessional loans from the GRA facilities. The GRA facilities can be used by all Fund members.

${ }^{6}$ More than half the debt owed to the PRGT at end-2020 was borrowed during the preceding 12 months, with repayments falling due from late-2025 through 2030.

7 To provide concessional financing, the PRGT borrows from member countries (currently 18) with which it has loan agreements, paying the SDR interest rate on these loans; it lends to LICs at a lower interest rate, creating a subsidy cost. PRGT lending has carried a zero-interest rate since the new framework was introduced in 2010.
} 
recovery. Specifically, the paper proposes: i) enhancements to the lending framework that would make it fit-for-purpose to help meet LIC financing needs through the pandemic crisis and recovery period and ii) a funding strategy that would rebuild the PRGT's finances to ensure sustainability of the Fund's concessional lending over the longer-term. The focus of attention in the paper is on the next 3-4 years, with the expectation being that a comprehensive review of concessional financing and policies will be undertaken in 2024-25-by which time the exceptional uncertainty surrounding projections of Fund lending and of LIC financing needs should have abated.

8. The remainder of the paper is organized as follows. Section II reviews the evolution of concessional financing levels and policies since the onset of the pandemic and looks at prospects for demand for Fund financial support from LICs through end-2021. Section III discusses potential modifications to the PRGT lending architecture to help meet LIC financing needs during this period, recognizing that there are many other official sector vehicles for providing such support, and outlines an integrated package of proposed reforms. Sections IV and V provide detailed projections of demand for Fund financing from LICs through 2024 under alternative scenarios and the associated PRGT resource needs and outline a proposed two-stage funding strategy for addressing these needs. Section VI discusses proposed interest rates for PRGT lending (which are reviewed every two years); Sections VII and VIII discuss developments in regard to the financing of debt relief provided by the Fund and enterprise risks. Finally, Section IX identifies key issues for discussion. Proposed decisions to implement staff proposals will be circulated separately in a supplement.

\section{IMF LENDING TO LICS: RECENT EXPERIENCE}

\section{In the years immediately prior to the pandemic (2017-19), lending to LICs averaged} some SDR 1.1 billion per annum, with concessional (PRGT) loans accounting for about five-sixths of the total. Access levels and annual disbursements had been gradually increasing, notably in 2019, but repayments on prior loans - consistent with the revolving nature of Fund lending-meant that the (SDR) stock of credit outstanding was increasing at a modest 3 percent per annum (1 percent in the case of PRGT credit). Ninety percent of the new financing was provided via Fund arrangements, with the remainder coming from emergency financing via the RCF (four requests, one also involving financing from the RFI) during these three years. ${ }^{8}$

\section{The onset of the COVID-19 pandemic saw LIC demand for Fund financial support grow} dramatically, with the bulk of new financing being provided via the EF instruments (Figure 1): lending to LICs during March-December 2020 amounted to SDR 9.1 billion (SDR 6.56 billion from the PRGT), of which almost 90 percent was provided via the RCF and RFI. The surge in emergency financing was facilitated by the temporary doubling of annual limits on access to the EF facilities on

\footnotetext{
${ }^{8}$ Financial support from the Fund is typically provided via multiyear arrangements (or programs) in which the quality of economic policies being supported under the arrangement must meet the standards of upper credit tranche (UCT) conditionality. Financial support provided through the EF facilities takes the form of single disbursements; there is no ex post conditionality and the policy framework being supported is not required to meet UCT standards. We use the terms "arrangements" and "UCT-quality programs" interchangeably in this paper.
} 
April 6, 2020. ${ }^{9}$ By end-year, 47 LICs had received financial support through these facilities (with 6 countries receiving two EF disbursements), with 3 more countries receiving financial support through disbursements under new or augmented UCT programs. The stock of outstanding credit to LICs at end-2020 amounted to SDR 15.7 billion (SDR 12.4 billion from the PRGT), twice the amount outstanding at end-2019.

Figure 1. Fund Financing to LICs, 2013-2020

Frequency of Use of Lending Facilities

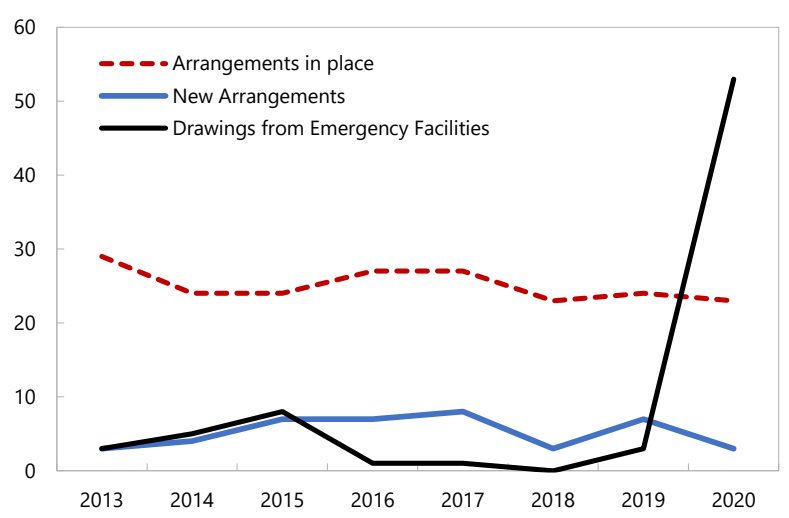

Amount of Financing Disbursed

(in billions of SDR)

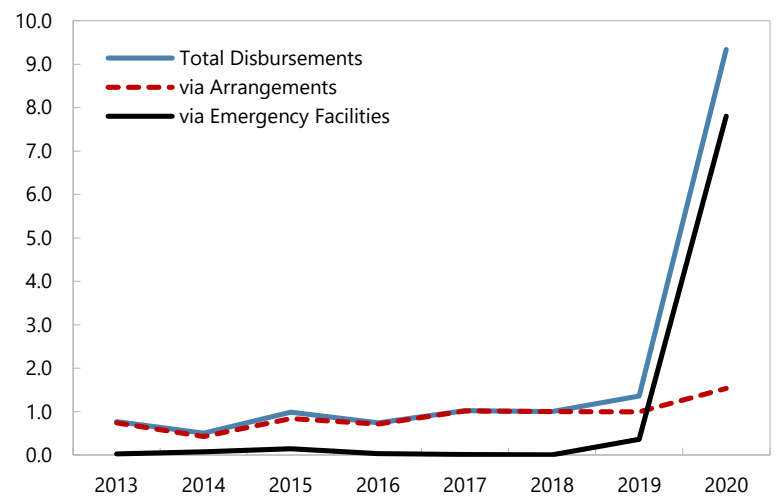

Sources: MONA and IMF staff calculations.

11. The pattern of Fund lending to LICs has evolved over the course of the pandemic period, both in terms of volumes and use of facilities (Figure 2):

- New lending to LICs in March-July 2020 surged

Figure 2. Level of Financing Disbursed: January 2020-May 2021

(In billions of SDR)

to SDR 7.97 billion (PRGT plus GRA), with

90 percent of this amount delivered via

47 disbursements to 44 countries under the

EF instruments; the remainder was provided through 2 new and 7 pre-existing UCT programs. ${ }^{10}$

- Following this initial unprecedented spike, the pace of lending slowed but remained elevated relative to pre-crisis levels. New lending provided during August-December amounted to

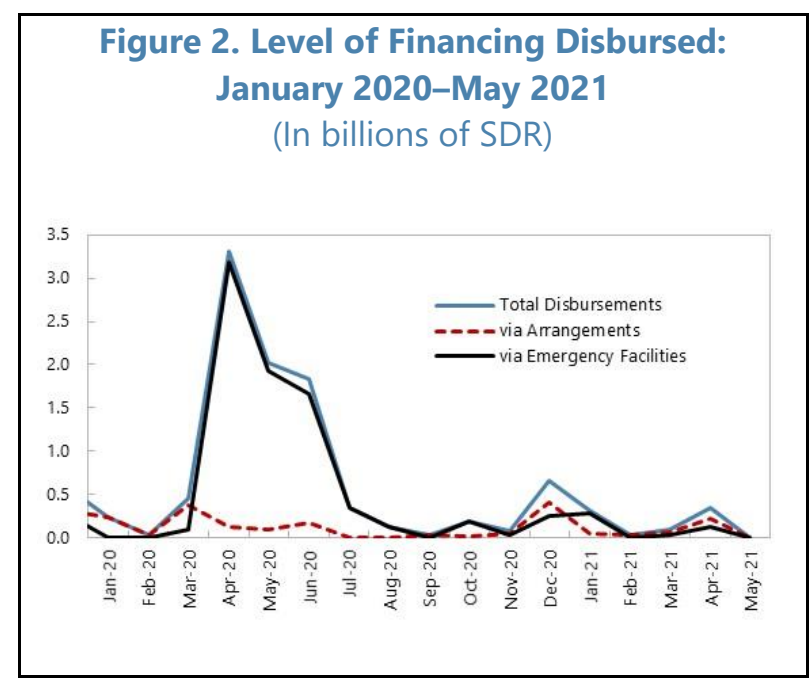

\footnotetext{
9 See Annex IV for a discussion of the various temporary changes made to access limits in both the GRA and the PRGT since March 2020.

10 The two new UCT arrangements (with The Gambia and Somalia) were approved in March, with negotiations completed before the scale of the pandemic had become apparent.
} 
SDR 1.1 billion, split almost equally between 6 disbursements under the EF instruments and 10disbursements under UCT programs (including 1 new arrangement, with Afghanistan). Lending to LICs in this 5-month period was similar in scale to average annual lending levels in 2017-19.

- During the first six months of 2021, new lending amounted to SDR 2.51 billion, with SDR 2.1 billion of this coming from disbursements under UCT programs, including five new arrangements with Kenya, Madagascar, Senegal, Uganda and Sudan, and the remainder from five disbursements under the EF instruments (three involving countries that had already received EF disbursements in 2020).

12. The pick-up in lending is set to continue in the remainder of 2021, reflecting new program requests coming to the Board in the coming months (see below) and disbursements on some of the SDR 5.14 billion in undrawn commitments under the 15 arrangements currently in place. Discussions on new arrangements are at an advanced stage with 8 countries, ${ }^{11}$ with 2 of these expected to come to the Board by end-July: all cases involve arrangements of around 3 years in length, with proposed access ranging from 86 percent of quota to 280 percent of quota and an average access level of 146 percent of quota. ${ }^{12}$ Active discussions are also well underway in several other cases, albeit with timing for completion being less predictable given the need to reach understandings with creditors on a debt restructuring framework. Discussions on further UCT-quality programs will begin in some months' time. Staff also anticipate additional requests for emergency financing through end-2021, including for pandemic-related financing needs. ${ }^{13}$

\section{The Fund has complemented scaled up emergency financing with broad-based debt} flow relief to its poorest members through the CCRT. This involved a reform of the CCRT to allow 29 countries to qualify and immediately receive grants to meet debt service payments falling due to the Fund. Following modifications to the CCRT approved by the Board in late-March 2020, the 29 eligible countries have received grant support in the amount of SDR 520 million, covering all debt service payments to the IMF falling due from mid-April 2020 through mid-October 2021. A further SDR 160 million in grants, covering debt service from mid-October 2021 through mid-April 2022, is expected to be made available if there are sufficient resources in the Trust. Donors have disbursed or pledged some SDR 575 million to the CCRT since March 2020. The Fund also mobilized large internal and donor resources to support arrears clearance and debt relief in Somalia and Sudan.

\section{An expected general SDR allocation of $\mathbf{\$ 6 5 0}$ billion would provide further support to}

LICs. The allocation, which is expected to be approved by the Fund's Board of Governors in August

\footnotetext{
${ }^{11}$ In these cases, Management has approved a staff policy position and proposed access levels and staff do not see any significant obstacles to completing program discussions and bringing the program to the Board speedily.

${ }^{12}$ Access levels under the six arrangements already approved in the past nine months ranged from 80 percent of quota to 305 percent of quota, underscoring the diversity of countries' financing needs.

${ }^{13}$ Staff expect to see one request for EF reaching the Board before end-July-a request from St. Vincent and the Grenadines for assistance in responding to a major (volcanic eruption). More requests could occur where urgent health-related spending, creating BoP needs, is required before a program can be put in place.
} 
2021, would make available potential financing of $\$ 21$ billion (about SDR 14.6 billion) to LICs. ${ }^{14}$ Countries may decide to use the allocation to augment international reserves or for other purposes, including to meet budgetary financing needs or support debt management operations. As a supplement to this support, IMF members with strong economic positions are considering options for channeling a portion of their SDR holdings to finance additional low-cost loans to other members, including LICs.

\section{MODIFYING PRGT FACILITIES AND LENDING SAFEGUARDS}

15. The basic architecture of the PRGT facilities worked broadly as intended during the 2010-2019 period and has served member countries well during the pandemic. Given the exceptional conditions prevailing during much of 2020 , the generalized shift from providing financial support to LICs via arrangements under the PRGT to support from the EF instruments allowed for a pragmatic and speedy response to the onset of the pandemic. With the initial shock largely passed, this shift is being reversed, with multiyear arrangements supported under the ECF set to be the main vehicle for providing financial support over the next three-four years.

\section{With LICs now facing severe financing challenges, the limits on access to PRGT} resources are likely to push many LICs with sound economic programs into seeking support through the Fund's non-concessional lending facilities, financed from the IMF's GRA. While LICs have the right to access GRA resources under the same conditions as any other IMF member, such loans come with higher floating interest rates, shorter maturities, and policy requirements not tailored to resolution of protracted balance of payments problems as is the case with loans extended under the ECF. Given that PRGT access limits are set to become binding for a significant number of LICs, reliance on additional GRA financing is likely to become more common over time.

\section{Expanding lending to countries that already have significant outstanding debt to the} Fund comes with some risks, although the policies in place to manage credit risk are important mitigating factors. Access to additional low-cost (zero-interest) financing from the PRGT provides clear benefits to borrowers but also adds to the already significant levels of non-restructurable debt that the country owes. ${ }^{15}$ Should the country face a situation in which it cannot service its external debts, the space for resolving debt problems via a negotiated debt restructuring is correspondingly reduced and the risk of running arrears to the Fund (or the World Bank)—usually a very difficult situation for countries to emerge from-is heightened. Providing high levels of Fund credit to a

\footnotetext{
${ }^{14}$ An SDR provides the right to request, and be provided with, the equivalent amount in strong currencies from the Fund. Countries pay the SDR interest rate (currently at its minimum level of 0.05 percent per annum) on the amount of their SDR allocation that has been used (i.e., on the difference between their allocation of SDRs and their current holdings of SDRs). There is no set period for countries to rebuild their holdings of SDRs: many LICs have made active use of almost all of their existing allocation of SDRs.

15 Loans extended by the World Bank and some other multilateral creditors are also afforded preferred creditor status and hence are effectively non-restructurable.
} 
country thus needs to be linked to careful scrutiny of public debt sustainability over the mediumterm. ${ }^{16}$

18. The analysis in this section is divided into two parts, the first focusing on proposals to adjust limits on norms and access to PRGT resources and associated safeguard measures, the second on proposals to simplify blending polices (which affect how higher-income LICs can access the PRGT). As explained in Annex III, non-blend countries can currently access PRGT resources up to the relevant limits without seeking access to the GRA; blend countries can access PRGT resources only in conjunction with access to GRA resources. ${ }^{17}$ Countries are expected to shift from non-blend to blend status as income per capita levels rise and/or access to international financial markets increases, and from blend status to graduation from PRGT eligibility as rising income levels and/or expanded market access reach threshold levels. ${ }^{18}$

\section{Proposed Changes to PRGT Access Limits and Associated Safeguards}

19. The limits on normal access to PRGT resources $(100 / 300$ percent of quota) were set at the conclusion of the 2018-19 Review of Facilities for LICs. ${ }^{19}$ These limits were expected to remain in place through the next regular review of LIC facilities and financing on a fiveyear cycle, but have been increased on a temporary basis during the pandemic, with the current limits (245/435 percent of quota) set to expire in the coming weeks. Separately, the subset of non-blend countries that are eligible for EA may request up to 33/100 percent of quota in additional PRGT funding if the program request meets the relevant EA criteria.

\section{There is a strong case for raising limits on access to PRGT resources given the large projected external financing needs of} many LICs in the coming years. This would provide LICs with greater access to low-cost-financing from the Fund and would limit the number of non-blend LICs that are required to access the GRA. There are a substantial number of countries with credit outstanding to the PRGT in excess of 150 percent of quota, many of whom can be

\footnotetext{
16 The linkage between the provision of Fund financial support and sustainability of a country's debt position applies to all potential borrowers, not just LICs. The Fund may provide support to countries with very high levels of debt, as long as such debt is sustainable on a forward-looking basis, which may require an agreement with creditors on a debt restructuring sufficient to render debt sustainable over time. Efforts to delay restructuring where debt is clearly unsustainable are almost always harmful to the borrowing country.

17 The terms "blend" and "non-blend" countries is used throughout this paper as a shorthand for the technical terms "presumed blender" and "non-presumed blender" (see Annex III).

18 Graduation from PRGT eligibility is not automatic, but also requires a judgment that the country does not face serious short-term vulnerabilities.

19 The notation "A/B percent of quota" refers to annual and cumulative access limits, respectively. To simplify the exposition, the discussion focuses in the main on the "permanent" (non-transitory) access limits, which are reviewed at regular intervals (now a five-year cycle): the temporary changes made to access limits are described in Annex IV.
} 
expected to request sizeable UCT-quality arrangements as they seek to navigate their way through the pandemic period and its aftermath (see Text Table 1). Absent changes to the PRGT access limits, many of these countries, among the poorest of the Fund's LIC members, would likely be required to request financing from GRA instruments, which would be less appropriate for their needs.

\section{Staff propose the following set of principles to guide the setting of access limits:}

- Non-blend countries seeking access to PRGT resources at levels viewed as "normal access" for other member countries should be able to borrow the entire amount from the PRGT. Normal access here is access that would not trigger application of the GRA EA framework or Policy Safeguards for High Combined Credit to GRA-PRGT Resources (PS-HCC).

- Poorer LICs are eligible for access to PRGT resources in excess of normal access limits: this access should no longer be subject to hard caps, but the proposed arrangements must meet the PRGT EA criteria.

- $\quad$ LICs that meet the income criterion for blending, which is based on the International Development Association (IDA) operational cutoff, should not be eligible for access to PRGT resources above the normal access limits.

\section{These principles entail some important departures from current concessional lending} rules, where i) access limits are set at levels that constrain demand for PRGT resources to align with the available PRGT resource envelope and ii) there are hard caps on all countries' access to concessional resources. ${ }^{20}$ They also involve significant continuities: only poorer LICs are eligible for EA, while access levels for all financing requests continue to be based on case-by-case assessment of program design and country circumstances, applying long-established criteria (see $\llbracket 28$ below).

\section{The financial cost to the PRGT of raising the access limits in this manner is expected to} be modest. While higher access limits create more room for PRGT borrowing, this does not necessarily translate into higher borrowing in individual cases; access will continue to be determined on the basis of case-by-case assessment, taking account of such factors as BoP needs, the strength of the program, and capacity to repay/debt vulnerabilities. Using the Baseline projections for Fund lending through 2024 (see $\mathbb{P 5 1}$ below), returning to the 2019 access limits and caps after the temporary increases now in place expire would affect only about a dozen countries and reduce PRGT lending by about SDR $1 \frac{1}{2}$ billion through 2024-which can be contrasted with a Baseline projection of PRGT lending of SDR 21.5 billion during 2020-24. For the countries affected in such a scenario, those with programs that meet the policy requirements of the GRA (see Annex 1) would be in a position to replace the reduced PRGT lending with GRA resources.

\section{Applying these principles under current circumstances yields the proposals on access} limits outlined in Box 1: these proposals take account of the temporary access limit increases currently in place. Going forward, non-transitory changes to PRGT access limits would be taken up in the context of the regular reviews of LIC facilities, given the need to align the entire package of PRGT

\footnotetext{
${ }^{20}$ How these principles can be reconciled with PRGT financial self-sustainability over the medium-to-longer term will need to be examined in the context of the post-crisis LIC facilities review and the analysis of PRGT financing needs.
} 
policies with financial self-sustainability of the PRGT over time. Access limits (which are expressed as a share of quota) would also be revisited in the context of any general quota increase.

\section{Box 1. PRGT Access Limits-Staff Proposals}

\section{Background}

The GRA exceptional access (EA) framework applies to all requests for financing from the GRA that exceed threshold levels for annual and cumulative access. The threshold levels were set at 145/435 percent of quota in February $2016 .^{1}$ The threshold level for annual access was increased on a temporary basis to 245 percent of quota in July 2020: this temporary increase is set to expire at end-2021, when the threshold would revert to 145 percent. $^{2}$

Policy safeguards for countries seeking financial support from the Fund involving high levels of combined GRAPRGT exposure were introduced in September 2020. ${ }^{3}$ The threshold levels for combined exposure that trigger application of these safeguards are the same as those that trigger application of the EA framework in the GRA-currently 245/435 percent of quota, with the annual threshold set to decline to 145 percent of quota at end-December 2021.

Normal access to PRGT resources

Staff propose that the limits on normal access to the PRGT be set at 145/435 percent of quota, with the limit on annual access temporarily increased to 245 percent through end-December 2021. The limits on normal access to the PRGT were temporarily increased from 100/300 to 245/435 percent of quota in March 2021, with the current limits (245/435 percent of quota) set to expire in the coming weeks. The staff proposal implies that:

- the limit on normal cumulative access would (absent a new Board decision) continue at 435 percent of quota until the next full review of LIC facilities, expected to be conducted in 2024-25;

- the limit on normal annual access would (absent a new Board decision) continue at 245 percent of quota until end2021, after which it would decline to 145 percent of quota until the next full review of LIC facilities.

- changes to the thresholds triggering application of the EA framework in the GRA or the Policy Safeguards for High Combined Credit (PS-HCC) before the next full review of LIC facilities would not affect PRGT access limits ahead of that review.

The proposed increases in access limits would apply to new financing requests and to existing arrangements as of the date of the effectiveness of the proposed changes, with the exception of arrangements that were grandfathered when the PS-HCC policy was adopted, which will remain subject to the PRGT EA thresholds and criteria in place at the time of the approval of these arrangements. This is to ensure adequate safeguards and evenhanded treatment for exceptional/high access across all PRGT borrowers. In the event of an augmentation under such an arrangement, the grandfathering from the application of the PS-HCC policy would end and the new PRGT access rules would apply. ${ }^{4}$

\section{Exceptional access to PRGT resources}

LICs that meet the relevant eligibility criteria can request EA (access above the normal limits) to PRGT resources (see Annex II). Eligibility is currently limited to countries that have not had sustained past access to international financial markets ${ }^{5}$ and have income at or below the prevailing operational cutoff for assistance from IDA. Available access is currently subject to a hard cap of 33.3/100 percent of quota on top of the normal access limits. The staff proposal is that:

- A country is eligible for PRGT EA only if it does not meet the proposed income threshold for blending (discussed below). It will not be disqualified from EA on the basis of market access.

- Access to PRGT resources for countries eligible for EA is not subject to hard caps; a financing request may be approved in amounts exceeding the normal access limits if the PRGT EA criteria are satisfied.

${ }^{1}$ The thresholds determining EA under the GRA were set in February 2016: see "Review of Access Limits and Surcharge Policies" (IMF (2016a), March 29, 2016).

${ }^{2}$ All temporary changes to access limits introduced since the beginning of the pandemic are expected to be reviewed after the 2021 Annual Meetings.

${ }^{3}$ See IMF (2020e).

${ }^{4}$ Only one existing arrangement (with Ethiopia) is subject to the current PRGT EA criteria and was grandfathered from the application of the PS-HCC in September 2020.

${ }^{5}$ Countries with per capita GNI below 80 percent of the IDA operational cutoff are not precluded from EA on the basis of market access. 
Norms

\section{Access norms have been a feature of PRGT facilities design since the overhaul of the}

LIC facilities architecture in 2010. Norms have played a nuanced role in influencing access levels in PRGT arrangements: they are neither ceilings on nor floors to access and should not be viewed as an entitlement, but play a useful guiding role in setting access in cases where it is difficult to accurately determine the BoP need. ${ }^{21}$ This role has been particularly useful in the context of repeated arrangements with LICs making steady progress in addressing protracted BoP problems, but less relevant in cases where countries face pressing BoP needs triggered by shocks or crises.

\section{Under the current system, access norms are linked to the initial stock of credit}

outstanding: 120 percent of quota for a 3-year ECF when credit outstanding is below 100 percent of quota, 75 percent of quota when credit is between 100 and 200 percent of quota, and undefined if outstanding credit exceeds 200 percent of quota. Past practice in reviews has been to increase these parameters (both the access level and associated credit ranges) in line with any increase in normal PRGT access limits.

\section{Staff proposes a simplification of the access norms, with a unified access norm set at} 145 percent of quota for any three-year ECF arrangement. ${ }^{22}$ The basis for differentiated normsto tilt the use of scarce resources towards countries that have made less use of them-does not align well with current circumstances, where the pandemic has created large and diverse financing needs across countries: the current priority is to tackle the most pressing needs, rather than allocating resources on the basis of pre-existing exposure (which, in many countries, is elevated because of pandemic-related emergency financing). Staff also sees simplification as strengthening the signaling function of norms, providing a clear uniform starting point (but not end-point) for discussion of appropriate access levels in PRGT-supported programs. Setting the unified norm at 145 percent of quota is broadly in line with the proposed increase in normal limits on access to the PRGT. ${ }^{23}$ The role of norms in PRGT facilities will be reassessed at the time of the next comprehensive review of LIC facilities in 2024/25.

\section{Safeguards}

28. The Fund relies on a multilayered framework to mitigate and manage credit risk across all its lending operations, including program design and access policies. The approach to setting access under an arrangement (PRGT or GRA) entails a case-by-case determination, where access has

\footnotetext{
21 See "Financing for Development: Enhancing the Financial Safety Net for Developing Countries-Further Considerations" (IMF (2016c), October 24, 2016).

22 The access norm for ECF arrangements longer than 3 years would be based on the length of the arrangement and the annual access norm under the three-year ECF arrangement. Consistent with earlier practice, the norm for access under a 18-month SCF would be set equal to that of the 3-year ECF arrangement, again varying proportionately with the length of the SCF arrangement, up to the amount allowable under a 2-year SCF arrangement (193.33 percent of quota).

23 Increases of 45 percent to the access norm for low credit outstanding (120 percent of quota) and higher credit outstanding (75 percent) would yield an unweighted average of 141.4 percent, rounded to 145 percent of quota.
} 
to be justified on the basis of a rigorous assessment informed by the standard access policy criteria, including the size of the balance of payments need, the strength of the member's economic program, capacity to repay the Fund, and the track record of using Fund credit in the past. This caseby-case approach will remain critical to ensuring adequate safeguards for PRGT resources.

29. As noted above, Fund programs that result in high levels of debt for member countries involve risks for both the borrowing country and the Fund, implying a need for careful assessment of the sustainability of the country's debt position over time. In recognition of this issue, new measures were introduced in March 2021 to enhance staff's assessment of debt sustainability in LICs. ${ }^{24}$ These included: i) disclosure requirements and deeper analysis of debt composition and dynamics in staff reports, building on the disclosure requirements in the newly-modified Debt Limits Policy (DLP), which takes effect on June 30, 2021, and including cross-country comparisons of outstanding and projected Fund credit relative to key economic metrics, and ii) a requirement, in all cases of countries at high risk of/in debt distress (regardless of proposed access levels), that program objectives include the achievement of a concrete reduction in debt vulnerabilities over the course of the program and beyond. See Annex VI for elaboration on these points.

\section{Procedural Safeguards}

30. The PRGT lending framework has high access procedural safeguards, which are applied when a financing request entails proposed access such that i) access to PRGT resources over any 36 month period would exceed 180 percent of quota ("flow trigger"), or ii) aggregate exposure to the PRGT, net of repayments, would exceed 225 percent ("stock trigger"). The objective of these procedures is to ensure enhanced Board oversight of lending proposals involving high levels of access to PRGT resources, achieved via an early informal staff consultation with the Executive Board on a country case that should occur once management agrees that a new or augmented financing request involving high access could be appropriate. The information and process requirements for these consultations, which were upgraded in May 2019, are described in Box 2.

\section{Given the impact of the wave of pandemic-linked lending in 2020, these triggers were modified on March 22, 2021 as follows: ${ }^{25}$}

- With the majority of non-blend countries having obtained exceptional emergency financing in the first months of the pandemic, the flow trigger was set at 240 percent of quota through end2023 , by which time all the financing provided in response to the initial shock would have dropped out of the "36 month" calculation.

- With many countries already having exposure to the PRGT close to (or above) 225 percent of quota, the stock trigger was increased to 300 percent of quota through June 30, 2021 to avoid triggering the procedural safeguards in cases involving modest new access.

\footnotetext{
24 See IMF (2021a) and IMF (2021b); the new requirements are permanent in nature.

25 lbid.
} 


\section{It is proposed that these flow and stock triggers remain at the higher levels introduced} in March 2021 until the next full review of LIC facilities. ${ }^{26}$ With average program size in the coming years projected to be substantially higher than pre-COVID levels (see below), the case for returning to the pre-COVID flow trigger after end-2023 is not compelling. Similarly, with exposure to the PRGT expected to increase for the majority of borrowers over the next few years, there is a strong case for maintaining the stock trigger at 300 percent to avoid triggering procedural safeguards in cases involving modest levels of new access.

\section{Box 2. PRGT Facilities Framework: High Access Procedures}

The PRGT lending framework includes procedural safeguards ('high access procedures' or HAP) for new financing requests or augmentations involving access to concessional resources above specified levels. The HAP were introduced in 2009, when the PRGT Facilities Framework was established, with the aim of protecting PRGT resources via enhanced Board oversight of lending requests involving high access. Against the backdrop of rising debt vulnerabilities in many LICs, the 2018-19 Review of LIC Facilities (LIC FR) modified these procedures to enhance the focus on assessment of debt vulnerabilities and related risks to members' capacity to repay the Fund.

All requests for new PRGT financing where the proposed access meets the HAP thresholds require early engagement with the Board through an informal Board meeting. Since May 2019, this engagement has been expected for all financing requests where (a) access under the ECF, SCF, and RCF exceeds 180 percent of quota over any 36-month period ("flow trigger"), or (b) outstanding credit under all concessional facilities is above (or projected to be above) 225 percent of quota ("stock trigger"), based on cumulative access for past and future scheduled disbursements net of repayments. ${ }^{1}$

In such cases, the Board would be presented with an initial assessment of the member's BoP need, macroeconomic situation, and potential fiscal and debt vulnerabilities, as well as information on the proposed program and related impact on concessional resources. Specific informational requirements (which are the same as those required for EA under the PRGT) would include:

- Factors underlying the large BoP need, after accounting for financing from donors.

- A brief summary of the main policy measures and macroeconomic framework.

- The expected strength of the program and an assessment of the capacity to repay the Fund, including an updated capacity-to-repay table.

- An analysis of debt vulnerabilities, including the identification of potential data weaknesses and discussion of results from "realism" tools included in the LIC DSF.

- A reference to the impact on the Fund's concessional resources.

- The likely timetable for discussion with authorities.

- An SEl table.

- DSA charts.

To ensure Directors' views on access levels are appropriately reflected in the negotiations, the informal HA Board meetings should take place as soon as management concurs that a new request involving HA could be appropriate.

${ }^{1}$ The thresholds that trigger the HAP were temporarily raised in response to the pandemic, as discussed in the main text.

\footnotetext{
26 The specification of the flow and stock triggers could be revisited in the period between now and the next such review if Directors, in reviewing the development of PRGT finances, called for such a move.
} 


\section{Other Safeguards: Alignment of PRGT EA Criteria with Existing Policy Safeguards}

33. There are currently two separate sets of standards that may apply to LICs requesting levels of access to Fund resources in excess of the proposed 145/435 percent of quota limits: the PRGT EA criteria and the Policy Safeguards for High Combined Credit (PS-HCC) relating to requests for high combined access to GRA and PRGT resources. The two are closely related but not identical; the PS-HCC conditions (introduced in September 2020) sought to adapt the standards specified in the GRA EA criteria to accommodate the distinctive features of LICs and of the LIC debt sustainability framework, while the PRGT EA criteria (introduced in 2009) focused on limiting EA to poorer LICs with comparatively strong adjustment programs, with programs with countries at high risk of (or in) debt distress expected to include a debt restructuring operation. ${ }^{27}$

34. To simplify the policy framework governing EA requests involving PRGT resources, it is proposed that the PRGT EA criteria be modified to align them with the PS-HCC requirements specified in IMF (2020e), with one significant exception. As noted above, countries would be eligible for PRGT EA only if they do not meet the income threshold for blending at the time when a new financing request is made: in all other respects, the PRGT EA criteria and the PS-HCC would be substantively similar, as illustrated in Annex II. Staff does not see this proposed change in the PRGT EA criteria as being material from a risk perspective: it eliminates the formal requirement that, for countries at high risk of/in debt distress, EA should be made available only in support of programs that include debt relief or debt restructuring operations, but the more fundamental requirement that the program achieve moderate risk of debt distress within the program period remains.

\section{Proposed Changes to Blending Policies}

35. PRGT-eligible countries are divided into two groups: i) blend countries, who can access concessional financing from the Fund only in conjunction with GRA resources and ii) non-blend countries, who can access PRGT resources up to the relevant access limits, needing to tap GRA resources only if their financing requests exceed these limits. Moving from non-blend to blend status has significant implications for a LIC, with Fund financial support now provided on less concessional terms and with programs required to meet the policy requirements of the GRA as well as the PRGT.

36. Blend status is determined by GNI per capita, access to international financial markets, and severity of debt vulnerabilities. In broad terms, LICs with GNI per capita above the IDA operational cutoff (currently $\$ 1,185$ ) or with significant access to international financial markets and income above 80 percent of the IDA cutoff are required to blend if debt vulnerabilities are assessed to be contained (low or moderate risk of debt distress); countries assessed to be at high risk of debt distress that meet both the income and market access criteria (including market access on a forwardlooking basis) are also required to blend; all other countries are not required to blend. These rules are described in detail in Annex III.

\footnotetext{
27 The case for aligning the PS-HCC conditions to the standards underpinning the GRA EA criteria is discussed in IMF PP 2020/039 (IMF, 2020e).
} 


\section{Staff sees a strong case for targeted reforms to the blending framework to make it both more robust and less complex:}

- Robustness of blending status: Countries can flip back and forth too easily between blend and non-blend status, in a manner inconsistent with the important implications of the shift to blend status for a country and that can also create operational difficulties.

- Income threshold: A low/moderate debt risk country can move to blend status following a modest increase in GNI per capita to above the IDA cutoff, and then revert back to nonblend status with a modest decline in GNI per capita (or an upward shift in the IDA cutoff, which moves modestly from year to year). ${ }^{28} \mathrm{~A}$ request for an arrangement in year one would have to be a blend; a request the following year could involve PRGT access only.

- Market access threshold: Countries at high risk of debt distress with income above the IDA cutoff and substantial past market access are expected to blend if they are assessed to have prospective market access. Assessing prospective market access requires judgment at the time of a financing request; this will move in line with significant shifts in market sentiment. Thus, Kenya was viewed as a non-blend case when it asked for EF in May 2020 but as a blend case when it requested Fund financing in April 2021. ${ }^{29}$

- Complexity: The blending rules have become quite complex over time, impairing the visibility of key principles in some areas. For example, access to PRGT resources in a blended arrangement is guided by the 1:2 ratio on the PRGT-GRA mix (1:1 prior to July 2015)_but this is capped at the applicable norm for an arrangement, which can be i) 120 percent of quota, ii) 75 percent, or iii) undefined, depending on the initial level of PRGT credit outstanding (see Box 3, footnote 3). A simpler rule would allow full operation of the 1:2 principle in situations of normal access.

38. Reforms of the blending rules are proposed in three areas: a) the income criterion for blending, b) the impact of debt vulnerabilities and financial market access on blend status, and c) the mix of GRA and PRGT resources applied in blended arrangements.

\section{The income criterion for blending would operate as follows:}

- Countries are deemed to meet the income threshold for blending when GNI per capita has exceeded the IDA operational cutoff by at least 5 percent for two consecutive years.

- Having met the income threshold, the country continues to meet it provided that income per capita does not fall below 95 percent of the IDA operational cutoff: should income per capita fall below this level, the country no longer meets the income threshold.

28 For example, the Kyrgyz Republic moved to blend status in July 2019, based on 2018 GNI per capita; GNI per capita had also exceeded the IDA operational cutoff in 2014 but fell below it in 2016-17.

29 Similarly, Ghana was viewed as a non-blend case when it requested EF in April 2020 but would now likely be treated as a PB given its large dollar sovereign bond issue in late-March 2021. 
- Countries that do not meet the income threshold for blending are not required to blend, irrespective of market access.

The case for these specific parameter choices and the implications of applying these rules for the coming year (through end-June 2022) are discussed in Annex III.

40. This approach would substantially reduce the likelihood of a premature/soon-reversed shift to blend status, by raising the standard for meeting the income criterion and reducing the income level at which blend status, once achieved, would be lost. This asymmetry between the income threshold for achieving blending status and the threshold for re-entry to non-blend status also features in the income criterion for PRGT-eligibility and for similar reasons-to support robust (but not fully irreversible) graduation from PRGT eligibility. Specifying that countries who do not meet the income criterion are not required to blend simplifies the framework by eliminating cases where countries with income below the IDA cutoff must blend if they meet a market access criterion: the only country affected by this change is Tanzania, which would no longer be required to blend. ${ }^{30}$

\section{Debt vulnerabilities and access to international financial markets would influence blend status as follows:}

- Countries that meet the income criterion for blending are required to blend unless debt vulnerabilities limit their access to international financial markets.

- Countries are deemed to face such limits on their access to international financial markets if they are i) in debt distress or ii) at high risk of debt distress and a) have had limited past access to international financial markets or b) are small/micro-states.

- Countries are assessed to have had limited past access to markets if they do not meet the criterion of "durable and substantial access to international financial markets as defined in the first test of market access in the PRGT eligibility decision." ${ }^{31}$

\section{This set of proposals offers a simple intuitive approach that delivers a more robust} determination of blend status than is currently the case. It would remove the role of prospective market access in determining blend status (currently of relevance for countries at high risk of debt distress), thereby eliminating a difficult judgment call that shifts with market sentiment and a

\footnotetext{
30 This simplification would also improve consistency across instruments for supporting LICs: Tanzania is currently required to blend and is not eligible for PRGT EA, but is eligible for assistance from the CCRT (for which some 20 nonblend countries are not eligible). Tanzania's 2019 income per capita was 91 percent of the IDA cutoff, falling to 89.6 of the IDA cutoff in 2020.

31 See Decision No. 14521-(10/3), as amended, and Eligibility to Use the Fund's Facilities for Concessional Financing, 2020 (IMF, 2020b). This criterion is met if the country has issued or guaranteed eligible external debt in at least three of the past five years in a cumulative amount equivalent to at least 50 percent of its quota. The second test (if there were convincing evidence that the sovereign could have tapped international financial markets on a durable and substantial basis) does not apply. As discussed in the 2020 Review of PRGT Eligibility (IMF Policy Paper 20/016), staff assessment as to whether this criterion is met requires validation of the debt data (taken from the World Bank's International Debt Statistics) with country authorities. The 2020 eligibility review introduced refinements to the methodology for assessing past market access (the first test noted above), which apply also to assessment of market access under PRGT blending and EA policies.
} 
country's borrowing plans. It maintains the principle that countries in debt distress are not expected to blend and that better-off countries with contained debt vulnerabilities are expected to blend. It makes the reasonable assumption that countries at high risk of debt distress with little prior access to markets should not be viewed as having significant access; and it recognizes that small/micro states face particular challenges in accessing international markets given scale effects (e.g., bond issues typically have to be of substantial size to cover fixed transactions costs and ensure sufficient trading liquidity). ${ }^{32}$ The implication of these rules for blend status is discussed in Annex III.

\section{The formula for determining the mix of PRGT and GRA resources received by blend countries (PBs) would be as follows:}

- The funding mix made available to a blend country would follow the 1:2 ratio, with PRGT access capped at 145 percent of quota per arrangement.

A blend country requesting arrangements with combined PRGT/GRA access that would not trigger the Policy Safeguards (i.e., access not exceeding 435 percent of quota) would receive the 1:2 mix: a country seeking cumulative access of 435 percent or more would be capped at 145 percent of quota from the PRGT. Access to PRGT credit would also be subject to the limit on normal cumulative access to the PRGT of 435 percent (a limit that is very unlikely to become binding as it would require a series of successive high access arrangements).

\section{"All-PRGT" versus "1:2" Financing Terms for Presumed Blenders: A Possible Future Reform Option}

44. There are good arguments for differentiating between the terms on which concessional financing is provided to the poorest countries and the terms on which it is provided to LICs that are substantially better-off. Concessional resources are scarce: differentiated terms allow the lender to provide financing on more generous terms to the poorest countries than the terms provided to the better-off, while still providing loans to better-off countries at very attractive, albeit less generous, terms. Hardening the terms of concessional lending as countries move up the income ladder also prepares them for graduation from PRGT eligibility, after which point all borrowings from the Fund will come on regular GRA terms, linked to market rates. ${ }^{33}$ This logic underlies the hardening of lending terms when countries move from "IDA-only" to "IDA gap" status at the World Bank-and the hardening of terms when countries move from non-blend to blend status at the Fund.

\section{Fund policies achieve a hardening of terms for "blend countries" indirectly-not by means of dual pricing within the PRGT but rather by requiring that blend countries borrow from both the PRGT and the GRA. This delivers hardened financing terms-a (weighted) average of}

\footnotetext{
32 The exception for small/micro-states affects Cabo Verde, Dominica, and Maldives, all of which are at high risk of debt distress but meet the criterion of substantial past market access. The specification of market access, which also plays an important role in driving PRGT graduation decisions, will likely be subject to further analysis during the upcoming review of PRGT eligibility, due at the Board in Q1 2022.

33 Borrowing from the GRA will still likely be on more generous terms than those faced by the majority of PRGT or IDA graduates in the bond markets.
} 
PRGT and GRA financing terms-but has the side-effect of pushing blend countries into the GRA, where the policy requirements differ from those of the PRGT. In particular, GRA arrangements are not intended to deal with protracted BoP problems (in contrast with the ECF), but rather to address short-to-medium term BoP difficulties. Countries such as Cambodia or Comoros meet the current (and proposed) criteria for blending - but it is difficult to argue convincingly that they have broken through the development challenges that underpin protracted BoP problems and should face the same GRA policy requirements as middle-income countries responding to BoP shocks.

\section{One feature of the current approach is that blend LICs are treated in a similar fashion} to non-LICs, with the one exception that they obtain one-third of any Fund financing on PRGT terms. The distinction between non-blend LICs and blend LICs is much sharper than this, both in terms of cost of financing and required use of the GRA - a factor that partly motivated the attention to blending policy in this paper. Blend countries cannot, for example, rely on a protracted BoP problem standard to request multiyear financing, and would need to meet EFF/GRA qualification requirements, including regarding the pace of expected resolution of BoP needs under the program.

47. The objective of lending on harder terms to better-off LICs than to poorer LICs could be achieved more directly, and without requiring GRA program standards, through dual pricing within the PRGT, with all PRGT-eligible countries being able to meet their financing needs entirely via the PRGT. ${ }^{34}$ This can be achieved in a manner that allows for more flexible program design for countries now required to blend (e.g., by allowing all-ECF financing) while generating modest subsidy savings for the PRGT (Annex V and Box 3 in Section V).

48. However, such a reform would result in a substantial increase in PRGT credit outstanding and a sharp decline in reserve coverage in the PRGT (Section V, Box 3). Taking this issue further would thus require tackling policy and financial issues and assessing the legal implications that will take more time to resolve: work will continue on these issues, including a strategy to bolster reserve coverage of PRGT loans.

\section{LENDING SCENARIOS AND FINANCING NEEDS}

49. Demand for PRGT financing is expected to remain high over the coming years as LICs gradually recover from the pandemic. Following the unprecedented scale of IMF emergency support (SDR 8.4 billion, of which SDR 6.2 billion from the PRGT) in response to the outbreak of the COVID-19 pandemic, many LICs are now moving to multiyear financial arrangements. Total new lending commitments under ECF or blended arrangements have already reached SDR 2.5 billion (of which SDR 1.2 billion from the PRGT) through May 2021, with a large pipeline of additional programs likely to materialize over coming months and years. These programs are designed to meet the considerable financing needs created by the crisis (e.g., revenue losses, health expenditures) and create additional policy space to underpin a sustainable economic recovery. Demand for PRGT

\footnotetext{
${ }^{34}$ All PRGT-eligible countries would still have full rights to access the GRA, but none would be required to do so.
} 
financing is expected to remain elevated through the second half of the decade, given the expected significant scarring from the pandemic, with many LICs likely to seek successor arrangements.

\section{Based on the policy proposals in this paper, staff projects total PRGT lending to reach} around SDR 21 billion during the pandemic and its immediate aftermath (2020-24). However, this projection is subject to significant uncertainty around economic developments and demand over the coming years. Several factors are particularly difficult to predict at this juncture: (i) the number of LICs that will eventually request program support, (ii) the size of individual programs, which depends on BoP needs, policy strength, and capacity to repay, and (iii) the pace of recovery, which depends on external factors (availability of donor financing, export demand, global financial conditions) and domestic ones (health challenges, constrained policy space). To capture these uncertainties, staff has conducted a thorough country-by-country analysis to construct a benchmark scenario with accompanying sensitivity analysis (Annex VII summarizes the methodology):

- The "Baseline" scenario assumes that nearly two-thirds of LICs seek program support (in line with historical peak years) during the pandemic period (2020-24). Access per arrangement is calibrated to reflect the exceptionally high financing needs, with average access scaled up to almost twice the level observed in recent years, while differentiating across countries by individual quota, GDP, debt vulnerability, and Fund credit exposure.

- To capture uncertainty around the Baseline, a "Low Case" and "High Case" are calibrated by assuming a lower/higher share of LICs request programs. The High Case could be considered a tail event, constructed to "stress-test" PRGT resources in the event of an unprecedented high share of LICs seeking program support and per-country access levels at nearly three times historical levels.

- Without prejudging the appropriate longer-term target for PRGT lending capacity (to be discussed in the second stage review in 2024/25), staff assumes that a base self-sustained lending envelope of at least SDR 1.65 billion per year is preserved, which would maintain access in real terms compared to pre-crisis levels. This would accommodate room for many LICs to request successor arrangements in the second half of the decade (Annex VIII describes the main building blocks of the PRGT self-sustained financing model).

\section{The combination of new Fund lending and the planned general SDR allocation would} cover a significant share of the BoP needs of LICs estimated recently by staff. ${ }^{35}$ Under the Baseline, lending to LICs during the pandemic years would be more than four times the historical average, with total lending commitments of about SDR 34 billion (including SDR 21 billion from the PRGT) during 2020-24. PRGT credit outstanding would peak in 2025/26 at about SDR 22 billion, more than three times the pre-pandemic level, before gradually declining in the post-crisis decade as the share of LICs with programs in place reverts to historical levels and some countries move toward

\footnotetext{
35 The recent paper "Macroeconomic and Developments Prospects in Low-Income Countries—2021" (IMF Policy Paper No. 2021/020 (IMF, 2021C)) estimated LICs' total external financing needs for 2021-25 at US\$450 billion, of which some US\$150-200 billion could be met via new borrowing. Fund lending in the baseline/high case scenarios would cover somewhere between one-quarter and one-half of the available borrowing space.
} 
blending and PRGT graduation (Figures $3 \mathrm{~A}$ and $\mathrm{B}$ ). This will provide significant additional support to LICs at a particularly difficult time and can help catalyze grants and highly concessional loans from other development partners during and after the pandemic.

\section{The surge in lending to LICs will significantly increase country-level exposure to Fund credit, underscoring the need to carefully scrutinize capacity-to-repay in individual cases}

(Figures 3C, D, and E). Under the Baseline, the typical non-blend LIC would borrow about 11/2 percent of GDP from the PRGT annually during the crisis period (about twice the historical level), resulting in peak PRGT credit of 5-8 percent of GDP by 2025/26 (around 11 percent of government debt), before declining thereafter. Debt service would peak at around 2-3 percent of exports annually during 2025-30, compared to about 1 percent for the PRGT historically. Under the High Case scenario, nonblend LICs could have credit peaking at 6-12 percent of GDP.

\section{The unprecedented demand for Fund concessional financing is creating a large} resource gap in the PRGT (Figure 3F). The financial costs of the pandemic derive from (i) the unprecedented surge in RCF support in 2020 that will amortize over 10 years; (ii) the gradual shift toward multiyear program support, which will be committed and disbursed over the coming years, and amortized beyond the middle of the next decade; and (iii) elevated demand expected for the post-crisis decade as a result of somewhat more LICs seeking successor arrangements, higher access levels compared to pre-pandemic years, and delayed transitions into graduation and presumed blending, as a result of longer-term economic scarring.

\section{The reforms to access and blending policies proposed in this paper are estimated to} have a fairly modest impact on PRGT finances. Even under existing policies, PRGT crisis lending would reach unprecedented high levels, with credit peaking at around three times the pre-pandemic level. For illustration, reinstating the pre-pandemic PRGT access limits and caps (after the temporarily higher access limits expire) would affect about a dozen LICs for which access limits are most binding, and reduce PRGT lending by no more than SDR 11/2 billion during 2021-24-and much of this reduced PRGT lending could be offset by "top up" borrowing from the GRA by these LICs. ${ }^{36}$

\footnotetext{
36 Under the High Case, the impact would be more pronounced, with about half of eligible LICs affected, reducing PRGT lending by up to SDR $4 \frac{1}{4}$ billion, and lowering the subsidy resource gap by up to SDR 0.3 billion.
} 


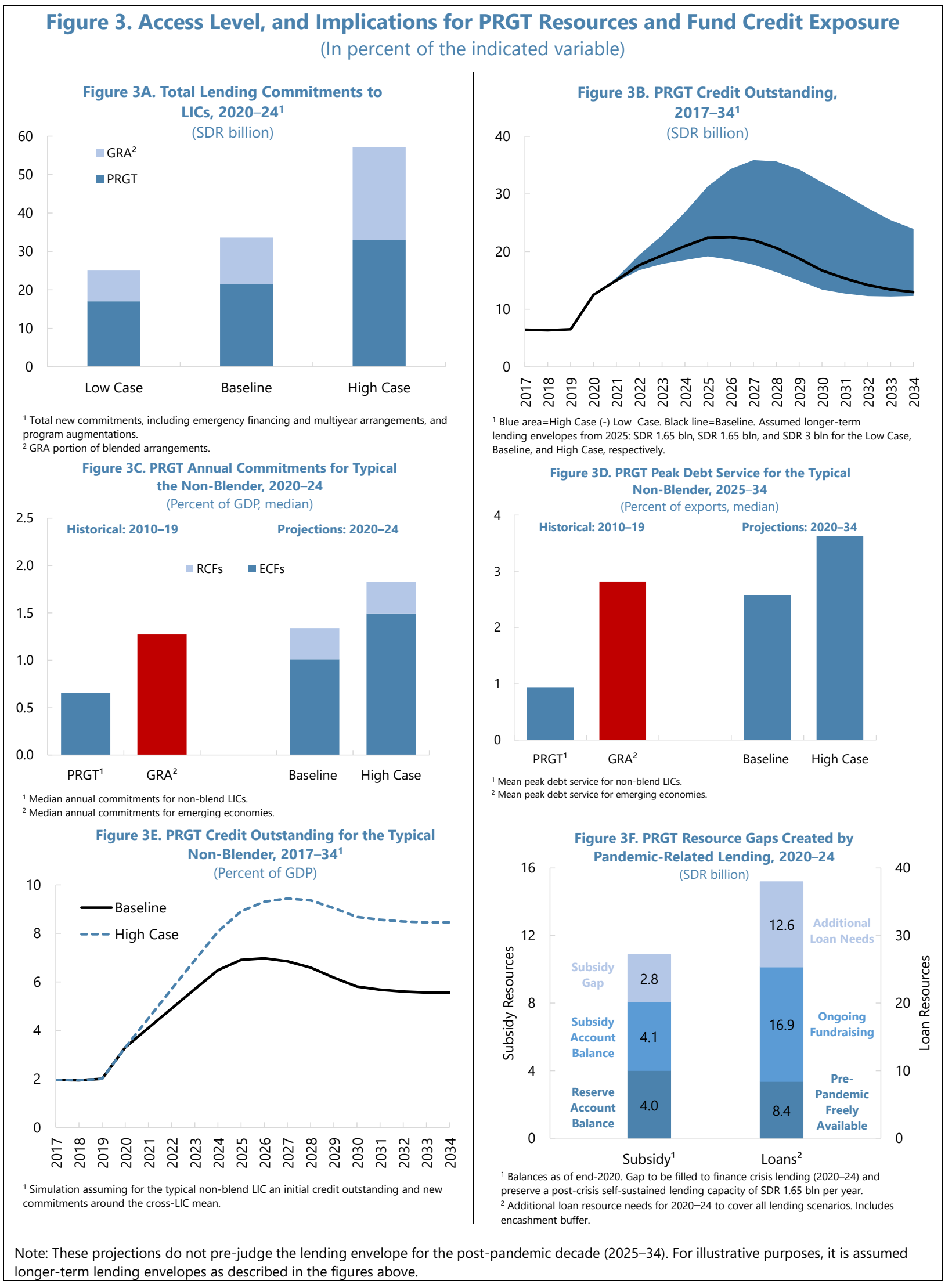




\section{FUNDING STRATEGY}

55. The PRGT's endowment has been built over several decades, relying on a mix of internal and donor contributions. The current framework for financing the Fund's concessional lending relies on loan resources periodically provided by members, credit risk mitigated by the Reserve Account, and interest rate subsidization from grant resources provided by members and Fund internal resources. Several fundraising rounds to secure loan and subsidy resources have been completed since then with the generous voluntary support of member countries. To date, members have voluntarily provided about SDR 5.3 billion to the framework's subsidy accounts and made close to SDR 55.5 billion available in loan resources. The Fund contributed about SDR 5.5 billion in internal resources, mostly derived from gold sales (see Annexes IX and X for details).

\section{Staff proposes a two-stage funding strategy to cover the resource costs created by} pandemic-related PRGT lending while preserving the long-term sustainability of the endowment-based financing model. In light of the significant uncertainties around potential demand for IMF concessional financing at this juncture, preliminary informal consultations suggest that most Executive Directors support mobilizing additional PRGT resources in two stages: (i) a medium-term fundraising effort to finance crisis-related lending while preserving the PRGT's capacity to subsidize lending in the longer term, to be followed in due course by (ii) a post-pandemic review to consider a long-term solution to PRGT self-sustainability, including through possible use of internal resources.

\section{7. "Stage one" of the strategy would aim to mobilize: (i) a further SDR $\mathbf{1 2 . 6}$ billion in} PRGT loan resources, and (ii) SDR 2.8 billion in new subsidy resources. This would close the resource gaps created by the pandemic-related financial support to LICs while preserving a base selfsustained subsidization capacity for post-crisis concessional lending.

- The additional loan resources (which require an increase in the cumulative PRGT borrowing limit from SDR 55.5 billion currently to SDR 68 billion) would increase the total loan mobilization round to almost SDR 30 billion, sufficient to cover the demand scenarios discussed above through 2024, including in the High Case. Staff would approach both current and potential new lenders to contribute these additional loan resources, on top of the SDR 17 billion already secured (Annex IX). Another round of PRGT loan mobilization would follow in 2024/25 to cover lending in the second half of the decade (part of "stage two" of the funding strategy). "Channeling" of SDRs by contributors, including from the proposed new allocation, could facilitate these loan mobilization efforts.

- The new subsidy resources would cover all pandemic-related lending under the Baseline while leaving a residual (post-crisis) self-sustained capacity of SDR 1.65 billion per year, sufficient to preserve access levels in real terms relative to pre-pandemic levels and allow for continued significant program support in the post-pandemic decade and beyond. The actual post-crisis residual self-sustained lending capacity might be somewhat higher or lower depending on the realized lending levels, to the extent they deviate from the Baseline. 
58. Staff proposes a suspension of PRGT administrative cost reimbursement through FY2026 to generate SDR 0.5 billion in subsidy resources and boost reserve coverage. ${ }^{37}$ Annual reimbursement from the PRGT Reserve Account to the GRA was made a key part of the Fund's New Income Model in 2008. The temporary suspension of reimbursement, however, is one of the recognized contingency measures under the PRGT's three-pillar framework when self-sustained capacity falls short of the target envelope (Annex X). The proposed suspension would retain these resources in the PRGT Reserve Account, which has the dual benefit of adding to the PRGT's endowment for subsidization purposes and improving the reserve coverage ratio. The proposed suspension would also slow the accumulation of Precautionary Balances in the GRA by an equivalent amount, although it is not expected to significantly delay reaching the current SDR 25 billion target.

59. Bilateral subsidy contributions of SDR 2.3 billion will be sought in a broad, burdenshared fundraising campaign involving economically stronger member countries based on their respective quota shares. Solidarity with low-income members and burden sharing among donors have been crucial to the PRGT's financing framework since its inception. Based on this approach and the proven generosity of the Fund's membership, IMF management would request bilateral contributions from a similar group that was asked to contribute to the recent CCRT grant mobilization campaign, in particular Financial Transactions Plan (FTP) members and other advanced and G20 countries, excluding any countries requiring IMF

Table 1. Proposed Burden Sharing for SDR 2.3 Billion in New PRGT Subsidy Resources (In SDR million unless otherwise noted)

\begin{tabular}{lcccc}
\hline & $\begin{array}{c}\text { Number of } \\
\text { countries in } \\
\text { the group }\end{array}$ & $\begin{array}{c}\text { Percent } \\
\text { share in total } \\
\text { member } \\
\text { quota }\end{array}$ & $\begin{array}{c}\text { Cumulative } \\
\text { PRGT subsidy } \\
\text { contributions } \\
\text { as of } \\
\text { April 30, 2021 }\end{array}$ & $\begin{array}{c}\text { 1llustrative new } \\
\text { contributions } \\
\text { request based on } \\
\text { SDR 2.3 billion } \\
\text { target and quota } \\
\text { shares }\end{array}$ \\
\hline All members & $\mathbf{1 9 0}$ & $\mathbf{1 0 0 . 0 0}$ & $\mathbf{5 , 3 0 4}$ & $\mathbf{2 , 3 0 0}$ \\
FTP members & 50 & 83.01 & 4,874 & 2,172 \\
G-7 & 7 & 43.47 & 3,077 & 1,138 \\
Other advanced & 22 & 18.20 & 1,290 & 476 \\
Other FTP members & 21 & 21.34 & 508 & 558 \\
Non-FTP members & 11 & 4.89 & 125 & 128 \\
Total from 61 members & $\mathbf{6 1}$ & $\mathbf{8 7 . 9 0}$ & $\mathbf{4 , 9 9 9}$ & $\mathbf{2 , 3 0 0}$ \\
Total from other members ${ }^{3}$ & $\mathbf{9 3}$ & $\mathbf{1 2 . 1 0}$ & $\mathbf{3 0 5}$ & $\mathbf{\ldots}$ \\
\hline
\end{tabular}

${ }^{1}$ Staff estimates of cumulative contributions (i.e., grants, returns on members' deposits and implicit contributions) made to the PRGT and its predecessors under all fundraising efforts since 1987, including income earned on outstanding balances of the contributions and excluding amounts transferred to the MDRI-II Trust in January 2006.

${ }^{2}$ All contributions are voluntary. Indicative contributions are calculated based on quota shares of 61 economically stronger member countries, including those participating in the Financial Transaction Plan (FTP) and G-20 and European Union members that have not used Fund resources for BoP needs over the last 3 years.

${ }^{3}$ Of the 190 members of the Fund, 154 provided subsidy contributions to the PRGT. BoP support in the last three years (Table 1). To ensure the PRGT reform and funding package is fully financed, management would request bilateral subsidy pledges in the coming months, even if these pledges are still subject to domestic procedures.

\footnotetext{
37 The reimbursement of the PRGT can be waived notwithstanding the fact that the PRGT contains Special Disbursement Account (SDA) resources derived from gold sales profits. For details, see Annex VIII.
} 
60. To provide donors with flexibility, various options for bilateral subsidy contribution schemes are available, with resources pledged upfront and disbursed over time. In the current low interest rate environment, PRGT subsidy resources will not run out any time soon. The Fund can thus accommodate options that involve a gradual accumulation of subsidy contributions so long as the agreed PRGT funding package is backed up by sufficient upfront pledges. Individual donors could choose one or a combination of methods for delivering their pledged subsidy contributions. These include (also see Annex $\mathrm{XI}$ ):

- Budgetary grants. For many donors, this will be the most straightforward approach. Individual donors could disburse pledged budgetary grants upfront or in future years, possibly in annual tranches, depending on domestic budgetary procedures. It would also be possible to provide PRGT subsidy contributions over a longer period, say 10 years, based on subsidized loan or deposit/investment agreements (see below).

- Donating SDRs or interest earnings. Outright donations of SDR holdings are possible but typically constrained by domestic institutional frameworks (e.g., central banks' legal mandates) and entail ongoing costs for donors that remain responsible for SDR charges on their SDR allocation, as well as potential permanent costs should the Fund ever decide to cancel SDRs. To the extent that donations of SDRs require budgetary appropriations, many donors may prefer providing a budgetary grant in their country's own or other currency. Some donors may, however, be in a position to contribute part of the interest earned on their SDR holdings (or from their interest earnings on GRA lending), which can deliver subsidy resources over time (Table 2).

- Providing PRGT loans at below the SDR rate. Such loans, which can be in currencies or members' SDR holdings, provide savings to the Trust on its subsidization expenses and can be counted as a source of implicit subsidy grant contributions. One way to operationalize such loan agreements would be to introduce a cap on interest paid to lenders at a level below the projected SDR rate. While the implicit subsidy contribution would be low in the current interest rate environment, it can deliver a significant benefit over time as rates rise, with the implicit subsidy provided by the loan to the PRGT co-moving with the cost of subsidization of PRGT

Table 2. Subsidy Value of a SDR 1 Billion 10-Year Contribution to the PRGT Under Alternative Methods ${ }^{1}$ (In SDR million)

\begin{tabular}{|c|c|c|c|c|}
\hline \multirow[t]{2}{*}{ Contribution Method } & \multicolumn{2}{|c|}{$\begin{array}{c}\text { Baseline Interest } \\
\text { Assumptions }^{2}\end{array}$} & \multicolumn{2}{|c|}{$\begin{array}{l}\text { Interest Rates 100bp } \\
\text { Above Baseline }\end{array}$} \\
\hline & Nominal & NPV & Nominal & NPV \\
\hline Grant provided in 10 annual tranches & 1,000 & 946 & 1,000 & 889 \\
\hline Implicit subsidy loan to PRGT provided at $5 \mathrm{bp}$ rate $^{3}$ & 110 & 102 & 182 & 157 \\
\hline Interest on member's SDR holdings in excess of $5 b p^{4}$ & 151 & 138 & 251 & 216 \\
\hline \multicolumn{5}{|l|}{ Earnings on investment pooled with PRGT assets ${ }^{5}$} \\
\hline a. Remunerated at $5 \mathrm{bp}$ & 268 & 230 & 398 & 306 \\
\hline b. Remunerated at SDR rate & 94 & 80 & 94 & 72 \\
\hline \multicolumn{5}{|l|}{ Memorandum item } \\
\hline Subsidy cost of SDR 1 billion PRGT credit outstanding ${ }^{6}$ & 156 & 143 & 256 & 221 \\
\hline \multicolumn{5}{|c|}{$\begin{array}{l}{ }^{1} \text { Unless otherwise noted, estimated for } 10 \text {-year contribution period starting in } 2022 \text {, end- } 2020 \\
\text { NPV discounting at the assumed SDR rate, and remuneration of non-grant contributors at the } \\
\text { floor SDR rate of } 5 \mathrm{bp} \text {. } \\
{ }^{2} \text { Assumes gradual normalization of interest rates to a steady state of } 3 \text { percent. } \\
{ }^{3} \text { Based on stylized ECF commitment with disbursements starting in } 2022 \text { and repayments } \\
\text { completed by end } 2033 \text {. } \\
{ }^{4} \text { A member could instruct the IMF to transfer from its SDR holdings an amount of interest } \\
\text { earned above } 5 \text { bp. } \\
{ }^{5} \text { Assuming annual return on PRGT assets at SDR rate plus } 90 \text { bp margin. } \\
{ }^{6} \text { Based on SDR } 1 \text { billion of credit outstanding over ten year period and zero rate paid by PRGT } \\
\text { borrowers. }\end{array}$} \\
\hline
\end{tabular}


lending. For illustration, a SDR 1 billion loan to the PRGT provided at a fixed 5 basis points and disbursed over three years would generate an expected NPV subsidy contribution of about SDR 100 million over 13 years assuming a gradual normalization of interest rates (Table 2).

- Investing resources in the Trust (in eligible investments under the PRGT's investment strategy or BIS obligations) in the context of deposit or investment agreements where the member's principal is invested and generates net investment returns that are used as subsidy resources. The member eventually receives back the principal at maturity or another terminating event (see Annex XI). Such investments could be done in currencies or from a member's SDR holdings for a period of time (e.g., 10-20 years or until such time as the pledge contribution has been met) with all or part of the net earnings on the investments retained in the Trust as subsidies. Investment agreements entail a certain degree of investment risk-realized investment returns could turn negative, particularly over shorter horizons, leading to a potential loss in the principal. Incorporating some flexibility in the maturity schedule for the investment agreement could help manage investment risk by linking the maturity to the attainment of the pledged contribution. The speed at which the overall subsidy contribution accumulates depends both on realized investment returns and on the remuneration received by the contributor-for instance, a flat remuneration at 5 basis points would generate significantly higher subsidy contributions over a given investment horizon than an investment that is remunerated at the prevailing SDR rate (Table 3).

61. To facilitate bilateral subsidy contributions and reinforce reserve coverage, staff proposes the creation of two new PRGT accounts that can receive member contributions-a "Subsidy Reserve Account" (SRA) and a "Deposit and Investment Account" (DIA). The SRA would have the dual purpose of holding and investing PRGT subsidy resources while also providing an additional backstop to the PRGT Reserve Account (RA) to help manage credit risk. The DIA would allow members to channel SDRs (or currencies) for generating investment returns that could be used as PRGT subsidy resources. Resources held in both accounts would be invested alongside the balances in the existing PRGT subsidy accounts and the RA. ${ }^{38}$

\section{The proposed SRA would complement existing subsidy accounts and could receive} bilateral grants or investment returns contributed by members to finance PRGT subsidization. Members providing subsidy resources as part of the "stage one" SDR 2.3 billion bilateral fundraising campaign could choose whether to place their contribution in the SRA or any of the four existing PRGT subsidy accounts. The SRA would invest these subsidy resources alongside the pool of PRGT assets based on a Board-approved investment strategy. The main purpose of the SRA would be to provide an additional flexible vehicle for subsidizing PRGT lending while also enhancing reserve coverage by serving as a second-line backstop for the RA in the event of arrears, providing a medium-term funding bridge toward the longer-term self-sustained PRGT endowment model. Specifically:

\footnotetext{
38 The necessary amendments to the PRGT to introduce the accounts could be adopted by a majority of the votes cast and would not require the consent of current contributors to the PRGT.
} 
- SRA resources would be used for subsidizing PRGT lending after resources in the existing subsidy accounts are exhausted, and before resources in the RA become the sole funding source for subsidization under the self-sustained PRGT endowment model (where the RA has become large enough to generate investment returns that cover all subsidy needs over the long run).

- In addition, the SRA would be designated as a "second line" backstop for reserve coverage in the (highly unlikely) event that resources in the RA were to be depleted as a result of very large arrears. Resources contributed to the SRA would thus have the dual benefit of bolstering the PRGT's self-sustained subsidization capacity (similar to grants provided to other subsidy accounts) while at the same time mitigating (tail) credit risks by increasing effective reserve coverage of credit outstanding. ${ }^{39}$

- As with other contributor-funded accounts in the PRGT, it is proposed that any amendments to the provisions of the SRA that would adversely affect the interests of contributors would be subject to the consent of creditors, who would retain the right to receive their pro-rata contributions back in the event of changes that they did not agree with. ${ }^{40}$

\section{The proposed DIA would become the main vehicle for borrowing SDRs or currency from members with the objective of generating investment returns for PRGT subsidization} Members wishing to contribute subsidy resources via a long-term investment in the PRGT can already enter into deposit or investment agreements. The purpose of the DIA would be to centralize any such new resources in a separate account, which could support larger-scale investments by facilitating liquidity management and an encashment regime.

- Members' investments in the DIA would be remunerated at a fixed or floating rate, between zero and the SDRi, depending on contributor preferences. The investment returns (above the agreed rate of remuneration) attributed to a contributor would be transferred as a subsidy contribution to the SRA at the final maturity of the member's investment agreement.

- Investment agreements would generally be long term (e.g., 10-20 years), with the final maturity depending on the total amount placed in the DIA, the member's target subsidy contribution, and the interest remuneration paid to the member (lower flat rates would generate the targeted amount of subsidy resources more quickly). As discussed above, investors would bear some degree of investment risk, which can be managed by building flexibility into the maturity schedule of the investment agreement. ${ }^{41}$

- The resources could be pooled and invested alongside other PRGT assets, based on a Boardapproved investment strategy (the current one aims to generate a long-term return of the SDR

39 The SRA proposal has several advantages over the (alternative) option of contributors directly placing grants in the RA: (i) resources derived from SDA resources are not co-mingled with contributor resources; (ii) grant contributions would more quickly be used for their primary purpose of subsidization (before the RA); and (iii) grants would be used only for coverage of arrears after the resources in the RA are exhausted.

${ }^{40}$ Existing protected provisions are listed under Section IX of the PRGT Instrument.

41 Borrowed resources would fall under the existing investment authority to invest temporary resources from members in which the contributing member bears the investment risk. See Annex XI and "Investment of Temporary Resources to Generate Income to Contribute to PRG, PRG-HIPC and CCR Trusts." IMF (2017b) 
rate plus 90 basis points). An alternative would be to develop a separate investment strategy specifically for DIA assets, assuming that the pool of resources is sufficiently large and the riskreturn profile is considered to be substantially different from the PRGT subsidy accounts and RA. Staff will develop an appropriate investment strategy following consultations with potential contributors to the DIA. This will be discussed with the Executive Board in the context of the ongoing Review of the Investment Account and Trust Asset Investment Strategy.

- SDRs or currencies placed in the DIA could retain their reserve asset status if they can be encashed upon the representation that the relevant member is experiencing a BoP need, ${ }^{42}$ subject to a commitment that the contributor reconstitutes the investment once the relevant member no longer has a BoP need. An encashment buffer could be created by participating contributors depositing an additional amount of SDRs equivalent to 20-30 percent of their invested resources into the DIA (remunerated at the SDRi), which would be kept available to allow any participating contributor to encash its DIA assets quickly if needed. An alternative would be to invest DIA resources based on an investment strategy that allocates a certain share of the portfolio in sufficiently liquid assets that can support encashment, which would however result in lower expected investment returns and hence a reduced subsidy contribution for a given principal amount and investment period. DIA investments would be best placed by members with strong BoP and reserve positions and low risk of encashment needs.

- If donors choose a combination of methods for delivering their pledged subsidy contributions, the DIA could facilitate the "stage one" subsidy fundraising campaign by providing contributing members the option of contributing up to half of their prospective subsidy contribution through a long-term investment agreement. If all contributors pursued this option, it would result in around SDR 10 billion in DIA investments.

- To the extent that the DIA can facilitate channeling of SDRs, which will be in ample supply if the proposed SDR allocation is approved, it may also be a useful vehicle for generating additional subsidy resources as part of stage two of the funding strategy.

\footnotetext{
42 Where a contributor is not a member but rather an institution of a member, the representation of BOP need would be made by the contributor based on the BOP situation of the relevant member.
} 
64. The first stage of the funding strategy would fully finance crisis-related resource needs and help preserve adequate reserve coverage under the Baseline. The suspension of PRGT reimbursement to the GRA through FY26 would retain additional resources in the $R A$, which would increase gradually over time based on investment returns. Reserve coverage of PRGT credit outstanding would decline from currently 32 percent to an average of 22-34 percent in 2025-29 (depending on demand for PRGT loans and the level of subsidy contributions channeled to the proposed SRA), before gradually increasing thereafter. For illustration, and assuming that about half of PRGT subsidy contributions are channeled to the SRA, the reserve coverage ratio would remain above 20 percent throughout even if PRGT lending is 20 percent above the

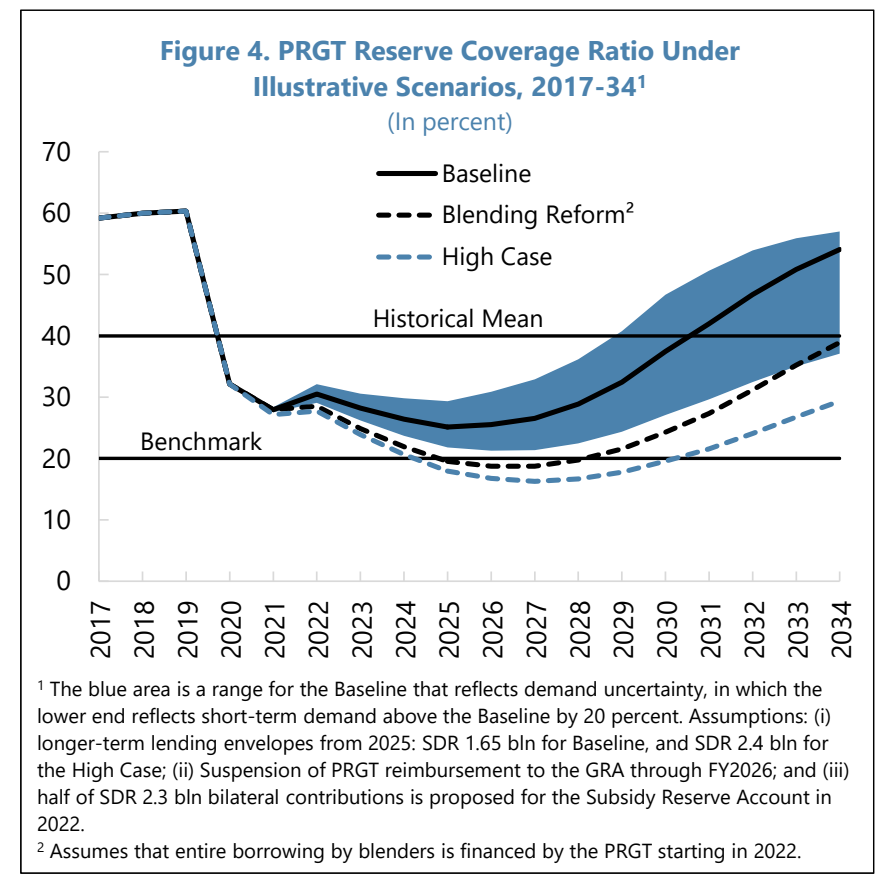
Baseline (Figure 4). If a significantly higher lending trajectory were to materialize, or the reform option of providing "all-PRGT" financing to presumed blenders is implemented (see Box 3), an interim review of concessional financing and policies would be called for, including to assess options for bolstering credit protections (see below).

\section{The adequacy of PRGT resources would need to be carefully monitored throughout the} first phase of the funding strategy. The two-stage funding strategy is designed to be robust enough to allow for some variation around Baseline lending and fundraising assumptions, as well as deviations from assumed interest rates and investment returns. For instance, under the Baseline scenario, a shortfall of one-third in bilateral contributions would reduce the self-sustained capacity in the post-crisis decade by more than 10 percent, to below SDR 1.5 billion per year. Such a shortfall would increase the amount of needed contributions to be raised in the second stage of the proposed funding strategy by about SDR 0.7 billion - which is the minimum amount that would need to be raised to achieve a self-sustained lending envelope of at least SDR 1.65 billion a year. However, under the Low Case, this illustrative shortfall would not undermine the PRGT's self-sustainability, as it would be roughly offset by the lower subsidy needs estimated for this scenario (see last block of Table 3).

66. Annual reviews by the Executive Board could trigger contingency measures when the evolution of lending and/or fundraising points to substantial risks to PRGT resources that would warrant urgent remedial actions prior to the second stage review in 2024/25. Annual reviews will include: (i) an update of lending developments and demand projections, (ii) an update on loan and subsidy resource mobilization, as well as investment and interest developments, (iii) an assessment of the PRGT's lending capacity and resource outlook, (iv) an assessment of credit risks, 
Fund exposure across LICs, and reserve coverage outlook, and (v) possible options for adapting the funding strategy if warranted. In the event of a significant fundraising shortfall, an exceptionally high lending trajectory, and/or a significant deterioration in multiple borrowers' capacity to repay the Fund, it may be necessary to take remedial measures to ensure adequate subsidy and loan resources, and/or credit protections. IMF management may then propose possible contingency measures ahead of the second stage review. These could include:

- Additional bilateral fundraising efforts, led by IMF management and supported by the Executive Board; the focus could be on any countries that have not yet pledged/disbursed a quota-based share for the stage one fundraising target;

- A decision to extend the suspension of reimbursements to the GRA for PRGT administrative costs for a number of years beyond FY2026; while it would take some time to have a material impact on reserve coverage, it would be a lasting one, and provide additional subsidization capacity;

- Seeking member support for a "gold pledge" that would provide a backstop for possible future credit losses and possibly also a restoration of subsidization capacity under certain conditions; while a gold pledge could be potentially implemented more quickly than outright gold sales, it would require the same broad support, including 85 percent of the total voting power for the Executive Board decision and parliamentary procedures where applicable;

- A coordinated effort to secure government guarantees from a group of advanced countries as an ultimate backstop against possible credit losses, in the event that reserve coverage is deemed insufficient;

- A Board decision to consider a distribution of GRA reserves to facilitate contributions to the PRGT, contingent on a minimum threshold of pledges being reached, once precautionary balances have reached their medium-term target;

- Recalibration of access limits and norms; any reductions in room for PRGT access would need to consider possible spillovers of LICs' demand into top-up financing through the GRA;

- A review of the PRGT interest framework that could lead to higher, though still concessional lending rates.

67. A decision on the appropriate longer-term PRGT envelope would be taken up at the second stage of the funding strategy, as part of the next full Review of Concessional Financing and Policies scheduled for $\mathbf{2 0 2 4 / 2 5}$. As is customary, this would include a review of policies and possible reforms, the financial situation of the endowment under different policy and demand scenarios, and a broad range of possible funding options. A central question for the review will be the appropriate longer-term self-sustained lending capacity of the PRGT. The additional funding needs at stage two will depend on the actual crisis-period lending levels, the outlook for demand for concessional resources, which is highly uncertain, and any further policy reforms.

- A self-sustained lending envelope of SDR 1.65 billion annually would essentially maintain access per country at the pre-pandemic level in real terms, allowing for future periodic upward revisions to access limits and norms to avoid eroding access relative to nominal GDP, consistent with the 
approach taken during the 2018/19 LIC facilities review. ${ }^{43}$ This envelope would accommodate supporting LICs with longer-term scarring from the pandemic, several of which would be expected to seek successor arrangements in the second half of the decade. However, if realized lending during the pandemic turns out to be at high levels, such an envelope could constrain the scope for a smooth transition of LICs as they reduce their exposure to Fund credit in the postpandemic period.

- The second stage review will consider the merits of a larger self-sustained PRGT lending envelope. For instance, a lending capacity of SDR 2.4-3.0 billion a year would make room for percountry PRGT access levels broadly in line with GRA arrangements for EM countries, and limit the risk of LICs resorting to "top up" GRA borrowing. Such an increased steady-state lending capacity could help smooth the transition of LICs reducing their exposure to Fund credit in the postpandemic period. For instance, if lending evolves as assumed under the Baseline, mobilizing additional subsidy resources of SDR 3.4 billion in stage two (on top of the SDR 2.8 billion mobilized in stage one) would increase the long-term self-sustained lending capacity from SDR 1.65 billion to SDR 2.4 billion a year.

- The more Fund lending that materializes during the crisis years, the larger will be the need to supplement PRGT finances at the second stage. For instance, in the extreme case that near-term demand evolves along the High Case trajectory, the residual self-sustained annual lending capacity would decline to around SDR 1.3 billion by end-2024 (assuming the fundraising target of the stage one funding campaign has been met). Such reduced lending capacity would severely constrain the Fund's ability to support LICs in the longer term and would justify mobilizing additional subsidy resources, potentially in the range of around SDR 5-71/2 billion to increase the self-sustained lending capacity to SDR 2.4-3.0 billion a year.

\section{Voluntary "channeling" of SDRs would facilitate the mobilization of additional PRGT loan resources, which could range from SDR 24-34 billion for the remainder of this decade (2021-29), and significantly more if blenders were to receive "all PRGT" financing. ${ }^{44}$ These} ranges assume a significant spike in crisis lending through 2024, and another round of loan mobilization in 2024/25 to cover concessional lending over the second half of the decade. The higher end of the range assumes a scaling up of the PRGT's longer-term lending capacity. If the Board were to endorse a move toward the reform option of "all PRGT" financing for presumed blenders, loan resource needs could rise to around SDR 42-59 billion.

- Total SDRs channeled to the PRGT over the coming years are projected in the range of SDR 2035 billion, of which SDR 12-20 billion in the near term. These estimates include possible channeling of SDRs as investment resources for the DIA.

\footnotetext{
43 See "2018-19 Review of Facilities for Low-Income Countries-Reform Proposals" (IMF Policy Paper No. 19/014, IMF (2019a)).

44 This would be on top of the SDR 17 billion already mobilized so far. The estimates take into account the assumed encashment buffer of 20 percent.
} 
- The overall range for the decade could increase to around SDR 33-54 billion if the additional blending reform is implemented, which would require large additional PRGT loan resources.

69. Use of IMF internal resources should be carefully considered during the "stage two" review, especially if the Board were to pursue a significantly larger PRGT lending envelope and associated endowment. This could include a limited sale of IMF gold, which could be used to boost the RA and also generate investment returns for subsidization, or alternatively a distribution of IMF reserves conditional on securing a critical threshold of commitments from members to contribute equivalent amounts for PRGT subsidies. Both options would need to be carefully assessed against their impact on the Fund's balance sheet. Broad support across the membership, and sufficient time for implementation, would be required for the use of either of these options. 


\begin{tabular}{|c|c|c|c|c|c|c|c|c|c|c|c|c|}
\hline & & & 3 & $\begin{array}{l}\text { ections U } \\
\text { (In SDR b }\end{array}$ & $\begin{array}{l}\text { nder Illus } \\
\text { illion, unl }\end{array}$ & $\begin{array}{l}\text { rative } \\
\text { ss indica }\end{array}$ & $\begin{array}{l}\text { land Sce } \\
\text { otherwi }\end{array}$ & $\begin{array}{l}\text { narios, } 2 \\
\text { se) }\end{array}$ & 20-34 & & & \\
\hline \multirow{4}{*}{ Scenario } & \multicolumn{12}{|c|}{ New Lending Commitments by Borrower Type } \\
\hline & \multicolumn{6}{|c|}{$2020-24$} & \multicolumn{6}{|c|}{$2025-34$} \\
\hline & \multicolumn{3}{|c|}{ PRGT } & \multicolumn{3}{|c|}{ PRGT+GRA } & \multicolumn{3}{|c|}{ PRGT } & \multicolumn{3}{|c|}{ PRGT+GRA } \\
\hline & Blender & Non-Blender & Total & Blender & Non-Blender & Total & Blender & Non-Blender & Total & Blender & Non-Blender & Total \\
\hline Low Case ${ }^{1}$ & 5.5 & 11.5 & 17.0 & 13.5 & 11.5 & 25.0 & 2.7 & 13.8 & 16.5 & 8.2 & 13.8 & 22.0 \\
\hline Baseline $^{2}$ & 7.3 & 14.1 & 21.5 & 19.5 & 14.1 & 33.6 & $2.7-4$ & $13.8-20$ & $16.5-24$ & $8.2-12$ & $13.8-20$ & $22-32$ \\
\hline \multirow[t]{2}{*}{ High Case $^{3}$} & 11.6 & 21.4 & 33.0 & 35.7 & 21.4 & 57.1 & $6.8-8.4$ & $17.2-21.6$ & $24-30$ & $20.3-25.3$ & $17.2-21.6$ & $37.5-46.9$ \\
\hline & \multicolumn{9}{|c|}{ Average Credit Outstanding ${ }^{4}$} & \multicolumn{3}{|c|}{ Average Reserve Coverage Ratio ${ }^{5}$} \\
\hline \multirow{2}{*}{ Scenario } & \multicolumn{3}{|c|}{$2020-24$} & \multicolumn{3}{|c|}{$2025-29$} & \multicolumn{3}{|c|}{$2030-34$} & $2020-24$ & $2025-29$ & 2030-34 \\
\hline & PRGT & GRA & Total & PRGT & GRA & Total & PRGT & GRA & Total & \multicolumn{3}{|c|}{ Percent of PRGT Credit Outstanding } \\
\hline Low Case $^{1}$ & 16.1 & 4.3 & 20.4 & 17.4 & 6.4 & 23.8 & 12.6 & 5.5 & 18.1 & 30.6 & 34.0 & 52.8 \\
\hline Baseline $^{2}$ & 17.1 & 5.0 & 22.1 & $21.3-22.4$ & $9.8-10.3$ & $31-32.7$ & $14.5-18.8$ & $7.2-8.8$ & $21.8-27.6$ & 29.1 & $26.1-27.7$ & $35.4-46.2$ \\
\hline High Case $^{3}$ & 19.4 & 6.8 & 26.2 & $33.2-34.3$ & $21.8-22.4$ & $54.9-56.7$ & $24.3-27.8$ & $19.2-19.1$ & $43.5-46.8$ & 26.3 & $17.1-17.7$ & $24.3-28$ \\
\hline \multirow{4}{*}{ Scenario } & \multicolumn{12}{|c|}{ PRGT Resource Gap and Fundraising } \\
\hline & \multicolumn{6}{|c|}{ Phase 1: 2021-24 } & \multirow{2}{*}{\multicolumn{3}{|c|}{ Phase 2: 2025-29 }} & \multicolumn{3}{|c|}{ Phase 2: 2025-34 } \\
\hline & \multicolumn{3}{|c|}{ Loan Resources } & \multicolumn{3}{|c|}{ Subsidy Resources } & \multicolumn{2}{|c|}{ Loan Resources } & & \multicolumn{3}{|c|}{ Subsidy Resources } \\
\hline & Needs $^{6}$ & Available $^{7}$ & Gap & GRA Reimb. ${ }^{8}$ & Bilateral $^{9}$ & Gap & Needs $s^{6,10}$ & Available & Gap & GRA Reimb. & Bilateral $^{8,9}$ & Gap \\
\hline Low Case $^{1}$ & 19.6 & 25.4 & -5.8 & 0.5 & 2.3 & -0.6 & 11.8 & 0.0 & 11.8 & 0.0 & 0.0 & 0.0 \\
\hline Baseline $^{2}$ & 24.7 & 25.4 & -0.7 & 0.5 & 2.3 & 0.0 & $11.8-16.4$ & 0.0 & $11.8-16.4$ & 0.0 & $0-3.4$ & $0-3.4$ \\
\hline High Case $^{3}$ & 38.0 & 25.4 & 12.6 & 0.5 & 2.3 & 5.0 & $17.8-21.3$ & 0.0 & $17.8-21.3$ & 0.0 & $5-7.7$ & $5-7.7$ \\
\hline $\begin{array}{l}{ }_{1} \text { For 2020-24 } \\
{ }^{2} \text { For 2020-24 } \\
{ }^{3} \text { For 2020-24 } \\
{ }^{4} \text { Credit outsta } \\
{ }^{5} \text { Assumes sus } \\
{ }^{6} \text { Total loan re } \\
7 \text { Pre-pandem } \\
{ }^{8} \text { Suspension } \\
{ }^{7} \text { Needed bila } \\
{ }^{10} \text { Assumes th }\end{array}$ & $\begin{array}{l}\text { at about one } \\
\text { at nearly twe } \\
\text { at about fou } \\
\text { pre-existing } \\
\text { reimbursen } \\
\text { for the indi } \\
\text { loan resour } \\
\text { ement to th } \\
\text { s from the } n \\
\text { rm envelope }\end{array}$ & $\begin{array}{l}\text {-third of LICS seek } \\
\text {-thirds of LICs seek } \\
\text {-fifths of LICs seek } \\
\text { palances) of PRGT } \\
\text { ent to the GRA thro } \\
\text { ated period, includ } \\
\text { es plus new loan r } \\
\text { GRA through FY2C } \\
\text { embership. } \\
\text { as described abo }\end{array}$ & $\begin{array}{l}\text { d financ } \\
\text { nd finan } \\
\text { nd finan } \\
\text { jible col } \\
\text { h FY } 202 \\
\text { encash } \\
\text { urces se }\end{array}$ & $\begin{array}{l}\text { that average acce } \\
\text { d that average acc } \\
\text { that average acce } \\
\text { sver the indicated } \\
\text { of SDR } 2.3 \text { bln bila } \\
\text { ffer. } \\
\text { so far under the or } \\
\text { needs for the peri }\end{array}$ & $\begin{array}{l}\text { ess is somewhat } \\
\text { ess is almost twi } \\
\text { ess is almost thr } \\
\text { period. Reflects } \\
\text { teral contributior } \\
\text { ngoing loan mob } \\
\text { od 2025-29. }\end{array}$ & $\begin{array}{l}\text { ove the histor } \\
\text { the historical } \\
\text { times the his } \\
\text { e range of cor } \\
\text { is proposed } \\
\text { ization round. }\end{array}$ & $\begin{array}{l}\text { erage. For } 202 \\
\text { ge. For } 2025-3 \\
\text { average. For } 2 \\
\text { ents and longe } \\
\text { supplementar }\end{array}$ & $\begin{array}{l}5-34 \text {, it is assum } \\
4, \text { it is assumed } \\
25-34 \text {, it is assu } \\
\text {-term lending e } \\
\text { reserve accoun }\end{array}$ & $\begin{array}{l}\text { an illustrativ } \\
\text { illustrative le } \\
\text { ed an illustrat } \\
\text { elopes as de } \\
\text { 2022; and a }\end{array}$ & $\begin{array}{l}\text { ing envelopes of } \\
\text { envelopes of SDF } \\
\text { nding envelopes } \\
d \text { above. } \\
\text { iger-term lending }\end{array}$ & $\begin{array}{l}\text { f SDR } 1.65 \text { billion } \\
\text { R } 1.65-2.4 \text { billion } \\
\text { of SDR } 2.4-3 \text { bill } \\
\text { g envelopes as } d\end{array}$ & scribed above \\
\hline
\end{tabular}




\section{Box 3. Financing Implications of Alternative Loan Terms for Presumed Blenders}

The reform option discussed in Section III would provide presumed blenders with "all PRGT" lending at a differential (but still concessional) interest rate from non-blenders, rather than the current 2:1 mix of GRA and PRGT. This would have important implications for subsidy and loan resources, as well as reserve coverage. To illustrate:

- $\quad$ Under Baseline demand projections, PRGT credit outstanding would peak at SDR 27.5 billion, rather than SDR 22.5 billion, reflecting the shift from blended to all-PRGT financing for blenders.

- The reform would increase PRGT loan resource needs by SDR 26 billion for the remainder of the decade, which could be facilitated by SDR "channeling."

- Under Baseline demand assumptions, the reform would generate net subsidy savings to the PRGT of around SDR 40 million during 2023-25, and SDR 500 million through 2034.

- Reserve coverage would reach a trough of 17 percent under the reformed Baseline. To keep reserve coverage above 20 percent, the Reserve

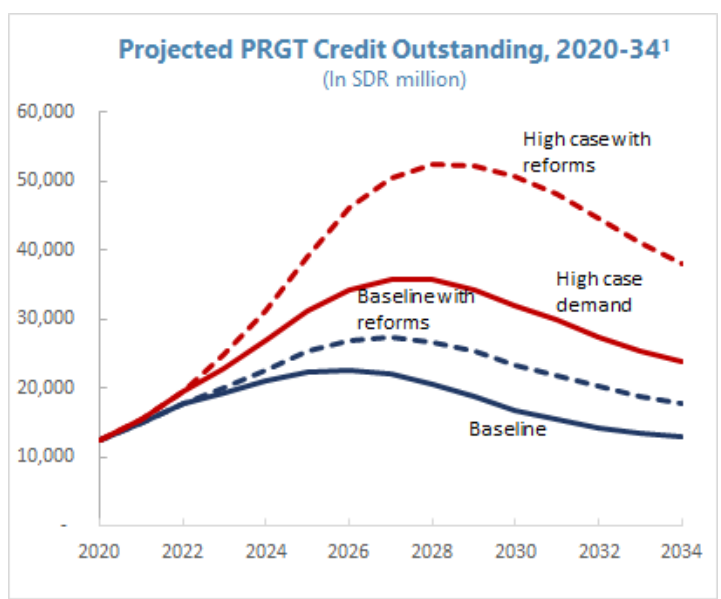

1 Assuming projected demand under the baseline and under reforms, when entire borrowing by blenders is financed by the PRGT starting from 2023. Account would need to be augmented by more than SDR 1 billion.

Providing "all-PRGT" loans to presumed blenders would have a number of other financial implications. It would introduce a floating rate for concessional lending, which could have potential implications for financial reporting under IFRS-9 and donors' accounting of the amount of ODA provided to the PRGT. System changes would be required to track different loan terms under the same facility depending on the borrower's blend status at the time of financing approval. Under the proposed interest formula (two-thirds of the GRA rate of charge), the net interest paid by presumed blenders to the PRGT when global rates are low would have to be tracked and attributed in financial reporting.

\section{PRGT INTEREST RATE REVIEW}

70. In line with the approved PRGT interest rate mechanism, staff proposes keeping zero interest rates for all PRGT credit outstanding under the ECF, SCF, and RCF. The PRGT interest rate mechanism, adopted in 2009 and most recently modified in 2019, established the interest rate across PRGT facilities and links them to the global interest rate, which have been historically low. The current interest rate mechanism has served borrowers well, allowing for zero rates on all facilities. Applying the PRGT's existing interest rate setting mechanism and thresholds and based on the average SDR interest rate over the most recently observed 12 -month period $\left(0.08\right.$ percent $\left.{ }^{45}\right)$, staff proposes a continuation of a zero interest rate for the ECF, the SCF as well as for the RCF until July 2023. Staff also proposes that the next review of PRGT interest rates will be held according to the

${ }^{45}$ Covering the period from June 2020 to May 2021. 
usual schedule in two years by July 2023. This could include a discussion of interest rates for presumed blenders if the Executive Board decides to consider the reform option discussed above. See Annex XII for background on the current interest mechanism.

\section{DEBT RELIEF FINANCING}

\section{Catastrophe Containment and Relief Trust (CCRT)}

71. Additional resources are needed to fund the mandate of the CCRT. The CCRT was created in 2015 to provide grants for debt relief to eligible low-income members hit by catastrophic natural disasters or fast-spreading public health disasters. In March 2020, the Executive Board adopted a set of reforms to the CCRT to provide immediate debt service relief to the poorest and most vulnerable member countries affected by the COVID-19 pandemic. In April 2020, the Fund approved debt service relief for all 29 eligible countries of up to two years until April 2022, to be disbursed in tranches and subject to resource availability. So far, the Fund has disbursed SDR 520 million in debt service relief in three tranches through mid-October 2021, helping free up scarce financial resources for vital emergency health, social, and economic support to mitigate the impact of the COVID-19 pandemic.

72. Additional grants are urgently needed to deliver the fourth and final tranche of COVIDrelated CCRT relief. In April 2020, the IMF launched an urgent fundraising effort of SDR 1 billion (US\$1.4 billion) to provide the needed resources to cover two years of relief (SDR 679 million) and address the initial CCRT underfunding (SDR 200-275 million). To date, grant pledges of about half of the target (SDR 575 million) have been secured from 18 contributors (Annex XIII). Substantial additional grant resources are needed to unlock the fourth and final tranche of debt service relief (estimated at SDR 160 million), ending in April 2022.

\section{Heavily Indebted Poor Countries (HIPC) Initiative}

73. The HIPC Initiative is nearly completed. The Fund has provided SDR 2.6 billion in debt relief to 38 of the 39 eligible countries. ${ }^{46}$ The protracted arrears cases (Liberia, Somalia, Sudan) were not included in the original costing of the HIPC Initiative to avoid undermining the Fund's financial capacity as a result of debt forgiveness. ${ }^{47}$ Consequently, the Fund needed to mobilize the necessary resources to cover the Fund's share of debt relief for these countries.

74. In March 2020 and June 2021, the IMF and the World Bank jointly committed to provide HIPC and "beyond-HIPC" debt relief to Somalia and Sudan, respectively. A large share of the membership provided generous and timely contributions to both Somalia's and Sudan's financing packages, which utilized distributions from internal resources and new cash grants.

\footnotetext{
46 Eritrea has yet to start the HIPC qualification process.

47 See The G-8 Debt Cancellation Proposal and Its Implications for the Fund.
} 
- For Somalia, 121 countries pledged an equivalent of SDR 280.1 million to finance the IMF's share of debt relief, estimated at SDR 252.9 million. This included cash grants from 13 member countries in addition to their contributions from internal Fund resources as part of Somalia's financing package. The European Commission also provided a grant of EUR 9 million, bringing total grants for Somalia to SDR 114.2 million. Of the total pledged amount, SDR 237.3 million have materialized to date.

- For Sudan, 120 countries pledged SDR 1,059 million to finance the IMF debt relief, which is estimated at SDR 992 million. This included cash grants from 8 member countries in addition to their contributions from internal Fund resources as part of Sudan's financing package. The European Commission also provided a grant of EUR 12 million, bringing total grants for Sudan to SDR 136.5 million. As of end-April 2021, the balance in the PRG-HIPC Trust stood at SDR 258 million. 48

\section{VIII.ENTERPRISE RISKS}

75. The proposals in this paper seek to mitigate multiple enterprise risks, with risks created by the proposals consistent with current Board-approved risk acceptance levels under baseline scenarios. The proposals to increase the PRGT's access limits could mitigate strategic risks and credit/repayment risks arising from emergency lending to date by providing more headroom under existing or follow-up UCT programs on PRGT terms, reducing the need for LICs to access GRA resources. As noted in paragraph 6 above, the proposed higher access limits themselves have a relatively modest impact on PRGT resource needs in stage one of the fundraising strategy, with the primary driver of resource needs being the unprecedented surge in lending levels over the course of 2020-24. PRGT credit/repayment risks may rise by increasing the threshold for EA, although the application of staff's proposed safeguards/associated higher scrutiny should serve to mitigate this risk. Under the Baseline demand scenario and implementation of "stage one" of the funding strategy (suspension of reimbursement to the GRA and new bilateral subsidy contributions, including to the proposed SRA), the PRGT's reserve coverage ratio would remain well above 20 percent during the anticipated peak in PRGT credit outstanding, and is expected to gradually increase to above 40 percent over the longer term. The impact of suspending reimbursement to the GRA for PRGT administrative expenses through FY2026 will slow the accumulation of the Fund's precautionary balances, although there would not be a significant delay in terms of reaching the Board-approved target of SDR 25 billion.

76. Residual liquidity and credit risks remain, so the adequacy of PRGT resources would
need to be carefully monitored throughout the first phase of the funding strategy. The twostage funding strategy is designed to be robust enough to allow for some variation around baseline lending and fundraising assumptions, as well as deviations from assumed interest rates and investment returns. In addition, the proposed annual reviews of PRGT resources could trigger

\footnotetext{
48 This amount includes income earned on members' deposits agreed during 1997-2001, 14 of which have been recently extended beyond the original maturity date and continue to benefit the PRG-HIPC Trust. Five of these deposits were repurposed for the benefit of the CCRT and three for the benefit of the PRGT.
} 
contingency measures when the evolution of lending and/or fundraising point to substantial risks to PRGT resources that would warrant urgent remedial actions prior to the second stage review in 2024/25. In the event of a significant fundraising shortfall, an exceptionally high lending trajectory, and/or a significant deterioration in multiple borrowers' capacity to repay the Fund, remedial measures will likely be needed to ensure adequate subsidy and loan resources, and/or credit protections as described in the previous section.

\section{ISSUES FOR DISCUSSION}

77. Do Directors support the proposed reforms to enhance the PRGT lending framework, including:

a. increases in the normal access limits for the PRGT?

b. elimination of hard caps on PRGT exceptional access?

c. safeguards on debt sustainability/capacity to repay as endorsed by the Board in March 2021 and further elaborated in Annex VI?

d. thresholds for triggering the High Access Procedures?

e. alignment of the PRGT EA criteria with the criteria under the policy on Policy Safeguards on High Combined Credit?

f. simplification of the specification of norms?

78. Do Directors support the proposals on modifying the blending rules, including:

a. adjusting the income threshold used in determining blend status?

b. simplifying the role of market access and debt vulnerabilities in determining blend status?

c. simplifying the rules for determining the mix of PRGT and GRA resources in arrangements for presumed blenders?

79. Do Directors see merit in continued work to explore reforms that would introduce a dual interest rate mechanism in the PRGT while allowing PRGT-eligible countries to meet all their financing needs from the PRGT?

80. Do Directors support the two-stage funding strategy, with (i) a medium-term fundraising effort to finance crisis-related lending while preserving the PRGT's capacity to subsidize lending in the longer-term, to be followed in due course by (ii) a long-term solution to PRGT self-sustainability?

81. Do Directors support a "stage one" medium-term fundraising effort to mobilize (i) SDR 12.6 billion in additional loan resources, which will require an increase in the PRGT cumulative borrowing 
limit from SDR 55.5 billion currently to SDR 68 billion and (ii) SDR 2.8 billion in new subsidy resources, including a suspension of reimbursement to the GRA through FY26 and SDR 2.3 billion via a burden-shared bilateral grant fundraising campaign, providing donors flexibility in terms of timing and method of contributions?

82. Do Directors agree with the proposal for the Executive Board to review annually concessional resources and progress with stage one fundraising?

83. Do Directors support the creation of two new PRGT accounts that can receive member contributions-a "Subsidy Reserve Account" (SRA) and a "Deposit and Investment Account" (DIA)?

84. Do Directors agree that the PRGT interest mechanism remains appropriate, and that PRGT interest rates on all facilities will be set at zero through end-July 2023 ? 


\section{Annex I. PRGT Facilities-Selected Features}

\section{PRGT-eligible countries, currently 69 in number, can be divided into subgroups based on the conditions under which they can access PRGT resources (see Annex III for a full listing):}

- Blend countries (shorthand for "presumed blenders") can access PRGT resources only in conjunction with GRA resources, with the financing combined in a mix of 1:2 (PRGT: GRA) subject to a cap on the level of access to PRGT resources. Blend countries hence must meet the policy requirements of the GRA as well as the PRGT. A blend country is thus similarly positioned to a GRA-only country, except that it can access to up to one-third of its Fund financing on (more favorable) PRGT terms.

- Non-blend countries are required to access the GRA only if they are seeking Fund resources above the relevant limits on PRGT access: an access request in excess of these limits moves them to a position where their economic program must meet the policy requirements of the GRA (and PRGT). This group can be further divided into i) countries eligible to seek EA to PRGT resources and ii) countries not eligible to seek EA.

\section{PRGT lending facilities (available only to LICs) differ from the regular GRA facilities (available to all members) in some important dimensions:}

- Lending terms for the PRGT's concessional lending facilities are more generous than those provided under the corresponding GRA facility.

- The PRGT's main lending vehicle, the ECF, has distinct policy requirements from its GRA counterpart.

- Programs supported under the GRA are designed to resolve the member's BoP problems during the program period. Specifically, policy actions needed to resolve a member's BoP problem should be undertaken during the program period; implementation of these policies should lead to a strengthening of the member's BoP before repurchases begin such that repurchases from the Fund can occur without strain.

- The ECF is available to LICs that face protracted BoP problems (where underlying macroeconomic imbalances are expected to be resolved over an extended period): the purpose of programs supported under the ECF is to enable PRGT-eligible members with protracted BoP problems to make significant progress toward a stable and sustainable macroeconomic position.

- All PRGT financing instruments are expected to support policies that lead toward a sustainable macroeconomic position that is consistent with strong and durable poverty reduction and growth. ${ }^{1}$

\footnotetext{
1 PRGT-supported programs with an initial duration of more than two years are expected to be informed by an explicit Poverty Reduction and Growth Strategy (PRGS).
} 
- Given that the ECF arrangement is designed to address a member's "protracted BoP problem," a member may require a series of ECF-supported programs to resolve BoP difficulties, rather than in a single arrangement (as is normally expected to be the case for GRA-supported programs).

- Access to PRGT resources is subject to hard limits. All 69 countries are eligible for access up to the normal limits, set at 100/300 percent of quota in May 2019. ${ }^{2}$ A subgroup of 28 countries, all with incomes below the IDA operational threshold (currently \$1,185), are eligible for EA, subject to hard limits of $133 / 400$ percent of quota, provided that the programs for which they are seeking support meet the PRGT EA criteria.

2 The notation "A/B percent of quota" refers to annual and cumulative access limits, respectively. Unless otherwise stated, the access limits cited are the access limits set during the 2018-19 Review of LIC Facilities: several limits have been increased on a temporary basis since March 2020. 


\section{Annex II. The PRGT Exceptional Access Criteria and Policy Safeguards for High Combined Credit Exposures}

The PRGT EA Criteria specify safeguards that must be satisfied for use of PRGT resources above the normal access limits. PS-HCC exposure, which were approved in September 2020, specify safeguards for a member to receive combined PRGT and GRA access above the GRA exceptional access limits. The PSHCC build on the respective PRGT and GRA EA frameworks and are broadly aligned with the GRA EA criteria.

1. The PRGT EA criteria are outlined in column 1 of the table below. Requests for PRGT financing that exceed 100/300 percent of quota (temporarily increased to 245/435 through end-June 2021) can be accommodated only if these criteria are met. The language on "reduce the risk of debt distress to a moderate level or low level" in criterion 2 has been interpreted, outside the HIPC process, to mean achieving a projected assessment of moderate/low risk of debt distress within three years of program approval.

2. The PS-HCC are outlined in column 2 of the table below. Requests for Fund financing that would entail combined access to GRA and PRGT resources in excess of 145/435 percent of quota (temporarily increased to $245 / 435$ through end-December 2021) can be accommodated only if these criteria are met.

\section{Differences between the PS-HCC and the PRGT EA criteria include:}

- PRGT EA 1 requires that the country experience an exceptionally large BoP need that cannot be resolved within the normal limits. PS-HCC 1 instead requires that the country is experiencing or alternatively has the potential to experience exceptional BoP pressures (on the current or capital account) that cannot be met within the normal limits.

- PRGT EA 2 requires that the member have a comparatively strong adjustment program and ability to repay the Fund. PS-HCC 4 requires that the member's program have a reasonably strong prospect for success, taking account of both program policies and the institutional and political capacity to deliver them. The operational distinction between these conditions is not substantial: under both formulations, a program involving exceptional levels of access would be expected to be strong and have reasonably strong prospects for success.

- For countries at high risk of/in debt distress, PRGT EA 2 requires that the program being supported i) include the provision of debt relief or restructuring by creditors and ii) is projected to reduce the risk of debt distress to a moderate/low level, with the interpretation to date being that (outside the HIPC process) this must be achieved within a three-year time-frame. By contrast, PS-HCC 2 does not require a debt-restructuring as part of the program, while the timeframe for achieving moderate/low risk of debt distress (for a new program) is "within 36 months from Board approval of the financing request or within the period of a newly approved arrangement (whichever is longer)." The removal of the debt restructuring requirement contained in PRGT EA 2 from PS-HCC 2 allowed greater flexibility as to how the improved debt position 
would be achieved; adapting the three-year time frame to accommodate cases where programs would exceed three years was seen as an operationally pragmatic adjustment.

The proposed new specification of the PRGT EA criteria is contained in column 3.

\begin{tabular}{|c|c|c|c|}
\hline \multicolumn{4}{|c|}{ Annex II Table 1. Current and Proposed PRGT Exceptional Access Criteria } \\
\hline & $\begin{array}{c}\text { Current PRGT } \\
\text { EA Criteria }\end{array}$ & $\begin{array}{l}\text { HCCE (High Combined Credit Exposure) } \\
\text { Safeguards }\end{array}$ & Proposed PRGT EA Criteia \\
\hline Criterion 1 & $\begin{array}{l}\text { Countries that } \\
\text { experience an } \\
\text { exceptionally } \\
\text { large balance of } \\
\text { payments need } \\
\text { that cannot be } \\
\text { met within the } \\
\text { normal limits. }\end{array}$ & $\begin{array}{l}\text { The member is experiencing or has the } \\
\text { potential to experience exceptional } \\
\text { balance of payments pressures on the } \\
\text { current account or capital account, } \\
\text { resulting in a need for Fund financing that } \\
\text { cannot be met without giving rise to a } \\
\text { combined access to PRGT and GRA } \\
\text { resources in amounts exceeding the } \\
\text { thresholds that apply as limits in the GRA. }\end{array}$ & $\begin{array}{l}\text { The member is experiencing or has the } \\
\text { potential to experience exceptional } \\
\text { balance of payments pressures on the } \\
\text { current account or capital account, } \\
\text { resulting in a need for Fund financing that } \\
\text { cannot be met within the normal limits. }\end{array}$ \\
\hline Criterion 2 & $\begin{array}{l}\text { The member has } \\
\text { a comparatively } \\
\text { strong } \\
\text { adjustment } \\
\text { program and } \\
\text { ability to repay } \\
\text { the Fund. } \\
\text { This criterion } \\
\text { would generally } \\
\text { not be met for } \\
\text { countries with a } \\
\text { high risk of debt } \\
\text { distress or those } \\
\text { that are in debt } \\
\text { distress as } \\
\text { defined under } \\
\text { the joint Bank- } \\
\text { Fund DSA, unless } \\
\text { expected debt } \\
\text { relief or } \\
\text { restructuring is } \\
\text { projected to } \\
\text { reduce the risk of } \\
\text { debt distress to a } \\
\text { moderate level } \\
\text { or low level (IMF } \\
\text { Policy Paper "A } \\
\text { New Architecture } \\
\text { of Facilities for } \\
\text { Low Income } \\
\text { Countries" June } \\
26,2009, \\
\text { Footnote } 62 \text { ). }\end{array}$ & $\begin{array}{l}\text { Risks to the sustainability of public debt } \\
\text { are adequately contained. This is } \\
\text { evidenced by } \\
\text { - For members for whom use of the } \\
\text { Bank-Fund Debt Sustainability } \\
\text { Framework for Low Income Countries } \\
\text { (the "LIC-DSF") is warranted: } \\
\text { A rigorous and systematic analysis } \\
\text { indicates that there is a high } \\
\text { probability that the member's public } \\
\text { debt is sustainable in the medium } \\
\text { term. This is generally considered to } \\
\text { be met for countries that are } \\
\text { assessed under the LIC-DSF as } \\
\text { having low or moderate overall risk } \\
\text { of public debt distress; or } \\
\text { Where the member's public debt is } \\
\text { not assessed to be sustainable with } \\
\text { high probability, combined access } \\
\text { above the proposed thresholds will } \\
\text { only be made available if the } \\
\text { combination of the member's } \\
\text { policies and financing from sources } \\
\text { other than the Fund, which may } \\
\text { include debt restructuring, restores } \\
\text { public debt sustainability with high } \\
\text { probability (i.e., to a point where } \\
\text { application of the LIC-DSF would } \\
\text { yield a rating of low or moderate } \\
\text { overall risk of public debt distress) } \\
\text { (i) within } 36 \text { months from Board } \\
\text { approval of the financing request or } \\
\text { within the period of a newly } \\
\text { approved arrangement (whichever is } \\
\text { longer) or (ii) within the remaining } \\
\text { period of an arrangement, in cases } \\
\text { where the Board approves an } \\
\text { augmentation or rephasing request. }\end{array}$ & $\begin{array}{l}\text { Risks to the sustainability of public debt } \\
\text { are adequately contained. This is } \\
\text { evidenced by } \\
\text { A rigorous and systematic analysis } \\
\text { indicates that there is a high } \\
\text { probability that the member's public } \\
\text { debt is sustainable in the medium } \\
\text { term. This is generally considered to } \\
\text { be met for countries that are } \\
\text { assessed under the LIC-DSF as } \\
\text { having low or moderate overall risk } \\
\text { of public debt distress; or } \\
\text { Where the member's public debt is } \\
\text { not assessed to be sustainable with } \\
\text { high probability, access above the } \\
\text { proposed thresholds will only be } \\
\text { made available if the combination of } \\
\text { the member's policies and financing } \\
\text { from sources other than the Fund, } \\
\text { which may include debt restructuring, } \\
\text { restores public debt sustainability } \\
\text { with high probability (i.e., to a point } \\
\text { where application of the LIC-DSF } \\
\text { would yield a rating of low or } \\
\text { moderate overall risk of public debt } \\
\text { distress) (i) within } 36 \text { months from } \\
\text { Board approval of the financing } \\
\text { request or within the period of a } \\
\text { newly approved arrangement } \\
\text { (whichever is longer) or (ii) within the } \\
\text { remaining period of an arrangement, } \\
\text { in cases where the Board approves an } \\
\text { augmentation or rephasing request. }\end{array}$ \\
\hline
\end{tabular}




\begin{tabular}{|c|c|c|c|}
\hline \multicolumn{4}{|c|}{ Annex II Table 1. Current and Proposed PRGT Exceptional Access Criteria (concluded) } \\
\hline & $\begin{array}{c}\text { Current PRGT EA } \\
\text { Criteria }\end{array}$ & $\begin{array}{c}\text { HCCE (High Combined Credit Exposure) } \\
\text { Safeguards }\end{array}$ & Proposed PRGT EA Criteia \\
\hline & & $\begin{array}{l}\text { For members for whom use of the } \\
\text { MAC DSA is warranted: the debt } \\
\text { sustainability requirements for } \\
\text { providing exceptional access to GRA } \\
\text { resources are met. }\end{array}$ & \\
\hline Criterion 3 & $\begin{array}{l}\text { Countries that } \\
\text { have GNI per } \\
\text { capita at or below } \\
\text { the prevailing } \\
\text { operational cutoff } \\
\text { for assistance } \\
\text { from IDA and } \\
\text { have not had } \\
\text { sustained past } \\
\text { access to } \\
\text { international } \\
\text { financial markets } \\
\text { (if GNI per capita } \\
\text { is below } 80 \\
\text { percent of the IDA } \\
\text { cutoff, market } \\
\text { access does not } \\
\text { preclude EA). }\end{array}$ & & $\begin{array}{l}\text { Countries that do not meet the income } \\
\text { criterion for presumed blending at the } \\
\text { time when a new financing request } \\
\text { (including augmentation/rephasing) is } \\
\text { made. }\end{array}$ \\
\hline Criterion 4 & & $\begin{array}{l}\text { The policy program of the member } \\
\text { provides a reasonably strong prospect of } \\
\text { success, including not only the member's } \\
\text { adjustment plans but also its institutional } \\
\text { and political capacity to deliver that } \\
\text { adjustment. }\end{array}$ & $\begin{array}{l}\text { The policy program of the member } \\
\text { provides a reasonably strong prospect of } \\
\text { success, including not only the member's } \\
\text { adjustment plans but also its institutional } \\
\text { and political capacity to deliver that } \\
\text { adjustment. }\end{array}$ \\
\hline
\end{tabular}




\section{Annex III. Blending Policies and Eligibility for Exceptional Access: Current and Proposed}

1. PRGT-eligible countries are divided into two groups: i) blend countries, who can access concessional financing from the Fund only in conjunction with GRA resources and ii) non-blend countries, who can access PRGT resources up to the relevant access limits, needing to tap GRA resources only if their financing requests exceed these limits. The current rules determining the set of blend countries and the applicable mix of PRGT and GRA resources for individual financing requests from these countries are outlined in Annex III Box 1.

2. The general principles guiding the blending framework would remain substantially unchanged under the reforms proposed in this paper. These can be summarized as: i) countries are required to blend only if they meet a per capita income threshold; ii) countries that meet the income threshold are required to blend unless debt vulnerabilities impair their access to international financial markets; iii) countries required to blend that request Fund financing receive PRGT and GRA resources in a 1:2 mix.

3. Proposed technical changes to the manner in which these principles are applied are intended to make the framework both more robust and less complex.

\section{The Income Threshold}

4. The income threshold for blending has been based on whether GNI per capita lies above or below the IDA cutoff level. The data (expressed in US dollars) are produced by the World Bank, with updates released each year at the beginning of the Bank's fiscal year (July 1).

5. Data on GNI per capita is volatile, with annual fluctuations in real GDP being augmented by the volatility of exchange rates, notwithstanding the use of smoothing mechanisms. ${ }^{1}$ Deciding that a country meets the income threshold for blending on the basis of data for a single year thus creates significant risks that countries with income per capita levels close to the IDA cutoff level (which itself moves each year) can shift back and forth between blend and non-blend status. This is undesirable given the important operational implications of shifting between nonblend and blend status.

6. The paper proposes to modify the specification of the income threshold to limit the risk of a premature/soon-reversed shift to blend status, raising the income requirements for meeting the threshold while tightening the conditions under which the threshold would no longer be met. $^{2}$ Specifically, it is proposed that:

\footnotetext{
${ }^{1}$ See https://datahelpdesk.worldbank.org/knowledgebase/topics/19373-data-compilation-methodology.

${ }^{2}$ A similar approach is taken in regard to the specification of the income criterion for PRGT eligibility.
} 
- A country is deemed to meet the income threshold for blending when GNI per capita has exceeded the IDA operational cutoff by at least 5 percent for two consecutive years. ${ }^{3}$

- Having met the income threshold, the country continues to meet it provided that income per capita does not fall below 95 percent of the IDA operational cutoff. Should income per capita fall below this level, the country no longer meets the income threshold.

7. In deciding on the proposed parameters, staff has analyzed the evolution of GNI per capita across LICs from 2000 through 2019 and can identify only four cases where a country, having recorded GNI per capita at least 5 percent above the IDA cutoff level for two successive years, later fell below the IDA cutoff level. These include: i) Solomon Islands (meeting the 5 percent margins in 2000-01, falling below the IDA cutoff from 2002-11); ii) Sudan (meeting the margins in 2011-17, falling below the IDA cutoff in 2018-19); iii) Tajikistan (meeting the margins in 2013-15, falling below the cutoff level in 2016-19); and iv) Yemen (meeting the margins in 2012-14, falling below the cutoff level in 2015-19). Three of the four cases reflect large declines in income levels linked to serious internal conflict-a situation involving fundamental changes in economic circumstances that clearly warrant re-classification to lower-income non-blend status. Increasing the margins used to set the income threshold to $7 \frac{1}{2}$ percent or 10 percent (or to 10 percent for the most recent year) would not significantly change the picture: for example, the margins over the cutoff for Tajikistan were 9 percent and 11 percent respectively in 2013-14. Since the 2000-2019 period covered periods of substantial volatility across LICS, we conclude that the proposed rules are quite robust.

8. The size of the shock to income levels in many (but not all) LICs in $\mathbf{2 0 2 0}$ has been exceptionally large, albeit with partial rebounds likely for many in 2021. Applying the proposed rules, the number of countries that do not meet the income threshold for blending would increase by five-Kyrgyz, Lesotho, Myanmar, Zambia, and Zimbabwe. Under the current rules, all except Myanmar (whose 2020 income level still exceeds the IDA cutoff but by less than 5 percent) would also have been classified as not meeting the income threshold. Separately, an upgrade of the national income accounts in Haiti has yielded a large increase in the measured level of national income: Haiti would meet the income threshold under current rules (with $2020 \mathrm{GNI}$ per capita above the threshold) but not under the new rules $(2020 \mathrm{GNI}$ per capita is not 5 percent above the IDA cutoff).

9. The list of countries that would meet/not meet the proposed income threshold for blending for the period through end-June 2022 is provided in Annex III Table 1, which also shows how the outcome differs from the results if one applied the current rules. ${ }^{4}$

\footnotetext{
3 The starting point for applying this test would be the years 2019-2020.

4 Estimates for income levels for 2019 are from the data release by the World Bank on July 1, 2020, with estimates for 2020 taken from the data to be released on July 1, 2021.
} 


\begin{tabular}{|c|c|c|c|c|c|}
\hline \multicolumn{6}{|c|}{ Annex III Table 1. Which Countries Meet the Income Threshold for Blending? } \\
\hline & \multicolumn{2}{|c|}{ GNI per capita/IDA cutoff } & \multirow{2}{*}{\multicolumn{2}{|c|}{$\begin{array}{c}\text { Current Rules } \\
\text { as of }\end{array}$}} & \multirow{3}{*}{$\begin{array}{c}\text { Proposed Rules } \\
\text { as of } \\
\text { July } 2021\end{array}$} \\
\hline & & & & & \\
\hline & 2019 & 2020 & July 2020 & July 2021 & \\
\hline Zambia & 122.4 & 98.8 & Yes & No & No \\
\hline Senegal & 122.3 & 118.7 & Yes & Yes & Yes \\
\hline Comoros & 119.8 & 120.3 & Yes & Yes & Yes \\
\hline Myanmar & 117.3 & 104.6 & Yes & Yes & No \\
\hline Zimbabwe & 117.3 & 90.5 & Yes & No & No \\
\hline Lesotho & 114.8 & 91.3 & Yes & No & No \\
\hline Benin & 105.5 & 106.2 & Yes & Yes & Yes \\
\hline Kyrgyz Republic & 104.6 & 96.3 & No & No & No \\
\hline Nepal & 92.0 & 98.8 & No & No & No \\
\hline Tanzania & 91.1 & 89.6 & Yes & Yes & No \\
\hline Haiti & 66.7 & 103.7 & No & Yes & No \\
\hline \multicolumn{6}{|c|}{$\begin{array}{l}\text { Notes: } \\
\text { 1. } 29 \text { countries that exceeded the IDA cutoff by at least } 20 \text { percent in } 2019 \text { and } 2020 \text { are not shown here. } \\
\text { 2. } 23 \text { countries that fell below the IDA cutoff by at least } 10 \text { percent in } 2019 \text { and } 2020 \text { are not shown here. } \\
\text { 3. } 6 \text { countries for which data is incomplete/not available are not shown here: Eritrea, Somalia, South Sudan, Tonga, Micronesia, and Marshall } \\
\text { Islands. For the latter three, } 2019 \text { GNI per capita was }>120 \text { percent of the IDA cutoff. } \\
\text { 4. Assessment for July } 2020 \text { is based on GNI per capita data for } 2019 \text {, issued by the World Bank on July 1, 2020. Assessment for July } 2021 \text { is based } \\
\text { on GNI per capita data for 2021, issued by the World Bank on July 1, } 2021 \text {. }\end{array}$} \\
\hline
\end{tabular}

\section{The Market Access Threshold}

\section{Countries that meet the income criterion for blending are currently required to blend} unless debt vulnerabilities limit their access to international financial markets; this general approach would be maintained with some technical simplifications. Specifically, debt vulnerabilities are deemed to limit a country's access to international financial markets when:

- the country is assessed to be in debt distress or

- the country is assessed to be at high risk of debt distress and a) has had limited past access to external financial markets or $b$ ) is a small/micro-state.

Countries are assessed to have had limited past access to markets if they do not meet the established criterion of "durable and substantial access to international financial markets." 5

11. The list of countries that could be required to blend under existing rules and/or under the proposed rules is outlined in Annex III Table 2. ${ }^{6}$ Three countries previously required to blend drop off the list because of sharp declines in national income in 2020 (Lesotho, Kyrgyz Republic,

\footnotetext{
${ }^{5}$ This criterion is met if the country has issued or guaranteed eligible external debt in at least three out of the past five years in a cumulative amount equivalent to at least 50 percent of its quota; a staff assessment on whether this is met requires validation of the debt data (from the World Bank's International Debt Statistics) with country authorities.

${ }^{6}$ Estimates for income levels for 2019 are from the data release by the World Bank on July 1, 2020); estimates for 2020 are based on the data to be released by the Bank on July 1, 2021.
} 
Myanmar). Of the eight countries previously assessed to be potential blend countries, three (Cameroon, Ghana, Kenya) are now required to blend, given the level of confirmed past market access; three do not have to blend, given their small island status (Cabo Verde, Dominica, and Maldives); and the blend status of two countries (Lao PDR, Papua New Guinea) would depend on validation of the data on past external borrowings with country authorities.

\begin{tabular}{|lccc|}
\hline \multicolumn{4}{|c|}{ Annex III Table 2. Blend Status of Potential Presumed Blenders ${ }^{1 / 2 /}$} \\
& Current Rules & Proposed Rules & Comment \\
\hline Cabo Verde & $/ 3$ & No & Small State \\
Cameroon & $/ 3$ & Yes & \\
Dominica & $/ 3$ & No & Small State \\
Ghana & $/ 3$ & Yes & \\
Kenya & $/ 3$ & Yes & Small State \\
Lao P.D.R & $/ 3$ & $/ 4$ & \\
Maldives & $/ 3$ & No & \\
Papua New Guinea & $/ 3$ & /4 & \\
\hline 1/ Excludes all countries that fail to meet the income threshold in 2021 & \\
2/ Countries required to blend under the current rules and under the proposed rules are not shown in the \\
table. \\
3/ Blend status dependent on staff assessment of prospective market access \\
4/ Blend status dependent on validation of scale of debt issuance in previous 5 years.
\end{tabular}

\section{Eligibility for Exceptional Access to PRGT Resources}

12. As of end May 2020, there were 28 countries eligible for EA to PRGT resources, based on GNI per capita levels in 2019 that lay below the IDA cutoff level. Absent any changes to this specification of eligibility, this number would increase to 32 with the release of GNI per capita data for 2020 on July 1, 2021, with the addition of Lesotho, Kyrgyz Republic, Zambia, and Zimbabwe.

13. With the proposal that eligibility for EA to PRGT resources be based on meeting the income threshold for blending, the number of countries eligible for EA would increase to 34, with the inclusion of Myanmar and Tanzania. ${ }^{7}$

\footnotetext{
${ }^{7}$ See paragraph 35 of the main text.
} 


\section{Annex III Box 1. Current Blending Policy}

A. Blending. PRGT-eligible countries are expected to receive a blend of PRGT and GRA resources when they meet the following criteria:

- For countries at low or moderate risk of debt distress (as assessed by the most recent joint Bank-Fund LIC Debt Sustainability Analysis (DSA)), blending is presumed if either (i) per capita income is above 100 percent of the International Development Association (IDA) operational cutoff; or (ii) the country has sustained past and prospective access to international financial markets and a per capita income that exceeds 80 percent of the IDA operational cutoff. The criterion for sustained past market access in such cases would be met if the country has issued or guaranteed eligible external debt during at least two of the past five years in a cumulative amount equivalent to at least 25 percent of the member's quota. ${ }^{1}$ The criterion for prospective market access in such cases is assumed to be met based on established past market access and limited debt vulnerabilities as evidenced by low or moderate risk of debt distress.

- For countries at high risk of debt distress, but not in debt distress, blending is presumed where (i) per capita income is above 100 percent of the IDA operational cutoff; (ii) the country has issued or guaranteed eligible external debt in at least three out of the past five years in a cumulative amount equivalent to at least 50 percent of its quota; and (iii) the country has prospective market access. The assessment of prospective market access in such cases would require judgment based on such factors as the evolution of debt vulnerabilities in the context of the program DSA, the evolution of sovereign spreads and credit ratings over time, program assumptions on commercial financing, and the scale and evolution of nonresident holdings of domestic-currency debt. The quality of public debt data-including coverage of public sector entities outside the central government and of publicly guaranteed debt, and transparency on terms and conditions-would also be an important factor in the assessment, given the threat to prospective market access from any significant debt surprises. ${ }^{2}$

B. Access limits. When financing is blended under a PRGT arrangement and an arrangement under the GRA, total access is determined based on the standard criteria, implying that total access should be comparable across country cases with similar balance of payments needs, program strength, and outstanding Fund credit, irrespective of whether the Fund's financial assistance comes in the form of blended or PRGT-only resources. The blending rules stipulate a 1:2 mix of PRGT and GRA resources, with access to concessional resources capped at the norm ${ }^{3}$ (or equivalent) applicable to unblended arrangements. All access above the norm needs to be met from the GRA.

${ }^{1}$ Accessing international financial markets refers to the issuance or guarantee by a public debtor of external bonds in international markets or disbursements under external commercial loans contracted or guaranteed by a public debtor in such markets: see "PRGT eligibility paper 2020."

${ }^{2}$ The potential for countries at high risk of debt distress to be classified as PBs was introduced in 2019 in the context of the 2018-19 Review of Facilities for Low-Income Countries: the reform was motivated by the observance of large-scale issuance of debt on international financial markets by countries at high risk of debt distress.

${ }^{3}$ High access norms (120 percent of quota for a 3-year ECF) apply if PRGT credit outstanding is less than 100 percent of quota. Low access norms (75 percent of quota) apply if PRGT credit outstanding is between 100 and 200 percent of quota. Norms are not applicable if PRGT credit outstanding $>200$ percent of quota. In such cases, access is guided by consideration of the cumulative access limit of 300 percent of quota under PRGT facilities (400 percent of quota in exceptional access cases), the expectation of future need for Fund support, and the repayment schedule. 


\begin{tabular}{|c|c|c|c|c|c|}
\hline \multicolumn{6}{|c|}{ Annex III Table 3. Blend Status of PRGT-Eligible Countries Under Proposed Reform } \\
\hline \multicolumn{3}{|c|}{ Countries not required to blend } & \multicolumn{3}{|c|}{ Presumed Blenders } \\
\hline Country & $\begin{array}{l}2020 \text { GNI per capita } \\
\text { (US \$) }\end{array}$ & $\begin{array}{l}\text { Risk of Debt Distress } \\
\text { (end-May 2021) }\end{array}$ & Country & $\begin{array}{l}2020 \text { GNI per capita } \\
\text { (US \$) }\end{array}$ & $\begin{array}{c}\text { Risk of Debt Distress } \\
\text { (end-May 2021) }\end{array}$ \\
\hline St. Lucia & 8,790 & High & Moldova & 4,570 & Low \\
\hline Grenada & 8,740 & In debt distress & $\begin{array}{l}\text { Bhutan } \\
\text { Bental }\end{array}$ & 2,860 & Moderate \\
\hline $\begin{array}{l}\text { St.Vinaa } \\
\text { Stincent the Grenadines }\end{array}$ & $\begin{array}{l}8,140 \\
7,340\end{array}$ & $\begin{array}{l}\text { High } \\
\text { High }\end{array}$ & $\begin{array}{l}\text { Bnutan } \\
\text { Vanuatu }\end{array}$ & $\begin{array}{l}2,800 \\
2,780\end{array}$ & Moderate \\
\hline Dominica & 6,870 & High & Lao PDR $1 /$ & 2,480 & High \\
\hline Maldives & 6,830 & High & Solomon Islands & 2,300 & Moderate \\
\hline Tuvalu & 5,820 & High & Côte d'lvoire & 2,280 & Moderate \\
\hline Samoa & 4,070 & High & Papua New Guinea " & 2,260 & High \\
\hline Djibouti & 3,320 & High & Ghana & $\begin{array}{l}2,200 \\
2,230\end{array}$ & $\begin{array}{l}\text { Migh } \\
\text { High }\end{array}$ \\
\hline Cabo Verde & $\begin{array}{l}3,060 \\
3,060\end{array}$ & $\begin{array}{l}\text { Hign } \\
\text { High }\end{array}$ & $\begin{array}{l}\text { Honduras } \\
\text { Honduras }\end{array}$ & $\begin{array}{l}2,200 \\
2,200\end{array}$ & $\begin{array}{l}\text { hown } \\
\text { Low }\end{array}$ \\
\hline Kiribati & $\begin{array}{l}3,000 \\
3,010\end{array}$ & $\begin{array}{l}\text { Hign } \\
\text { High }\end{array}$ & $\begin{array}{l}\text { Honnuaras } \\
\text { Bangladesh }\end{array}$ & $\begin{array}{l}2,200 \\
2,010\end{array}$ & $\begin{array}{l}\text { Low } \\
\text { Low }\end{array}$ \\
\hline $\begin{array}{l}\text { Sirrabat } \\
\text { Săó Tomé and Principe }\end{array}$ & $\begin{array}{l}3,070 \\
2,070\end{array}$ & $\begin{array}{l}\text { Aghn } \\
\text { In debt distress }\end{array}$ & $\begin{array}{l}\text { Bangladesesn } \\
\text { Nicaragua }\end{array}$ & $\begin{array}{l}2,010 \\
1,850\end{array}$ & Moderate \\
\hline Congo, Rep. & 1,830 & In debt distress & Timor-Leste & 1,830 & Low \\
\hline Mauritania & 1,640 & High & Kenya & 1,760 & High \\
\hline $\begin{array}{l}\text { Myanmar } \\
\text { Myar }\end{array}$ & 1,260 & Low & Uzbekistan & 1,670 & Low \\
\hline Haiti & 1,250 & High & Cameroon & 1,500 & High \\
\hline Nepal & 1,190 & Low & Cambodia & 1,490 & Low \\
\hline Zambia & 1,190 & In debt distress & Comoros & 1,450 & Moderate \\
\hline Kyrgyz Republic & 1,160 & Moderate & Senegal & 1,430 & Moderate \\
\hline Lesotho & 1,100 & Moderate & Benin & 1,280 & Moderate \\
\hline Zimbabwe & 1,090 & In debt distress & & & \\
\hline Tanzania & 1,080 & Low & & & \\
\hline Tajkistan & $\begin{array}{l}1,060 \\
1,00\end{array}$ & High & & & \\
\hline Guinea & $\begin{array}{l}1,000 \\
1,020\end{array}$ & Moderate & & & \\
\hline $\begin{array}{l}\text { Togo } \\
\text { Togre }\end{array}$ & $\begin{array}{r}1,020 \\
920\end{array}$ & Moderate & & & \\
\hline Ethiopia & 890 & $\begin{array}{l}\text { Mooferate } \\
\text { High }\end{array}$ & & & \\
\hline Mali & 830 & $\begin{array}{l}\text { Alinn } \\
\text { Moderate }\end{array}$ & & & \\
\hline Uganda & $\begin{array}{l}800 \\
800\end{array}$ & Low & & & \\
\hline Burkina Faso & 790 & Moderate & & & \\
\hline Rwanda & 780 & $\begin{array}{l}\text { Moderate } \\
\text { Moderate }\end{array}$ & & & \\
\hline Guinea-Bissau & 760 & High & & & \\
\hline Gambia, The & 750 & High & & & \\
\hline Chad & 660 & High & & & \\
\hline Sudan & 650 & In debt distress & & & \\
\hline Malawi & 580 & Moderate & & & \\
\hline Congo, Dem. Rep. & 550 & Moderate & & & \\
\hline Niger & 530 & Moderate & & & \\
\hline Liberia & 530 & Moderate & & & \\
\hline Central African Republic & 510 & $\begin{array}{l}\text { High } \\
\text { High }\end{array}$ & & & \\
\hline $\begin{array}{l}\text { Afghanistan } \\
\text {. }\end{array}$ & 500 & $\begin{array}{l}\text { Mign } \\
\text { High }\end{array}$ & & & \\
\hline Sierra Leone & 490 & $\begin{array}{l}\text { Mign } \\
\text { High }\end{array}$ & & & \\
\hline Madagascar & 480 & $\begin{array}{c}\text { Mgn } \\
\text { Moderate }\end{array}$ & & & \\
\hline Mozambique & 460 & $\begin{array}{l}\text { In debt distress } \\
\text { Interte }\end{array}$ & & & \\
\hline Somalia & 310 & In debt distress & & & \\
\hline Burundi & 270 & High & & & \\
\hline Eritrea & 210 & In debt distress & & & \\
\hline Marshall Islands & - & High & & & \\
\hline Micronesia & - & High & & & \\
\hline South Sudan & - & High & & & \\
\hline Tonga & - & High & & & \\
\hline Yemen & - & In debt distress & & & \\
\hline
\end{tabular}




\section{Annex IV. Evolution of PRGT Access Limits}

This annex discusses the evolution of PRGT access limits since 2015, including the changes implemented in the context of the pandemic.

1. Limits on access to PRGT resources have served in the main to ration access to scarce concessional resources: they also have helped to mitigate credit risk in cases where LICs eligible for EA request support in excess of normal access limits, given the stronger policy requirements of the EA criteria. These limits have been raised periodically to address erosion relative to established metrics of demand-including GDP, trade, and external financing needs-and to respond to higher financing needs arising from global economic developments.

- A member's total access under all concessional facilities is subject to "global" annual and cumulative limits. This includes the ECF, SCF, and RCF. The annual access limit refers to disbursements in any 12-month period, on a rolling basis. The cumulative access limit refers to total outstanding Fund concessional credit at any point in time, after accounting for projected disbursements and repayments. There are normal limits on access and exceptional limits (hard caps) on access, with EA available only to the poorest LICs.

- In addition to global limits on access under all PRGT facilities, access to the RCF is subject to annual and cumulative sub-ceilings. These sub-ceilings are differentiated across "the regular," "exogenous shocks," and "large natural disasters" windows of the RCF. Purchases under the RFI count towards the applicable RCF annual and cumulative sub-ceilings.

2. There have been three significant changes to PRGT access limits since establishment of the PRGT facilities framework in 2009:

- 2015-17: 1 Annual and cumulative access limits were raised by 50 percent across all facilities (including the RCF) on July 1, 2015 to address the erosion of access levels relative to trade, capital flows, and GDP since 2009-10 and to make available additional support to the poorest LICs in the context of supporting efforts to achieve the Sustainable Development Goals (SDGs). The increases in access limits, expressed as a share of quota, were reduced by one-half in January 2016 as the 14th General Review of Quotas became effective, leaving access in SDR terms for most countries unaffected by the quota increase. Additionally, in May 2017, a large natural disaster window, allowing higher annual access levels than other windows, was created under the RCF and RFI.

- 2018-19 Review of Facilities for LICs: ${ }^{2}$ Annual and cumulative access limits and norms were raised by one-third across all lending instruments in May 2019. The increase was intended to offset access erosion and restore access limits in relation to GDP and trade to the levels achieved

\footnotetext{
1 See "Financing for Development: Enhancing the Financial Safety Net for Developing Countries," (IMF (2015), July 2015) and "Large Natural Disasters-Enhancing the Financial Safety Net for Developing Countries," (IMF (2017a), May 2017).

2 See "2018-19 Review of Facilities for Low-Income Countries-Reform Proposals," (IMF (2019a), June 2019).
} 
when generalized access increases had occurred in 2009 and 2015, and preserve the potential financing contribution of Fund program engagement in LICs. The cumulative RCF/RFI access limits for disbursements associated with large natural disasters were raised by an additional onethird to provide room to support members hit by a large natural disaster that already had significant outstanding RCF/RFI exposure.

- 2020-21 Temporary modifications to access limits in response to COVID-19:3

i. In April 2020, with the onset of the pandemic, limits on annual and cumulative access under the RCF exogenous shocks window were increased from 50 percent of quota and 100 percent of quota to 100 percent and 150 percent, respectively, with similar increases introduced for the RFI. The new limits applied initially for a six-month period and were later extended through end-2021.

ii. In July 2020, the normal annual access limit (NAAL) ${ }^{4}$ on use of PRGT resources was raised from 100 to 150 percent of quota through April 6, 2021. The increase was intended to make room for higher access - without triggering the application of the EA framework - for countries that had used up much of the annual borrowing space under the NAALs due to COVID-19 related EF.

iii. In March 2021, PRGT global annual and cumulative access limits were temporarily raised through end-June 2021: the NAAL from 150 to 245 percent of quota, the normal cumulative access limit (NCAL) from 300 to 435 percent of quota. ${ }^{5}$ These increases were intended to create more room to provide concessional financing to LICs-and to avoid requiring LICS with high outstanding exposure to seek Fund support through the GRA-in the uncertain environment created by the pandemic, pending a wider discussion of the Fund's concessional finances and policies. On June 25, 2021, staff proposed a temporary extension of the increased limits to July 31, 2021.

iv. In June 2021, annual and cumulative access limits under the Large Natural Disaster (LND) window of the RCF and RFI were increased by 50 percent of quota, from 80 percent of quota and 133.33 percent of quota to 130 percent and 183.33 percent, respectively, until end-2021. The increase was in line with the April 2020 increase of normal and cumulative access limits under the RFI and RCF exogenous shocks window, and was intended to allow for augmented access by countries vulnerable to LNDs as was the case in the pre-pandemic period.

\footnotetext{
3 See "Enhancing the Emergency Financing Toolkit-Responding to the COVID-19 Pandemic," (IMF, (2020c), April 2020), "Temporary Modification to the Fund's Annual Access Limits," (IMF (2020d), July 2020), "Review of Enhanced Access Limits under the Rapid Credit Facility and Rapid Financing Instrument," (IMF (2020f), October 2020), and "Temporary Extensions and Modifications of Access limits in the Fund's Lending Facilities," (IMF (2021a), March 2021).

4 The increase in the NAAL was accompanied by an increase in the Exceptional Annual Access Limit (EAAL) by 50 percent of quota, to 183.33 percent, for the same period.

5 The EAAL and the exceptional cumulative access limit (ECAL) were increased by similar absolute amounts through June 30, 2021. Access norms in the PRGT have remained unchanged since May 2019.
} 


\begin{tabular}{|c|c|c|c|c|c|}
\hline \multicolumn{6}{|c|}{ Annex IV Table 1. PRGT Global Access Limits (in percent of quota) } \\
\hline & $\begin{array}{c}\text { Completion of 14th quota review } \\
\text { (January 2016) }\end{array}$ & $\begin{array}{l}\text { Review of Facilities for LICS } \\
\text { (May 2019) }\end{array}$ & $\begin{array}{l}\text { Temporary modification to annual access limits } \\
\text { until end-April } 2021 \text { (July 2020) }\end{array}$ & $\begin{array}{l}\text { Temporary modification to access limits } \\
\text { until end-June } 2021 \text { (March 2021) }\end{array}$ & Proposed access limits \\
\hline \multicolumn{6}{|l|}{ Cumulative access limits } \\
\hline All PRGT facilities-normal & 225 & 300 & 300 & 435 & 435 \\
\hline All PRGT facilities-exceptional & 300 & 400 & 400 & 535 & No hard cap \\
\hline \multicolumn{6}{|l|}{ Annual access limits } \\
\hline All PRGT facilities-normal & 75 & 100 & 150 & 245 & $\begin{array}{l}\text { Annual limit is at } 245 \text { percent of quota until end-2021, } \\
\text { after which it would decline to } 145 \text { percent of quota. }\end{array}$ \\
\hline All PRGT facilities-exceptional & 100 & 133.33 & 183.33 & 278.33 & No hard cap \\
\hline \multicolumn{6}{|l|}{ Norms } \\
\hline 3-year ECF - High access & 90 & 120 & 120 & 120 & Norm is set at 145 \\
\hline - Low access & 56.25 & 75 & 75 & 75 & independent of the stock of credit outstanding. \\
\hline
\end{tabular}

\begin{tabular}{|c|c|c|c|c|}
\hline \multicolumn{5}{|c|}{ Annex IV Table 2. Access Limits to Emergency Financing Instruments (in percent of quota) } \\
\hline & $\begin{array}{l}\text { Completion of 14th quota review } \\
\text { (January 2016) }\end{array}$ & $\begin{array}{l}\text { Large Natural Disasters-Enhancing the } \\
\text { Financial Safety Net (May 2017) }\end{array}$ & $\begin{array}{l}\text { Review of Facilities for LICs } \\
\text { (May 2019) }\end{array}$ & $\begin{array}{l}\text { Temporary modifications to access limit until end-2021 } \\
\text { (April 2020, October 2020, March 2021, June 2021) }\end{array}$ \\
\hline \multicolumn{5}{|l|}{ Cumulative access limits } \\
\hline RCF (regular window) & 75 & 75 & 100 & 100 \\
\hline RCF/RFI (large natural disasters window) & N.A. & 75 & 133.33 & 183.33 \\
\hline RCF (exogenous shocks window)/ RFI (regular window) & 75 & 75 & 100 & 150 \\
\hline \multicolumn{5}{|l|}{ Annual access limits } \\
\hline RCF (regular window) & 18.75 & 18.75 & 50 & 50 \\
\hline RCF/RFI (large natural disasters window) & N.A. & 60 & 80 & 130 \\
\hline RCF (exogenous shocks window)/ RFl (regular window) & 37.5 & 37.5 & 50 & 100 \\
\hline
\end{tabular}




\section{Annex V. A Dual Interest Rate Mechanism in the PRGT}

Under current policies, all loans extended from the PRGT carry the same interest rate, based on an interest rate mechanism that yields zero or near-zero rates, depending on prevailing SDR rates. This Annex illustrates how a potential dual interest rate structure could be introduced in the PRGT to allow all LICS to meet their entire financing needs from within the PRGT. The proposal here would provide benefits to countries that would otherwise need to blend PRGT and GRA resources, while providing a modest reduction in subsidy outlays by the PRGT. Such a reform would lead to a substantial increase over time in PRGT credit outstanding, PRGT loan resource needs, and a significant reduction in the reserve coverage ratio unless new resources to boost reserve coverage are made available.

1. The PRGT would have two interest rates: one $\left(R_{A}\right)$, set in accordance with the interest rate mechanism, which currently implies a zero rate for all PRGT facilities; and a second (higher) interest rate $\left(R_{B}\right)$ linked to, but less than, the GRA rate of charge (the SDR interest rate (SDRi) + 100 basis points).

\section{The blending criteria discussed in the main text would now serve as the criteria for} determining which of the two interest rates a country would incur when borrowing from the PRGT. Countries currently required to blend PRGT and GRA resources (henceforth "intermediate interest rate countries" (IIRs)) would now be eligible to meet their entire financing needs from the PRGT, with $R_{B}$ as the interest rate. LICs that are not IIRs would face unchanged borrowing conditions.

\section{To see how this would affect IIRs and PRGT finances, let $R_{B}$ be set at two-thirds of the} current rate of charge (the average interest rate paid on a 1:2 PRGT-GRA blending mix). Under this approach:

- IIRs would benefit in that i) they would no longer be required to meet the policy requirements of the GRA, which are less suitable for the needs of LICs than the conditions for borrowing under an ECF; ${ }^{1}$ ii) the repayment periods would be somewhat more generous than with current blended arrangements; and iii) they would not face GRA interest rate surcharges. ${ }^{2}$ Each of these features fits better the needs of LICs, which typically face protracted BoP problems, than does the current approach of mixing GRA and PRGT funding sources.

- Scarce PRGT subsidy resources would be conserved, with IIR country borrowers generating income for the PRGT endowment when SDRi < 2.0 percent and requiring fewer subsidy

\footnotetext{
${ }^{1}$ An arrangement supported under the GRA is expected to ensure that BoP difficulties are resolved before repayments to the Fund begin: an arrangement supported under the ECF is expected to help countries with protracted BoP problems to make significant progress towards a stable and sustainable macroeconomic position. The GRA thus implicitly requires a faster pace of adjustment than would be expected under the ECF.

2 IIR countries would also avoid the 0.5 percent one-off charge on each drawing of GRA resources.
} 
resources than the 1:2 PRGT-GRA funding at any level of SDRi. ${ }^{3}$ The improvement in the income position of the PRGT endowment would come at the cost of reduced income for the GRA.

4. The need for PRGT loan resources would increase significantly, since all IIRs' financing needs would now be met from the PRGT (rather than one-third with blending). Higher lending volumes from the PRGT would imply a substantial increase in credit outstanding and a decline in the reserve coverage ratio (see Box 3 in Section V).

\section{Adopting this alternative approach to the current blending framework would require several changes to PRGT rules and design, including:}

- the introduction of two sets of interest rates within the PRGT, with the group of countries not eligible for the lower interest rate being determined by what are now the blending rules;

- reforms to allow the transfer of interest income (net of the cost of payments to the loan provider) to either the subsidy or reserve account of the PRGT;

- transitional arrangements to exempt IIR countries with outstanding PRGT credit from higher interest rates on outstanding loans; and

- a mechanism to bolster the reserve coverage ratio, discussed in Section VI of this paper.

\section{Preliminary analysis of the legal changes needed to address the first three of these} issues suggests that the changes could be approved by the Executive Board with a majority of the votes cast.

7. Separate from these legal changes, lending at the IIR would need to be consistent with the general purpose of the PRGT to provide loans on concessional terms. ${ }^{4}$ While concessionality is not defined in the PRGT Instrument, the following arguments could be offered:

\section{Grant Element Approach:}

- Under the debt limits policy, the concessionality of a loan is measured by the associated grant element (GE), calculated using a discount rate determined during the periodic reviews of the Bank-Fund LIC-DSF: this rate has been 5 percent since October 2013.

- A zero-interest rate loan under the RCF/ECF has a GE of some 32 percent: a zero-interest rate on SCF terms has a GE of some 26 percent. By contrast, a loan on RCF/ECF maturities with an interest rate equal to $2 / 3^{*}(\mathrm{SDRi}+1.0)$ has a GE of about 28 percent at today's (very low) SDRi rate, declining to 20 percent at $\mathrm{SDRi}=2$ percent and falling further as SDRi rises.

\footnotetext{
${ }^{3}$ A PRGT loan of 1 SDR to an IIR country would generate annual net revenues equal to the interest earned $\left[2 / 3^{*}(\mathrm{SDRi}+1.0)\right]$ less the funding cost [SDRi], or $(0.67-1 / 3 *$ SDRi $)$, which $>0$ if SDRi $<2.0$. The net income to the PRGT of a blended loan of 1 SDR is $-1 / 3 *$ SDRi (the funding cost of the PRGT share).

4 The PRGT Instrument specifies that the Trust shall assist in fulfilling the purposes of the Fund by providing loans on concessional terms to low-income developing members that qualify for assistance under the Instrument.
} 
- Lending on concessional terms for purposes of the PRGT instrument could be defined as loans with a GE that exceeds some minimum threshold level: given ECF/RCF maturities, this would determine a maximum level of the interest rate paid by IIRs $\left(R_{c o n}\right)$ that would meet the concessionality requirement.

- The IIR would be set in the context of the biennial review of interest rates-for example, as the lesser of $\left[2 / 3^{*}(S D R i+1.0)\right]$ and $R_{\text {con. }}$. Rising levels of SDRi would eventually shift the interest rate to $R_{c o n}$ at which point the financial benefits to the PRGT cited above would decline/disappear.

Benefit to the Borrower:

- Lending from the PRGT at an intermediate-level interest rate can be viewed as concessional on the basis that it provides the borrower with funding on more attractive terms than the GRA and on more attractive terms than the current 1:2 blended arrangements. 


\section{Annex VI. Analysis of Debt Sustainability and Capacity to Repay}

\section{Debt vulnerabilities have been increasing in LICs for several years, with the onset of} the pandemic-and the associated weakening of tax bases and export receipts-adding new pressures. ${ }^{1}$ As of end-May 2021, some 42 percent of LICs were assessed to be at high risk of experiencing debt distress with a further 14 percent in debt distress: the comparable numbers for end-2016 were 26 percent and 7 percent, respectively.

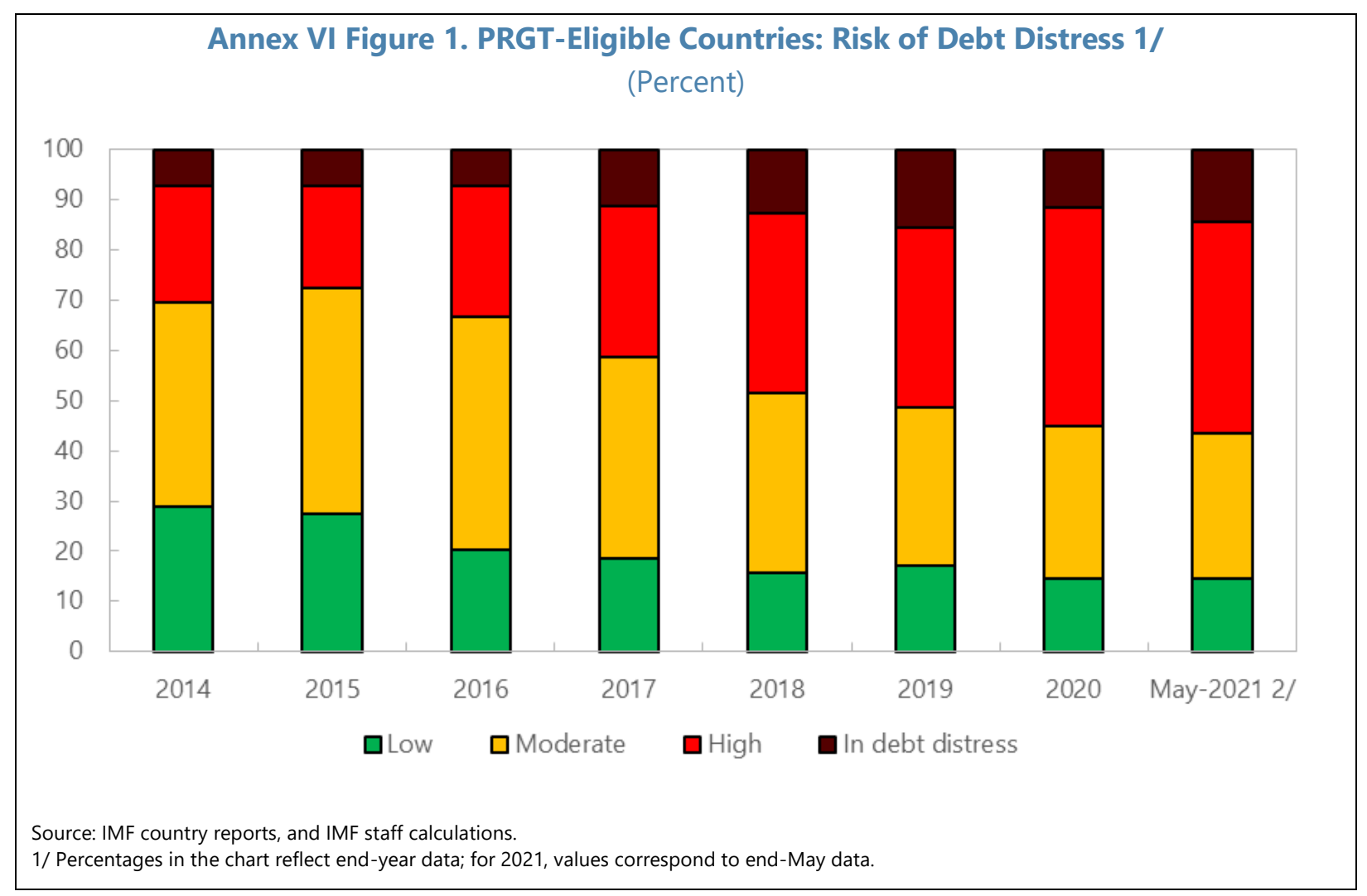

\section{Staff analytical and policy tools have been modified in response to these}

developments. An upgrade of the framework for analyzing debt sustainability in LICs (the LIC-DSF) was introduced in mid-2018, with a modified statistical methodology to improve prediction accuracy, new tools for assessing the realism of underlying macroeconomic projections, and greater scope to use customized scenarios adapted to the specific country context. ${ }^{2}$ A joint IMF-WB multipronged approach to addressing emerging debt vulnerabilities has been under implementation

\footnotetext{
${ }^{1}$ For analysis of pre-pandemic trends, see "Macroeconomic Developments and Prospects in Low-Income Developing Countries: 2018," IMF (2018b), March 2018, and "The Evolution of Public Debt Vulnerabilities in Lower Income Economies," IMF (2020a), February 2020.

2 See "Guidance Note on the Bank-Fund Debt Sustainability for Framework for Low Income Countries," IMF (2018a), February 2018.
} 
stage since late-2018. ${ }^{3}$ A review of the Fund's Debt Limits Policy, which guides how debt conditionality is deployed in Fund programs, was completed in October 2020, with reforms introduced to improve debt disclosure and allow better adjustment of debt conditionality to country circumstances: the new policy takes effect on June 30, 2021. ${ }^{4}$

3. The proposed increase in normal access limits in the PRGT would affect the approach taken to debt sustainability in certain circumstances-specifically, for programs with access requests in excess of the current normal access limits of 100/300 percent of quota but below the new limits of $145 / 435 .{ }^{5}$ For the 28 countries currently eligible for PRGT EA, a request for access to PRGT resources within this range would no longer require meeting the PRGT EA criteria (with its requirement to reduce debt vulnerabilities to low/moderate risk): for the 20-plus non-blend countries that are not currently eligible, access in this range could now be met entirely from the PRGT (and hence without meeting the policy requirements of the GRA).

\section{The March 2021 staff paper on temporary increases in access levels specified new} requirements intended to bolster scrutiny of debt sustainability and capacity to repay the Fund, applying to requests for arrangements with access above the current normal access limits $(100 / 300)$ and to all requests for arrangements from countries at high risk of, or in, debt distress. ${ }^{6}$

\section{In all such cases, program documents are expected to include discussion of: ${ }^{7}$}

- the structure of public external debt and its projected evolution over time, focusing on the amount and shares of debt owed to the Fund and other senior creditors, informed by tables showing two distinct breakdowns of public external debt: i) de facto senior debt (debt to the IMF; debt to the World Bank and other international financial institutions; known collateralized debt) and other debt and ii) multilateral versus official bilateral versus private debt. ${ }^{8}$

- the evolution of projected Fund debt and debt service relative to key economic metrics over the course of the repayment period as compared with other PRGT programs, supported by a set of standardized charts provided by the Finance Department (see below). Where financing requests would result in comparatively elevated levels of key capacity to repay indicators, the staff report would examine the severity of the implied risks and explain how program design-including access, phasing, and conditionality—seeks to mitigate these risks.

\footnotetext{
${ }^{3}$ See "Update on the Joint IMF-WB Multipronged Approach to Address Debt Vulnerabilities," IMF (2020g), December 2020.

4 See "Reform of the Policy on Public Debt Limits in IMF-Supported Programs," IMF Policy Paper 2020/61, IMF (2020h).

5 This abstracts from the temporary increases in access levels that are set to expire shortly.

6 These requirements were discussed in "Temporary Extension and Modifications of Access Limits in the Fund's Lending Facilities," IMF (2021a), March 12, 2021.

${ }^{7}$ Guidance and templates to implement these requirements are under preparation.

${ }^{8}$ The new Debt Limits Policy requires reporting of these details, but not an explicit discussion in program documents.
} 


\section{For countries at high risk of debt distress or in debt distress, the core program} objectives should include the achievement of a concrete reduction in debt vulnerabilities over the course of the program and beyond. ${ }^{9}$ Reducing debt vulnerabilities would typically involve reducing breaches of thresholds for the four key indicators in the LIC-DSF over the program period under the baseline scenario: ${ }^{10}$ staff do not propose a mechanical approach to assessing the projected improvement in debt vulnerabilities, favoring instead an overall assessment of the strength of the program and any assurances from creditors on new concessional financing or restructuring of existing claims.

\section{To facilitate a comparative assessment of projected levels of debt and debt service to} the Fund in a proposed program, staff in the Finance Department have developed a methodology that allows graphical comparison of the evolution of key debt metrics under the program with a control group of PRGT arrangements. ${ }^{11}$ The relevant metrics would include the projected stock of Fund credit outstanding relative to i) quota, ii) GDP, and iii) the aggregate level of public and publicly-guaranteed (PPG) external debt; and projected annual debt service to the Fund relative to i) fiscal revenues (excluding grants), ii) exports of goods and services, iii) all debt service on PPG debt, and iv) the level of gross international reserves. ${ }^{12}$ For an illustration focused on four key metrics, see Annex VI Figure 2. The comparative assessment will be based on the baseline scenario underpinning the proposed program but could also include information on downside scenarios included in program documents, and realism checks whenever warranted. Guidance will be provided to staff on how to reflect information on Fund debt metrics in capacity to repay assessments.

\footnotetext{
${ }^{9}$ While staff teams will usually make a reduction in debt vulnerabilities an important component of program design in cases where countries at high risk of/in debt distress, this has been a requirement only where PRGT EA or high combined GRA-PRGT access is involved

10 This need not necessarily involve steady reductions in all indicators for which thresholds are breached: for example, debt service ratios could still spike in individual years, reflecting a bunching of debt repayments (say, a Eurobond issue with a single bullet repayment).

11 The control group could be as broad as all PRGT arrangements during 2010-2020, but could also be customized to focus on a specific set of comparator cases, including to better reflect country-specific characteristics or the type of arrangement (e.g., fragile states, emergency financing, UCT-quality programs), while ensuring uniformity of treatment across programs. The underlying data on control groups will be updated regularly (e.g., once a year).

12 The methodology also allows for comparison of peak levels of debt service indicators with the peak levels of these indicators in a subset of cases in the control group (e.g., the top quartile of observations for the indicator), facilitating the identification of key stress points.
} 


\section{Annex VI Figure 2. Country X: Fund Credit Indicators Compared to All PRGT Arrangements} (In percent of the indicated variable)
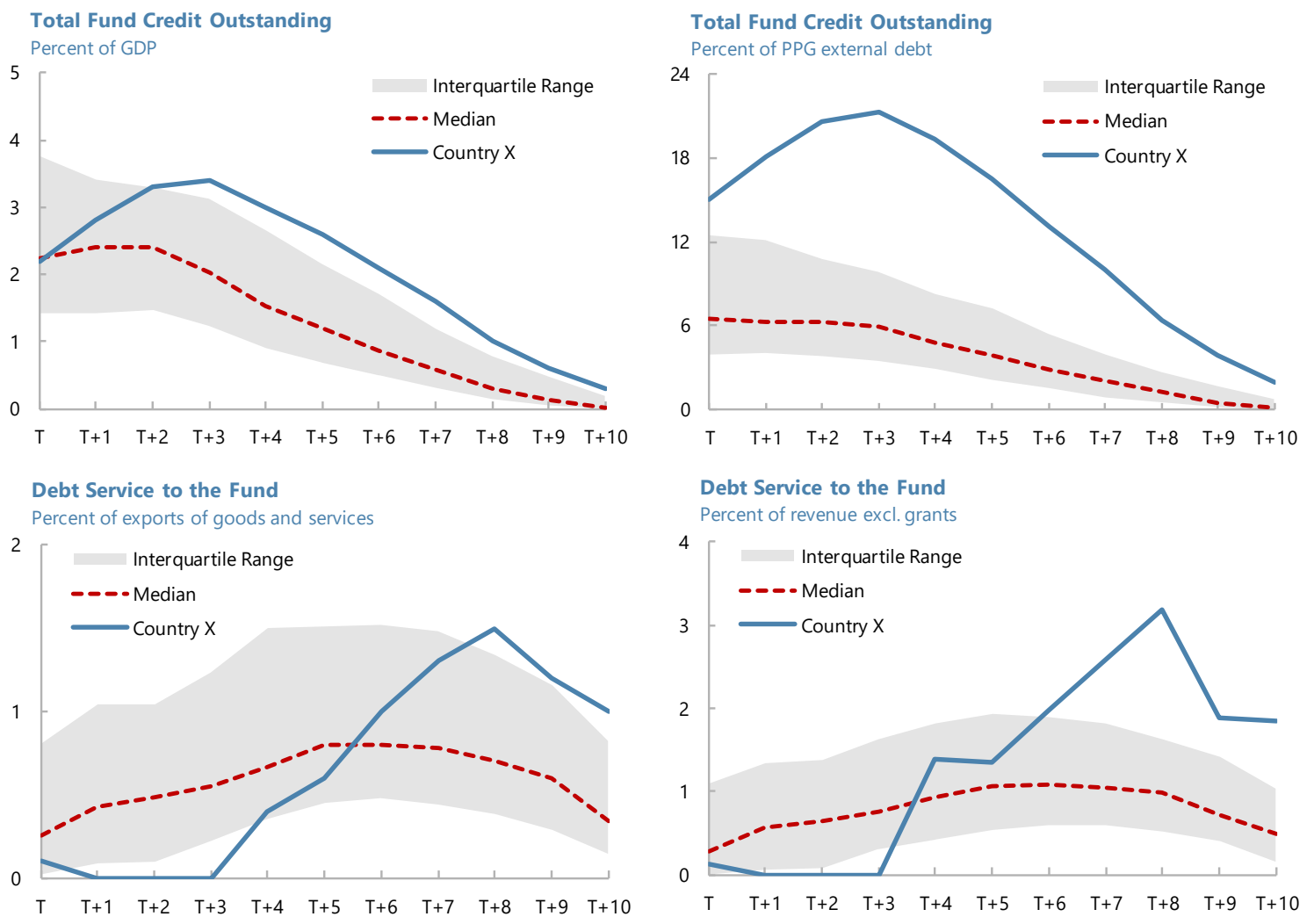

Debt Service to the Fund

Percent of exports of goods and services

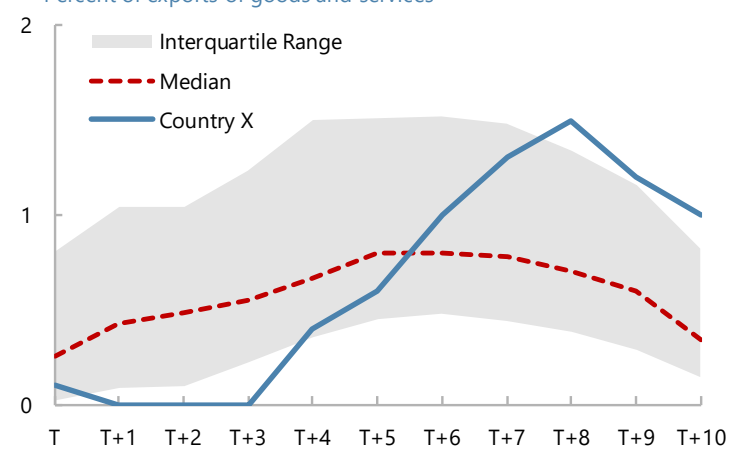

Main sources: Staff reports, IMF Financial Data Query Tool; and FIN staff calculations.

Notes:

1. The illustrative control group for these comparisons refers to all PRGT arrangements (including blends) for the period 2010-2020.

2. Countries with multiple arrangements are entered as separate events in the database.

3. Period $\mathbf{T}$ refers to the year in which the arrangement was approved (control group) or the year in which the arrangement was requested (country of interest).

4. PPG refers to public and publicly guaranteed.

\section{CInternational Monetary Fund. Not for Redistribution}




\section{Annex VII. Methodology for Estimating PRGT Resource Needs}

1. The lending scenarios presented in this paper draw on staff's analysis of crisis-related demand for PRGT resources and the outlook for the post-pandemic decade. Staff's scenarios comprise (i) an in-depth country-by-country analysis of the potential demand ranges for the crisis period (2020-24) and (ii) illustrative lending envelopes for the post-pandemic decade (2025-34), together with an analysis of the PRGT's self-sustainability. Key features are summarized below.

2. All lending scenarios build on the access and blending policy changes discussed in this paper, including an across-the-board 45 percent increase in normal annual and cumulative access limits to 145 and 435 percent of quota, respectively, a unified access norm of 145 percent of quota per 3-year arrangement, and the removal of a hard cap on PRGT access for countries that do not meet the proposed income threshold for blending on the IDA cutoff. These access policies are assumed to remain unchanged until the next LIC Facilities and Financing Review in 2024/25. The temporary access increases for the RCF and normal annual PRGT access are assumed to expire at end-2021.

3. All lending scenarios apply these access rules to demand projections by country, based on existing credit exposures and previous disbursements for each country. Subject to applicable caps, blenders are assumed to be financed by PRGT/GRA at a 1:2 ratio.

4. The scale of financing under multiyear financing arrangements during the pandemic period (through 2024) is calibrated to reflect the exceptionally high financing needs, with average access scaled up to almost twice the level observed in recent years (and at three times in the High Case). Access per arrangement is differentiated by the country's degree of debt vulnerabilities, blend status, and pre-existing credit exposure to the Fund, and subject to the access limits proposed in the paper. Given the wide range of quota/GDP ratios among LICs and to capture potential BoP needs, access is a function of both quota and GDP, subject to lower and upper limits.

5. The near-term projections make an allowance for new EF and augmentations of pre-existing arrangements subject to applicable sub-limits on access. All scenarios also accommodate some degree of Fund financing for health-related and vaccine needs.

6. Total PRGT lending is ultimately dependent on demand, i.e., on the share of LICs seeking Fund financial support. The Baseline through 2024 assumes that almost two-thirds of eligible LICs (on a quota-weighted basis) request program support, which is in line with peak demand years during the global financial crisis and the percentage of LICs that requested financial support in 2020. The Low Case assumes 40 percent (the longer-term average) and the High Case assumes about 80 percent, which would be unprecedented. The range between the Low and High Cases reflect the large uncertainty around economic developments and demand for Fund financing over the coming years.

7. The longer-term demand projection allows for periodic increases in nominal access levels per country in line with GDP growth, partly offset by savings from transitions from non-blending to 
blending, and from blending to graduation. The Baseline and Low Case projection for the post-crisis decade (2025-34) projects average annual demand of SDR 1.65 billion based on an assumption that future access increases are calibrated to preserve access in real terms relative to pre-pandemic levels. The longer-term envelope for the High Case is calibrated to per-country access in line with GRA arrangements for emerging market countries, implying SDR 3 billion of average annual lending in the post-crisis decade.

8. The demand projections are then fed into a capacity/supply model, which translates projected commitments into disbursements and credit outstanding, calculates subsidization costs and the evolution of investment returns on PRGT assets, and produces an estimate of the PRGT's self-sustained lending capacity at different points in time based on existing subsidy and reserve account resources. The combination of demand scenarios and supply analysis then provides a complete picture of the PRGT's lending capacity and the resource implications discussed in this note for each scenario. 


\section{Annex VIII. The PRGT Financing Model}

1. PRGT lending is supported by an endowment-based financing model that relies on loan and subsidy resources. Loan resources are provided through bilateral agreements with members and onlent by the PRGT on a passthrough basis to LICs. Loan resources are typically remunerated by the PRGT at the SDR interest rate and secured through the PRGT's RA and are mobilized periodically depending on expected resource needs. Balances in the PRGT's subsidy accounts and the RA (SDR 3.9 billion and SDR 4.1 billion respectively as of end-April 2021) as well as any investment earnings on these account-are used to cover the interest cost of PRGT loans, so that borrowers can benefit from concessional (currently zero) interest rates. Under the self-sustained model, the resources in PRGT subsidy accounts would be gradually drawn down to zero, while balances in the RA would grow over time by the amount of investment returns on the RA balance, until returns on its assets would subsidize PRGT lending in perpetuity.

2. The framework for the PRGT provides for the annual reimbursement of the GRA for the expenses of conducting the business of the PRGT. This reimbursement is an integral part of the Fund's new income model approved in 2008 based on the principle that the GRA should not crosssubsidize the PRGT's activities. However, it was explicitly recognized that reimbursement can be temporarily suspended when the resources in the PRGT are insufficient to meet expected demand.

- The reimbursement of the PRGT can be waived notwithstanding that the PRGT contains Special Disbursement Account (SDA) resources derived from gold sales profits. According to Article $V$, Section 12(i), the SDA needs to reimburse the GRA for expenses in administering resources of the Special Disbursement Account (SDA). The PRGT has SDA resources in the Reserve Account and the General Subsidy Account. Reimbursement has been waived for FY1998-FY2004 (to fund contributions for HIPC Initiative) and FY2005-FY2012 to provide contributions for PRGT. The suspension was taken on the understanding that reimbursable expenses would only arise where PRGT principal loan disbursements would be funded with SDA resources, and that absent such use, the Fund may decide that the GRA bear the cost of the PRGT. As indicated in the FY2020 and FY2021 income papers, staff has started a review of the reimbursement practices under various trusts funded with SDA resources, the completion of which has been delayed due to the many urgent Covid-19 response related priorities. While staff had aimed at completing the review as part of this review of concessional financing, this was not possible and staff will present it at the next possible opportunity.

3. The three-pillar strategy was adopted in 2012 to make the PRGT's lending self-sustaining without the need for periodic subsidy mobilization. Following the transfer of windfall profits from gold sales and additional bilateral grants, the PRGT's subsidy resources were considered adequate for a sustained level of lending in perpetuity without the need for regular subsidy contributions from the Fund's membership. The three-pillar strategy consists of (i) a base envelope of SDR 11/4 billion in annual PRGT lending capacity, which is expected to cover concessional lending needs during normal periods; (ii) contingent measures that can be invoked when average financing needs exceed the 
base envelope by a substantial margin for an extended period, including additional bilateral fundraising, suspending reimbursement of the GRA for PRGT administrative expenses for a limited period, and modifying access, blending, interest rate, and eligibility policies to reduce the need for subsidy resources; and (iii) a principle of self-sustainability under which future modifications to LIC facilities would be expected to ensure that demand for IMF concessional lending can be reasonably met with the available resources.

4. The adequacy of resources under the self-sustained PRGT is assessed annually. The analysis includes several elements: (i) short-term demand projections and sensitivity analyses derived from country desk surveys; (ii) a demand model that is used to project medium- to longer-term concessional lending, based on specific policy assumptions (e.g., access, blending, graduation) and plausible demand scenarios derived from historical patterns; (iii) an assessment of available PRGT loan resources under different near- to medium-term demand scenarios; and (iv) a capacity ("supply") model that calculates the PRGT's self-sustained lending capacity based on available subsidy resources and projected demand. This analysis informs staff's assessment of the adequacy of the overall framework, the affordability of any policy refinements, and the potential need for corrective contingency measures, including possible loan mobilization or subsidy fundraising.

5. In the May 2019 Reviews of LIC Facilities and Concessional Financing, the Fund adopted several reforms that were calibrated to be consistent with the self-sustainability of the PRGT. The reform package included a generalized one-third increase in access limits and norms. Together with other policy changes, this was projected to result in average annual demand of SDR 1.0-1.7 billion over the next decade. Based on this demand range, the PRGT's self-sustained annual lending capacity would reach a range of SDR 1.1-1.4 billion by 2028, symmetric around the target of SDR $11 / 4$ billion. Loan resources were deemed sufficient to cover the PRGT's lending operations well into the next decade. The review noted that the evolution of the PRGT's self-sustained capacity would require careful monitoring given downside risks.

6. The COVID-19 pandemic is a major negative shock that hit hard all LICs and led to unprecedented demand for concessional financing. Even under current policies, the crisis has already eroded the self-sustained annual lending capacity to the lower end of the above range. Without fresh subsidy resources, the lending capacity is projected to fall well below the range under any plausible scenarios featuring larger PRGT lending over the medium- to longer-term to better meet LICs' evolving financing needs. Bringing the lending capacity up to the "new normal" while preserving the self-sustained endowment model would require significant injections of new subsidy resources as discussed above. 


\section{Annex IX. PRGT Loan Resource Mobilization}

1. The fast-track PRGT loan mobilization round launched in April 2020 has secured about SDR 17 billion from 16 PRGT lenders. Members responded quickly to the call for urgently needed new loan resources. The resources provided so far are expected to cover loan needs under current policies. However, as mentioned in the main text, additional loan resources (almost SDR 13 billion) would be needed on top of the resources secured so far to cover crisis-related demand under all scenarios, including the High Case.

2. The new loan agreements include several improved features, including expanded use of SDRs; a broadened lender base compared to the previous round (e.g., Australia, Germany); deearmarking to allow use for all PRGT facilities; unification of lenders' interest rate at SDRi; easing of drawing limits; and extended drawdown period (2024-29).

\begin{tabular}{|c|c|c|c|c|c|c|}
\hline \multicolumn{7}{|c|}{$\begin{array}{c}\text { Annex IX Table 1. New PRGT Loan Resources Effected under the } 2020 \text { Round }^{1} \\
\text { (As of June 23, 2021) }\end{array}$} \\
\hline Country & $\begin{array}{r}\text { SDR } \\
\text { Million }\end{array}$ & $\begin{array}{r}\text { USD } \\
\text { Million }\end{array}$ & Modality & Media & $\begin{array}{c}\text { Type of } \\
\text { Agreement }\end{array}$ & Encashment \\
\hline Japan $^{2}$ & 3,600 & 5,143 & Augmentation & SDR & NPA & Yes \\
\hline Germany $^{3}$ & 2,534 & 3,619 & New agreement & EUR & Loan Agreement & No \\
\hline France & 2,000 & 2,857 & New agreement & SDR & Loan Agreement & Yes \\
\hline UK & 2,000 & 2,857 & Augmentation & SDR & NPA & Yes \\
\hline China & 1,000 & 1,429 & New agreement & SDR & NPA & Yes \\
\hline Italy & 1,000 & 1,429 & New agreement & SDR & Loan Agreement & Yes \\
\hline Spain & 750 & 1,071 & Augmentation & EUR & Loan Agreement & Yes \\
\hline Australia & 500 & 714 & New agreement & SDR & Loan Agreement & Yes \\
\hline Brazil & 500 & 714 & Augmentation & USD & NPA & Yes \\
\hline Canada & 500 & 714 & Augmentation & USD & Loan Agreement & No \\
\hline Netherlands & 500 & 714 & New agreement & SDR & Loan Agreement & No \\
\hline Sweden & 500 & 714 & New agreement & USD & Loan Agreement & Yes \\
\hline Switzerland & 500 & 714 & New agreement & EUR & Loan Agreement & No \\
\hline Norway & 400 & 571 & New agreement & USD & Loan Agreement & Yes \\
\hline Belgium & 350 & 500 & New agreement & EUR & Loan Agreement & No \\
\hline Denmark & 300 & 429 & New agreement & EUR & Loan Agreement & No \\
\hline Total & 16,934 & 24,191 & & & & \\
\hline \multicolumn{7}{|c|}{$\begin{array}{l}\text { Source: Finance Department. } \\
{ }^{1} \text { All agreements are for the benefit of the General Loan Account, remunerated at the SDR interest rate (with the exception of the } \\
\text { UK loan capped at } 0.05 \% \text { ) and expire at end-2029. With the exception of Germany, all loans are denominated in SDRs. } \\
{ }^{2} \text { To be available in two equal tranches. } \\
{ }^{3} \text { SDR equivalent of EUR } 3 \text { billion at the exchange rate of January } 11,2021 \text { when the agreement became effective. The actual value } \\
\text { of the loan will be calculated at the exchange rate at the time of drawings and net of operational expenses incurred by Germany. }\end{array}$} \\
\hline
\end{tabular}




\section{Annex X. PRGT Subsidy Resources and Reserve Account}

\section{The PRGT's endowment has been built over several decades, relying on a mix of} internal resources and donor contributions. The current framework for financing the Fund's concessional lending, with loans provided by members on market terms, credit risk mitigated by the Reserve Account, and interest rate subsidization from grant resources, was first established in $1987^{1}$ when the ESAF Trust, the predecessor of the current PRG Trust, replaced the early Trust Fund. ${ }^{2}$ Several fundraising rounds to secure loan and subsidy resources relying on members' generosity have been completed since then. To date, members have voluntarily provided about SDR 5.3 billion to the framework's subsidy accounts and made close to SDR 55.5 billion available in loan resources. The Fund contributed about SDR 5.5 billion in internal resources, mostly through the recycling of resources originating from the $1976-80$ gold sales $^{3}$ and non-reimbursement of the GRA. ${ }^{4}$ The funding sources varied:

- The PRGT's subsidy accounts have been mostly funded by bilateral contributions from economically stronger members, predominantly in the form of grants. Several members provided significant contributions through concessional loans remunerated at below market rate (allowing the Trust to save about SDR 0.3 billion in subsidy resources). The 2012-13 distributions of windfall gold sales profits facilitated bilateral contributions of about SDR 2.2 billion from a wider base of 152 members. The Fund also contributed some of the Trust Fund reflows to the PRGT's subsidy accounts, including SDR 148 million transferred from the Reserve Account in lieu of non-reimbursement of the GRA during FY2010-12.

- The PRGT's Reserve Account has been fully funded from resources originating from the 1976-80 gold sales. The Account's current balance of SDR 4.1 billion includes income earned over time on its balances and about SDR 324 million retained from non-reimbursement of the GRA during FY2005-09 and FY2021. Table 1 provides a summary of contributions provided to the PRGT in the past.

\footnotetext{
${ }^{1}$ The so called ESAF Trust established in December 1987 was allowed to borrow from donor countries to on-lend to eligible members on concessional terms. It was supported by newly created reserve and subsidy accounts financed from repayments of Trust Fund's loans, and further supplemented by bilateral contributions from members.

${ }^{2}$ The Trust Fund established in 1976 was providing concessional lending to eligible members on revolving basis.

${ }^{3}$ During 1976-80 the Fund sold 25 million ounces of gold it acquired in the conduct of its operations. These sales generated profits of US $\$ 4.6$ billion, of which US $\$ 1.3$ billion was distributed directly to 104 developing country members. The remainder of the profits, together with interest income and other transfers to the Trust (about SDR 3 billion in total) constituted the resources of the Trust Fund. For description of 1976-1980 gold sales and funding of the Trust see the IMF's Annual Report 1980, pp. 85-89.

${ }^{4}$ Please see further details in Annex VIII.
} 
2. Solidarity with low-income members and burden sharing among donors have been crucial to the PRGT's framework since its inception. Under

past fundraising rounds, bilateral contributions were provided mostly by economically stronger members and typically in proportion to their quota shares. Based on this approach and the proven generosity of the Fund's membership, the proposed concessional financing package relies on a mix of internal and donor resources.

- In the first stage of the two-stage funding strategy, staff now propose to suspend reimbursement to the GRA for PRGT administrative expenses through FY2026, which would retain an additional SDR 0.5 billion in the PRGT Reserve Account and support the PRGT's self-sustained concessional lending capacity.

- In addition, to fully cover the subsidy costs created by COVID-related PRGT lending to LICs, voluntary bilateral subsidy contributions totaling SDR 2.3 billion will be requested from 61 members considered to be in a comparatively stronger economic position, specifically those that currently participate in the IMF's Financial Transaction Plan (FTP), plus non-FTP members that belong to the G20 or EU (except those that have used Fund resources for BoP needs over the past three years). This group, which is similar to the one recently approached under the CCRT fundraising campaign, accounts for about 88 percent of current IMF quotas and in the past have supplied about 94 percent of total bilateral contributions to the PRGT's subsidy accounts.

- Table 2 provides a breakdown by country of cumulative PRGT subsidy contributions, including through implicit subsidization and investment returns. It also includes, for illustration, an indicative breakdown of how the SDR 2.3 billion subsidy gap could be closed through voluntary bilateral contributions based on the quota shares of these member countries.

- To provide donors with flexibility, various options for bilateral subsidy contribution schemes are available as discussed in the main text, with resources pledged upfront and disbursed over time.

- A decision on the appropriate longer-term PRGT envelope would be taken up at the second stage of the funding strategy. Possible additional use of IMF internal resources will be considered during the "stage two" review in 2024/25. 


\begin{tabular}{|c|c|c|c|}
\hline \multicolumn{4}{|c|}{$\begin{array}{l}\text { Annex X Table 2. Bilateral Contributions to the PRGT } \\
\text { (In SDR million unless otherwise noted) }\end{array}$} \\
\hline Country & $\begin{array}{c}\text { Percent } \\
\text { share in total } \\
\text { member } \\
\text { quota }\end{array}$ & $\begin{array}{c}\text { Cumulative } \\
\text { PRGT subsidy } \\
\text { contributions } \\
\text { as of } \\
\text { April } 30,2021^{1}\end{array}$ & $\begin{array}{l}\text { Illustrative new } \\
\text { contributions } \\
\text { request based on } \\
\text { SDR } 2.3 \text { billion } \\
\text { target and quota } \\
\text { shares }^{2}\end{array}$ \\
\hline All members & 100.00 & 5,304 & 2,300 \\
\hline FTP members & 83.01 & 4,874 & 2,172 \\
\hline G-7 & 43.47 & 3,077 & 1,138 \\
\hline Canada & 2.32 & 287 & 61 \\
\hline France & 4.24 & 390 & 111 \\
\hline Germany & 5.60 & 313 & 146 \\
\hline Italy & 3.17 & 257 & 83 \\
\hline Japan & 6.48 & 695 & 169 \\
\hline United Kingdom & 4.24 & 539 & 111 \\
\hline United States & 17.44 & 596 & 456 \\
\hline Other advanced & 18.20 & 1,290 & 476 \\
\hline Australia & 1.38 & 72 & 36 \\
\hline Austria & 0.83 & 93 & 22 \\
\hline Belgium & 1.35 & 107 & 35 \\
\hline Czech Republic & 0.46 & 24 & 12 \\
\hline Denmark & 0.72 & 67 & 19 \\
\hline Estonia, Republic of & 0.05 & 1 & 1 \\
\hline Finland & 0.51 & 41 & 13 \\
\hline Israel & 0.40 & - & 11 \\
\hline Korea & 1.80 & 90 & 47 \\
\hline Lithuania, Republic of & 0.09 & 2 & 2 \\
\hline Luxembourg & 0.28 & 18 & 7 \\
\hline Malta & 0.04 & 2 & 1 \\
\hline Netherlands & 1.84 & 210 & 48 \\
\hline New Zealand & 0.26 & 11 & 7 \\
\hline Norway & 0.79 & 74 & 21 \\
\hline Saudi Arabia & 2.10 & 100 & 55 \\
\hline Singapore & 0.82 & 27 & 21 \\
\hline Slovak Republic & 0.21 & 5 & 6 \\
\hline Slovenia, Republic of & 0.12 & 2 & 3 \\
\hline Spain & 2.00 & 78 & 52 \\
\hline Sweden & 0.93 & 146 & 24 \\
\hline Switzerland & 1.21 & 121 & 32 \\
\hline
\end{tabular}




\begin{tabular}{|c|c|c|c|}
\hline \multicolumn{4}{|c|}{$\begin{array}{r}\text { Annex X Table 2. Bilateral Contributions to the PRG } \\
\text { (In SDR million unless otherwise noted) }\end{array}$} \\
\hline Country & $\begin{array}{c}\text { Percent } \\
\text { share in total } \\
\text { member } \\
\text { quota }\end{array}$ & $\begin{array}{c}\text { Cumulative } \\
\text { PRGT subsidy } \\
\text { contributions } \\
\text { as of } \\
\text { April } 30,2021^{1}\end{array}$ & $\begin{array}{l}\text { Illustrative new } \\
\text { contributions } \\
\text { request based on } \\
\text { SDR } 2.3 \text { billion } \\
\text { target and quota } \\
\text { share }\end{array}$ \\
\hline Other FTP members & 21.34 & 508 & 558 \\
\hline Algeria & 0.41 & 17 & 11 \\
\hline Botswana & 0.04 & 2 & 1 \\
\hline Brazil & 2.32 & - & 61 \\
\hline Brunei Darussalam & 0.06 & 3 & 2 \\
\hline Chile & 0.37 & 2 & 10 \\
\hline China & 6.41 & 135 & 168 \\
\hline India & 2.76 & 80 & 72 \\
\hline Kuwait & 0.41 & 19 & 11 \\
\hline Malaysia & 0.76 & 40 & 20 \\
\hline Mauritius & 0.03 & 1 & 1 \\
\hline Mexico & 1.87 & 42 & 49 \\
\hline Oman & 0.11 & 6 & 3 \\
\hline Peru & 0.28 & 0 & 7 \\
\hline Philippines & 0.43 & 6 & 11 \\
\hline Poland, Republic of & 0.86 & - & 23 \\
\hline Qatar & 0.15 & 2 & 4 \\
\hline Russian Federation & 2.71 & 113 & 71 \\
\hline Thailand & 0.68 & 24 & 18 \\
\hline Trinidad and Tobago & 0.10 & 1 & 3 \\
\hline United Arab Emirates & 0.49 & 9 & 13 \\
\hline Uruguay & 0.09 & 5 & 2 \\
\hline Non-FTP members & 4.89 & 125 & 128 \\
\hline Advanced economies & 1.80 & 74 & 47 \\
\hline Cyprus & 0.06 & 2 & 2 \\
\hline Greece & 0.51 & 36 & 13 \\
\hline Ireland & 0.73 & 20 & 19 \\
\hline Latvia, Republic of & 0.07 & 2 & 2 \\
\hline Portugal & 0.43 & 15 & 11 \\
\hline
\end{tabular}

\section{CInternational Monetary Fund. Not for Redistribution}




\begin{tabular}{|c|c|c|c|}
\hline \multicolumn{4}{|c|}{$\begin{array}{r}\text { Annex X Table 2. Bilateral Contributions to the PRG } \\
\text { (In SDR million unless otherwise noted) }\end{array}$} \\
\hline Country & $\begin{array}{c}\text { Percent } \\
\text { share in total } \\
\text { member } \\
\text { quota }\end{array}$ & $\begin{array}{c}\text { Cumulative } \\
\text { PRGT subsidy } \\
\text { contributions } \\
\text { as of } \\
\text { April } 30,2021^{1}\end{array}$ & $\begin{array}{l}\text { Illustrative new } \\
\text { contributions } \\
\text { request based on } \\
\text { SDR } 2.3 \text { billion } \\
\text { target and quota } \\
\text { share }\end{array}$ \\
\hline Other non-FTP members & 3.08 & 51 & 81 \\
\hline Bulgaria & 0.19 & 7 & 5 \\
\hline Croatia, Republic of & 0.15 & 2 & 4 \\
\hline Hungary & 0.41 & - & 11 \\
\hline Indonesia & 0.98 & 5 & 26 \\
\hline Romania & 0.38 & 9 & 10 \\
\hline Turkey & 0.98 & 29 & 26 \\
\hline Total from 61 members & 87.90 & 4,999 & 2,300 \\
\hline Total from other members & 12.10 & 305 & $\ldots$ \\
\hline \multicolumn{4}{|c|}{$\begin{array}{l}{ }^{1} \text { Staff estimates of cumulative contributions (i.e. grants, returns on members' deposits and implicit } \\
\text { contributions) made to the PRGT and its predecessors under all fundraising efforts since } 1987 \text {, } \\
\text { including income earned on outstanding balances of the contributions and excluding amounts } \\
\text { transferred to the MDRI-II Trust in January } 2006 \text {. } \\
{ }^{2} \text { All contributions are voluntary. Indicative contributions are calculated based on quota shares of } 61 \\
\text { economically stronger member countries, including those participating in the Financial Transaction } \\
\text { Plan (FTP) and G-20 and European Union members that have not used Fund resources for BoP needs } \\
\text { over the last } 3 \text { years. }\end{array}$} \\
\hline
\end{tabular}

\section{CInternational Monetary Fund. Not for Redistribution}




\section{Annex XI. PRGT Investment Strategy and Options for Contributors}

1. The PRG Trust Instrument allows for borrowing from official lenders (i) for the purpose of on-lending to eligible PRGT borrowers and (ii) in order for subsidy accounts to benefit from net investment earnings on the proceeds of loans extended at a concessional interest rate. Such borrowings are based on bilateral agreements with lenders and can be done in both SDRs and currencies. The investment risk in case of borrowing for investment is carried by lenders. ${ }^{1}$

2. Members have used this vehicle for providing subsidy resources since 1988 with the principal of investments varying from SDR 1.5 million to SDR 135 million. In the context of reviewing the investment strategy for Trust assets in July 2017, the Executive Board approved the following two options for investments by members who wish to lend to the PRGT for the purpose of contributing income earned on investments: ${ }^{2}$

(i) Their investments may be pooled with the PRG Trust assets and share the same risk and return profile. ${ }^{3}$ The current long-term investment return target for PRGT assets is to achieve 90 bps over the SDR rate, however, the realized investment returns are subject to high uncertainty, including that returns may turn negative, particularly over shorter horizons, leading to a potential loss in the principal of investments. The risk of losses at a 10-year maturity is currently estimated at 11 percent. To avoid credit risk to lenders, the maturity date of investments could be linked to reaching the amount of the pledged contribution in NPV terms. Such investments would continue to be liquid with the possibility of encashment/early repayment from the proceeds of the liquidation of the investment itself, if needed.

\section{(ii) In case the risk related to investing in PRGT assets is not acceptable, contributors may elect to invest their resources in BIS obligations, managed separately from the PRGT}

assets. These obligations consist primarily of deposits with a maximum maturity of 12 months. The lower risk associated with BIS investments comes at the cost of lower returns, which are unlikely to significantly exceed the SDR rate. As currently observed, returns on BIS obligations are below the SDR rate.

\footnotetext{
${ }^{1}$ In line with Section IV, paragraph 3(b) of the PRGT Instrument, the repayment of principal and any payment of interest on borrowings for investment shall be made exclusively from the proceeds of liquidation of the investment and the earnings thereon.

2 Decision No. 16253-(17/70), adopted July 28, 2017. Under the PRGT instrument, Section VII, paragraph 3(a), the Executive Board would need to approve any new investment strategy for investing the PRGT subsidy accounts' borrowed resources beyond the two investment options adopted under Decision No. 16253.

${ }^{3}$ Under the current investment strategy, the PRGT portfolio has been structured to maintain its reserve-like properties, provide security to the PRGT loan providers, and ensure liquidity in the event of unexpected needs through its large allocation to short-term fixed-income instruments. The eligible asset classes reflect a moderately diversified portfolio. The target asset allocation assumes 45 percent in liquid and short-term fixed-income instruments, 30 percent in corporate bonds, 5 percent in emerging market government bonds, and 20 percent in publicly listed equities.
} 
3. Currently there are eight active agreements for the benefit of the PRGT, three of which for investment in the Trust's assets and five in BIS obligations. Members also contribute through deposit and investment agreements for the benefit of the PRG-HIPC and the CCR Trusts.

4. Due to the low interest rate environment in recent years, subsidization through income earned on investments has been slow in providing pledged subsidy resources and required extension of agreements with the contributing members. Annual rates and returns on investments from 2010-present are provided below.

\begin{tabular}{|l|llllllllllllll|}
\hline \multicolumn{10}{|c|}{ Annex XI Table 1. SDR Rate and Returns on PRGT Assets } \\
(In percent)
\end{tabular}

5. Large scale lending in SDRs for investment purposes would require operational arrangements for converting SDRs into currencies through VTAs and managing risks related to exchange rate fluctuations and currency conversion costs. 


\section{Annex XII. PRGT—Review of Interest Rate Structure}

\section{This Annex reviews in greater detail the interest rate charged on borrowing from the}

PRGT. The background section describes the PRGT interest rate mechanism and its application to date. The following section discusses the implications of the existing interest rate mechanism in the current economic environment. The final section sets out the proposed interest rate on PRGT lending based on the application of the PRGT's existing interest rate setting mechanism, as modified in 2019, of a zero rate for the ECF, the SCF, and the RCF for the period August 2021-July 2023.

\section{Background}

\section{The PRGT interest rate mechanism was adopted in $\mathbf{2 0 0 9}$ as part of a comprehensive} reform of the IMF's concessional facilities. Prior to the reforms, the Fund's concessional lending was traditionally extended at a uniform rate of 0.5 percent. The objective of the 2009 reforms was to increase the flexibility of IMF support to LICs and better tailor assistance to countries' diverse needs given their heightened exposure to global volatility. ${ }^{1}$ The interest rate structure and adjustment mechanism aimed to balance the following objectives: (i) increase concessionality of PRGT financing, especially in the context of low global interest rates at the time; (ii) preserve the Trust's scarce resources; (iii) avoid permanently zero interest rates; (iv) tailor financial terms to LICs' needs and capacity; and (v) limit fluctuations in concessionality of PRGT instruments and subsidy costs.

\section{The mechanism links interest rates on PRGT lending to global interest rates (Table 1).}

As conceived in 2009, interest rates on PRGT credit provided under different facilities are set for the upcoming two years in the context of biennial reviews; their level is linked to the average SDR interest rate over the most recently observed 12-month period; and the rate charged on SCF loans was initially set at 25 basis points above that for the ECF, as SCF users were expected to have somewhat higher capacity to service debt than ECF users, and reflecting also differences in the duration of their BoP financing and adjustment needs. The reform package in the parallel LIC Facilities Review in 2019 included a modification of the interest rate mechanism to align the SCF rate structure with that of the ECF (Table 1). The change made the SCF more concessional by (i) setting the SCF rate at zero when the SDR rate is below 2 percent and (ii) reducing the SCF rate by 0.25 percent when it is above 2 percent.

\footnotetext{
${ }^{1}$ See $A$ New Architecture of Facilities for Low-Income Countries and Reform of the Fund's Concessional Financing Framework-Supplementary Information, IMF (2009), July 20, 2009.
} 
Annex XII Table 1. Evolution of Interest Rate Mechanism for the Fund's Concessional Facilities $^{1}$

(In percent)

A. January 2010 - July $2015^{2,3,4}$

\begin{tabular}{lccc}
\hline SDR rate thresholds & ECF & RCF & SCF \\
\hline SDR rate $<2$ & 0.00 & 0.00 & 0.25 \\
$2 \leq$ SDR rate $\leq 5$ & 0.25 & 0.25 & 0.50 \\
SDR rate $>5$ & 0.50 & 0.50 & 0.75 \\
\hline \multicolumn{1}{l}{ SDR rate thresholds } & B. July 2015 - December 2016,4 & \\
\hline SDR rate $<2$ & ECF & RCF & SCF \\
$2 \leq$ SDR rate $\leq 5$ & 0.00 & 0.00 & 0.25 \\
SDR rate $>5$ & 0.25 & 0.00 & 0.50 \\
\hline & 0.50 & 0.00 & 0.75 \\
\hline SDR rate thresholds & C. December 2016 - June 20195 & \\
\hline SDR rate $\leq 0.75$ & ECF & RCF & SCF \\
$0.75<$ SDR rate $<2$ & 0.00 & 0.00 & 0.00 \\
$2 \leq$ SDR rate $\leq 5$ & 0.00 & 0.00 & 0.25 \\
SDR rate $>5$ & 0.25 & 0.00 & 0.50 \\
\hline & 0.50 & 0.00 & 0.75 \\
\hline SDR rate thresholds & D. July 2019 - July 2021 & & \\
\hline SDR rate $<2$ & ECF & RCF & SCF \\
$2 \leq$ SDR rate $\leq 5$ & 0.00 & 0.00 & 0.00 \\
SDR rate $>5$ & 0.25 & 0.00 & 0.25 \\
\hline & 0.50 & 0.00 & 0.50 \\
\hline
\end{tabular}

${ }^{1}$ This is based on the average SDR rate over the most recently observed 12-month period.

${ }^{2}$ An Interest Rate Mechanism for the Fund's Concessional Facilities was approved by the Executive Board in July 2009; it was in effect for January 7, 2010-July 2015.

${ }^{3}$ A temporary waiver of interest payment for PRGT-eligible members on all outstanding concessional loans was approved by the Executive Board in July 2009, became effective on January 7, 2010 and further extended in December 2011, December 2012, and December 2014 until end-December 2016, after which the mechanism would apply.

${ }^{4}$ The interest rate charge on RCF lending was set permanently to zero as of July 2015.

${ }^{5}$ In December 2016, IMF Executive Board approved a new Interest Rate Mechanism and set zero rates on all low-income country lending facilities through end-2018, which was subsequently extended to end-June 2019.

${ }^{6}$ In June 2019, IMF Executive Board approved a modification of the Interest Rate Mechanism and set zero rates on all low-income country lending facilities through end-June 2021, which was subsequently extended to end-July 2021.

4. Since the interest rate mechanism was first established in 2009 , no interest has been charged on PRGT credit. In 2009 as part of a comprehensive reform of the IMF's concessional facilities, the Executive Board granted interest waivers on all outstanding concessional credit during 2010-16 when LICs faced considerable headwinds from the global economic environment. The interest rate mechanism has been in operation since then, resulting in zero rates on credit under all three PRGT facilities on the basis of the prevailing low global interest rates.

5. In July 2015, the PRGT interest rate mechanism was modified to enhance support for PRGT-eligible countries in fragile situations or hit by natural disasters. As part of the Fund's 
response to the UN-sponsored dialogue on policies to promote financing of the 2030 Development Agenda, the Board approved an increase in concessionality of fast-disbursing support under the RCF by setting the interest rate levied on RCF financing permanently at zero, while preserving the PRGT interest rate mechanism for the SCF and ECF.

\section{In October 2016, the PRGT interest rate mechanism was amended to accommodate} periods of very low interest rates worldwide. A new threshold was proposed whereby both the ECF and the SCF rate would be set at zero when the average SDR rate over the most recently observed 12-month period was less than or equal to 0.75 percent (Table 1). This proposal in effect kept all PRGT interest rates under the mechanism at zero percent through December 2018, while incurring only modest subsidy costs for the PRGT. In addition, the interest rate charges on outstanding legacy balances under the ESF-which are not included under the PRGT interest rate mechanism-were waived until December 2018. Most Directors expressed the view that the merits and implications of unifying the interest rate structure for the ECF and SCF should be examined as one element of the forthcoming review of the LIC Facilities. ${ }^{2}$ In December 2018, the Executive Board postponed the deadline for the next interest rate review to no later than June 30, 2019 so that the PRGT interest rate mechanism could be assessed in light of the findings of the parallel LIC Facilities Review.

\section{In May 2019, the Board approved an amendment of the interest rate mechanism.}

Specifically, the Board approved reforms to align the interest rates on SCF loans with those on ECF loans to modestly increase the degree of concessionality of PRGT financing under the SCF, with moderate subsidy costs financed within the PRGT's self-sustaining financing envelope. ${ }^{3}$ Interest on RCF credit would remain permanently at zero, as decided in 2015. The Board also decided that the existing zero percent interest rates under the ECF and SCF continue to be applied to outstanding balances of PRGT loans through June 30, 2021 and the waiver of interest rate charges on outstanding legacy balances under the ESF was further extended until their full repayment in October $2020 .^{4}$

\section{PRGT Interest Rates in the Current Economic Context}

\section{Reflecting recent trends in global interest rates, the SDR interest rate has decreased to} average $\mathbf{0 . 0 8}$ percent over the last 12 months, which remains low by historical standards

(Figure 1). The SDR rate declined from 0.23 percent at the time of the first interest rate waiver in

\footnotetext{
2 See "IMF Executive Board Modifies PRGT Interest Rate Mechanism and Approves Zero Rates on All Low-Income Country Lending Facilities through end-2018," Press Release No. 16/448, IMF (2016b), October 6, 2016.

${ }^{3}$ For SCF arrangements treated as precautionary, no interest is charged. An availability fee of 0.15 percent applies at the end of each six-month period on available but undrawn credit.

4 See Decision No. 16521-(19/42), adopted May 24, 2019, and Poverty Reduction and Growth Trust-Review of Interest Rate Structure (IMF, 2019b). Staff has recently proposed for the Executive Board's approval on lapse of time basis: (i) to postpone the review of the PRGT interest rate mechanism scheduled for June 2021 to July 2021, (ii) to continue having the interest rates of zero percent per annum applicable to the outstanding balances of PRGT loans under the ECF and SCF through July 31, 2021; and (iii) to extend the waiver of the interest rate charge on the outstanding legacy balances under the ESF through July 31, 2021.
} 
January 2010 to 0.05 percent in September 2014 and remained at this level until September 2016. Since then, the SDR rate steadily increased to reach 1.14 percent by end-March 2019, then declined gradually until the onset of the pandemic, after which it fell sharply. It is currently 0.05 percent.

9. Given low global interest rates, the degree of concessionality of PRGT loans remains below the traditional benchmark of 35 percent-as it has been since the introduction of the current facilities architecture in 2010. The average grant element in PRGT loans is currently estimated to be 32 percent for ECF and RCF and 26 percent for SCF. ${ }^{5}$

10. The global economic outlook for LICs has substantively worsened since the previous review and since the onset of the pandemic, with significant downside risks. Global growth slowed to -3.3 percent in 2020, and LICs GDP growth is projected to be 4.3 percent in 2021. LICs have been hit harder and are expected to suffer more significant medium-term losses and to face substantial risks, including from limited access to vaccines, limited fiscal space to mount major health care policy responses or support livelihoods, high and rising debt levels, climate change and potent natural disasters. ${ }^{6}$ The bulk of the PRGT credit outstanding is under the RCF, following the increase in emergency financing in response to the COVID-19 pandemic, as well as credit outstanding under the ECF (Figure 2).

\section{PRGT Interest Rates for August 2021-July} 2023
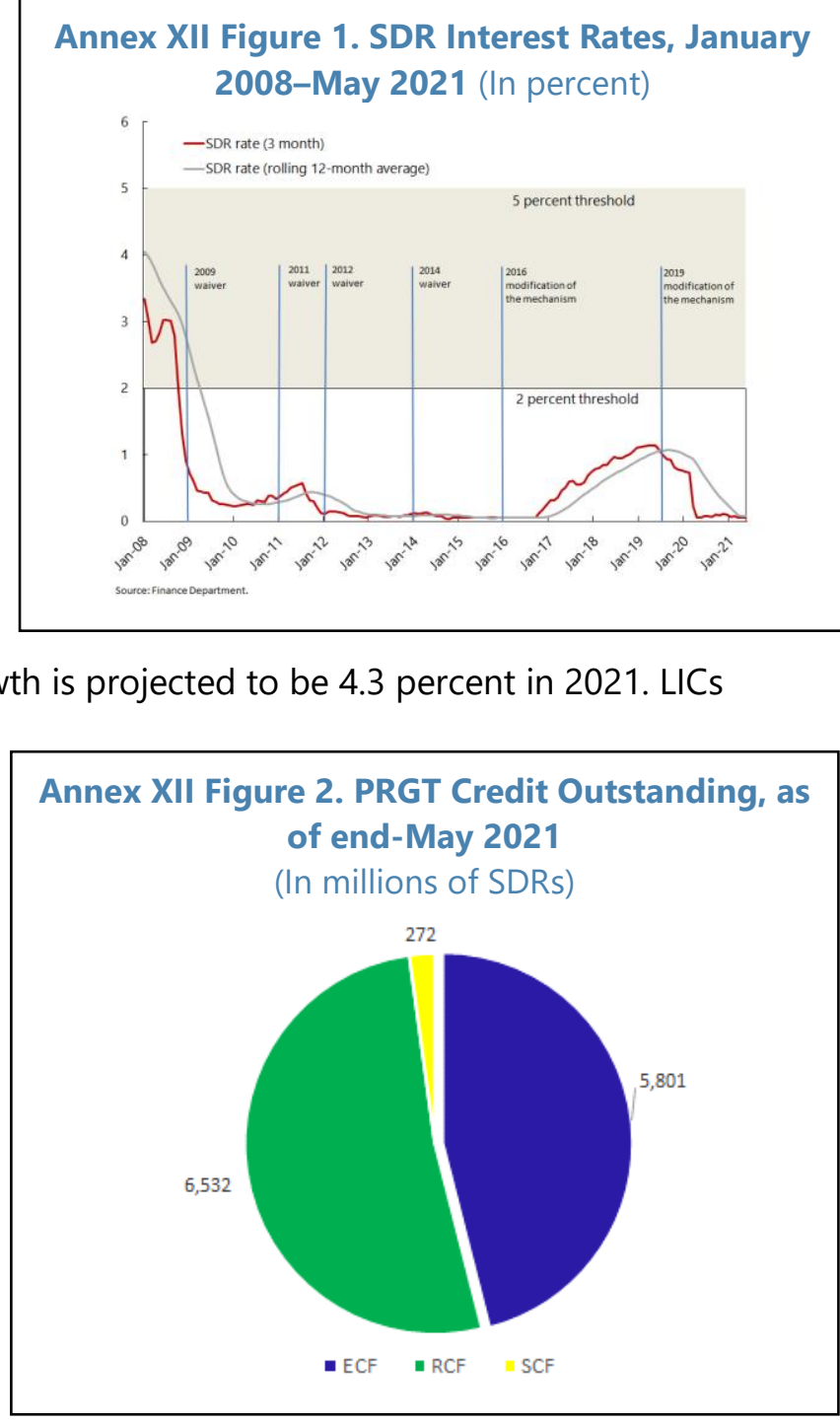

11. With the application of the interest rate mechanism as modified in 2019, no interest would be charged on PRGT credit until July 2023. With the 12-month average SDR rate currently well below the 2 percent threshold, the interest rate on SCF and ECF credit would be zero for the period August 2021-June 2023. As decided by the Executive Board in 2015, the RCF interest rate would remain permanently at zero. Consistent with Section II, Paragraph 4(b) of the PRGT Instrument, the next review of the PRGT interest rate structure would be completed by July 2023.

\footnotetext{
${ }^{5}$ See 2018 Review of Facilities for Low-Income Countries, IMF (2018c), August 1, 2018. Since October 11, 2013, a unified discount rate of 5 percent is used to calculate the grant element of individual loans.

${ }^{6}$ See World Economic Outlook (IMF, April 2021).
} 


\section{Annex XIII. CCRT Grant Mobilization}

\begin{tabular}{|c|c|c|c|c|}
\hline \multicolumn{5}{|c|}{$\begin{array}{c}\text { Annex XIII Table 1. New Contributions to the CCRT } \\
\text { (As of June 23, 2021) }\end{array}$} \\
\hline \multirow[b]{2}{*}{ Country } & \multicolumn{3}{|c|}{ CCRT grants } & \multirow[b]{2}{*}{$\begin{array}{l}\text { Current status } \\
\text { of contribution }\end{array}$} \\
\hline & $\begin{array}{l}\text { In millions } \\
\text { of SDRs }\end{array}$ & $\begin{array}{l}\text { In millions of } \\
\text { original currency } \\
\text { (if appl.) }\end{array}$ & $\begin{array}{l}\text { In millions } \\
\text { of US\$ }\end{array}$ & \\
\hline European Union ${ }^{1}$ & 152.5 & $€ 183$ & 217.8 & Partially disbursed \\
\hline UK & 135.8 & $£ 150$ & 194.0 & Disbursed \\
\hline Japan & 73.4 & $\$ 100$ & 104.8 & Disbursed \\
\hline Germany & 66.2 & $€ 80$ & 94.6 & Disbursed \\
\hline France & 33.7 & $€ 40$ & 48.1 & Pledge \\
\hline Spain & 20.9 & $€ 25$ & 29.9 & Pledge \\
\hline Netherlands & 20.8 & $€ 25$ & 29.7 & Disbursed \\
\hline Switzerland & 19.5 & CHF 25 & 27.8 & Disbursed \\
\hline Norway & 14.5 & NOK 180 & 20.7 & Disbursed \\
\hline Singapore & 12.2 & $\$ 17.6$ & 17.5 & Pledge \\
\hline Greece & 7.6 & $\$ 11.0$ & 10.9 & Pledge \\
\hline China & 5.6 & & 8.0 & Disbursed \\
\hline Mexico $^{2}$ & 2.9 & $\$ 4$ & 4.2 & Disbursed \\
\hline Philippines & 2.8 & $\$ 4$ & 4.0 & Pledge \\
\hline Sweden & 2.4 & SEK 30 & 3.5 & Disbursed \\
\hline Bulgaria & 1.9 & & 2.7 & Disbursed \\
\hline Luxembourg & 1.7 & $€ 2$ & 2.4 & Disbursed \\
\hline Malta & 0.6 & $\$ 0.8$ & 0.8 & Disbursed \\
\hline Total & 574.9 & & 821.3 & \\
\hline Target & SDR 1 billion & & US\$1.4 billion & \\
\hline
\end{tabular}




\section{References}

International Monetary Fund, 2009, "A New Architecture of Facilities for Low-Income Countries and Reform of the Fund's Concessional Financing Framework-Supplementary Information" (Washington).

_ 2015, "Financing for Development: Enhancing the Financial Safety Net for Developing Countries," IMF Policy Paper 2020/044 (Washington).

_ 2016a, "Review of Access Limits and Surcharge Policies" (Washington).

- 2016b, "IMF Executive Board Modifies PRGT Interest Rate Mechanism and Approves Zero Rates on All Low-Income Country Lending Facilities Through end-2018," Press Release No. 2016/448 (Washington).

_ , 2016c, "Financing for Development: Enhancing the Financial Safety Net for Developing Countries-Further Considerations" (Washington).

—, 2017a, "Large Natural Disasters_Enhancing the Financial Safety Net for Developing Countries" (Washington).

- 2017b, "Investment of Temporary Resources to Generate Income to Contribute to PRG, PRGHIPC and CCR Trust" (Washington).

_ 2018a, "Guidance Note on the Bank-Fund Debt Sustainability for Framework for Low Income Countries" (Washington).

_ 2018b, "Macroeconomic Developments and Prospects in Low-Income Developing Countries: 2018" (Washington).

_ 2018c, "2018 Review of Facilities for Low-Income Countries" (Washington).

_ 2019a, "2018-19 Review of Facilities for Low-Income Countries_Reform Proposals," IMF Policy Paper No. 2019/014 (Washington).

— 2019b, "Poverty Reduction and Growth Trust-Review of Interest Rate Structure" (Washington).

- 2020a, "The Evolution of Public Debt Vulnerabilities in Lower Income Economies," IMF Policy Paper No. 20/003 (Washington).

- 2020b, "Eligibility to Use the Fund's Facilities for Concessional Financing, 2020," IMF Policy Paper No. 2020/016 (Washington) 
_ 2020c, "Enhancing the Emergency Financing Toolkit-Responding to the COVID-19 Pandemic" (Washington).

- 2020d, "Temporary Modification to the Fund's Annual Access Limits," IMF Policy Paper 2020/036 (Washington).

- 2020e, "Policy Safeguards for Countries Seeking Access to Fund Financial Support that would Lead to High Levels of Combined GRA-PRGT Exposure," IMF Policy Paper No. 2020/039 (Washington).

_ 2020f, "Review of Enhanced Access Limits under the Rapid Credit Facility and Rapid Financing Instrument," IMF Policy Paper 2020/044 (Washington).

- 2020g, "Update on the Joint IMF-WB Multipronged Approach to Address Debt Vulnerabilities," IMF Policy Paper No. 2020/066 (Washington).

- 2020h, "Reform of the Policy on Public Debt Limits in IMF-Supported Programs," IMF Policy Paper 2020/061 (Washington).

- 2021a, "Temporary Extensions and Modifications of Access Limits in the Fund's Lending Facilities" (Washington).

- 2021b, "The Acting Chair's Summing Up - Temporary Extensions and Modifications of Access Limits in the Fund's Lending Facilities, Press Release (Executive Board Assessment)" (Washington).

- 2021c, "Macroeconomic Developments and Prospects in Low-Income Countries, 2021," IMF Policy Paper No. 2021/020 (Washington).

World Economic Outlook (WEO), 2021, WEO 2021, IMF, April 2021. 


\section{INTERNATIONAL MONETARY FUND}

July 1,2021

FUND CONCESSIONAL FINANCIAL SUPPORT FOR LOW

INCOME COUNTRIES-RESPONDING TO THE PANDEMIC-

SUPPLEMENTARY INFORMATION ON THE PROPOSED

SUBSIDY RESERVE ACCOUNT AND DEPOSIT AND

INVESTMENT ACCOUNT

\author{
Approved By \\ Seán Nolan and \\ Christian Mumssen
}

Prepared by the Strategy, Policy and Review Department, and Finance Department.

To facilitate bilateral subsidy contributions and reinforce reserve coverage, staff proposes the creation of two new PRGT accounts that can receive member contributions-a "Subsidy Reserve Account" (SRA) and a "Deposit and Investment Account" (DIA). As discussed in paragraphs 61-63 of Fund Concessional Financial Support for Low-Income Countries-Responding to the Pandemic:

- The SRA would have the dual purpose of holding and investing PRGT subsidy resources while also providing an additional backstop to the PRGT Reserve Account (RA) to help manage credit risk. The proposed SRA would complement existing subsidy accounts and could receive bilateral grants or investment returns contributed by members to finance PRGT subsidization. The main purpose of the SRA would be to provide an additional flexible vehicle for subsidizing PRGT lending while also enhancing reserve coverage by serving as a second-line backstop for the RA in the event of arrears, providing a medium-term funding bridge toward the longer-term self-sustained PRGT endowment model.

- The proposed DIA would become the main vehicle for borrowing SDRs or currency from members with the objective of generating investment returns for PRGT subsidization. Members wishing to contribute subsidy resources via a long-term investment in the PRGT can already enter into deposit or investment agreements. The purpose of the DIA would be to centralize any such new resources in a separate account, which could support larger-scale investments by facilitating liquidity management and an encashment regime.

The diagram below provides a stylized illustration for the revised financial structure of the PRGT. 


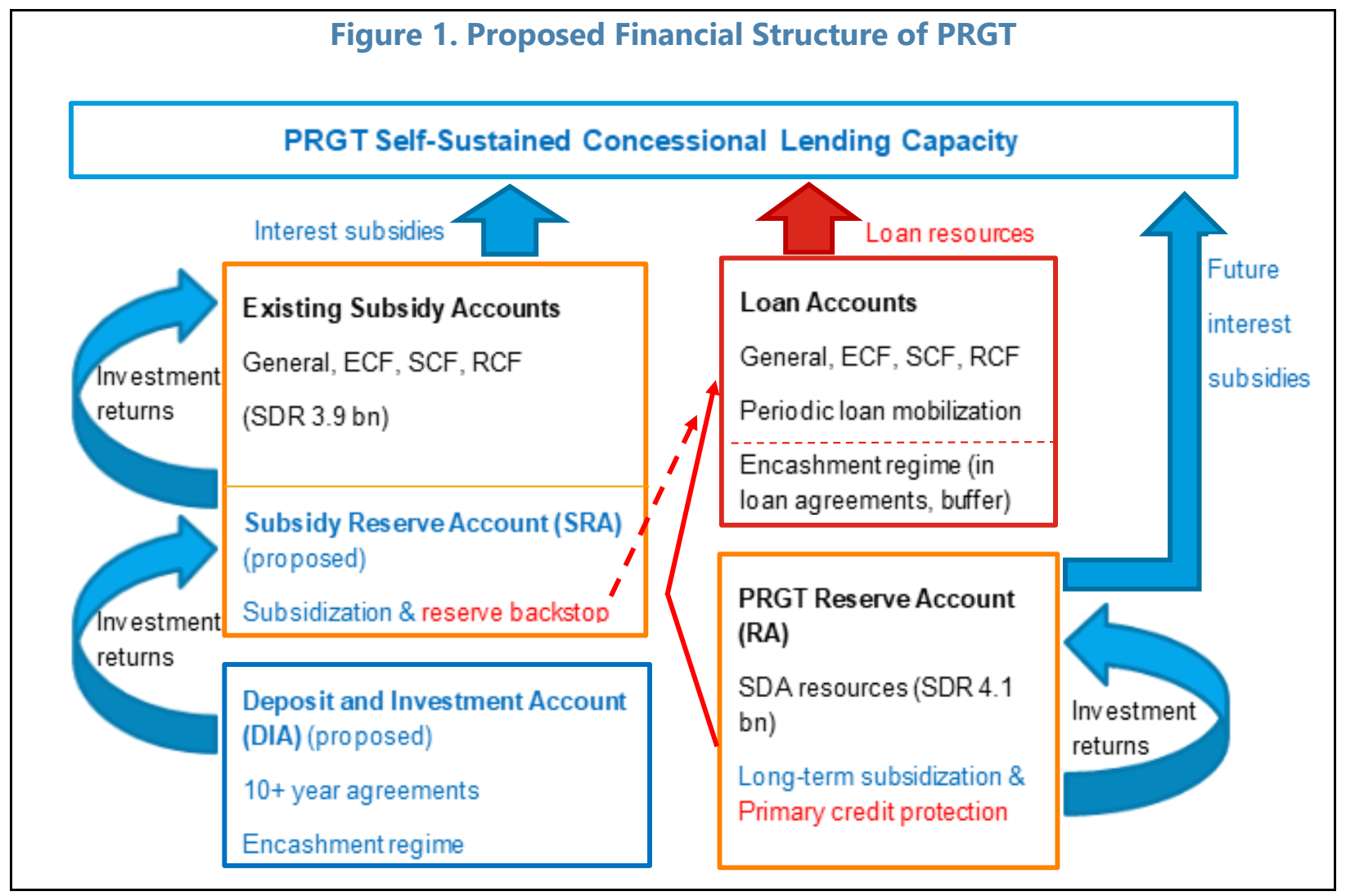

- The PRGT's endowment-based model relies on a combination of loan resources, other borrowed resources (for deposits and investments), subsidy resources, and reserves.

- Trust assets in the Subsidy Accounts and the Reserve Account (RA), together amounting to about SDR 8 billion at end-April 2021 (see boxes in orange), are invested to generate returns that can be used for subsidization of lending, underpinning the PRGT's self-sustained lending capacity. Currently, subsidization of lending relies entirely on existing assets in the Subsidy Accounts. The resources in the Subsidy Accounts would be gradually drawn down to zero, while balances in the RA would grow over time by the amount of investment returns. In the stead state, returns on RA assets would subsidize the entire PRGT lending in perpetuity. The RA has the dual purpose of generating subsidy resources and protecting PRGT lenders in the event of arrears. ${ }^{1}$

- Loan resources (see box in red) are mobilized periodically from bilateral lenders as needed, depending on demand for PRGT loans. The ongoing fast-track loan mobilization round, covering lending commitments through 2024, has raised about SDR 17 billion in new resources. Lenders participating in the encashment regime can request early repayment of their claims on the PRGT in case they experience a balance of payments need.

\footnotetext{
${ }^{1}$ The reimbursement of GRA for the PRGT's administrative expenses is also financed from the Reserve Account.
} 
- The proposed SRA would complement existing Subsidy Accounts, and be used for subsidization once resources in these accounts are insufficient, and before subsidization would be covered by RA investment earnings in the long run. The SRA's would thus hold, invest, and eventually provide subsidy resources, while also serving as a backstop, in addition to the RA, to cover residual credit risk to lenders.

- The proposed DIA (blue box) would centralize long-term borrowing from members provided for the purpose of generating deposit and investment returns that would be transferred to the SRA for PRGT subsidization. Contributors' claims would be remunerated at an agreed rate below the expected rate of return on the investment. Members would be able to encash their claims on the DIA in the event they experience a balance of payments needs. 


\section{INTERNATIONAL MONETARY FUND}

July 8,2021

FUND CONCESSIONAL FINANCIAL SUPPORT FOR LOW

INCOME COUNTRIES-RESPONDING TO THE PANDEMIC-

SUPPLEMENTARY INFORMATION AND PROPOSED

DECISIONS

Approved By

Rhoda Weeks-Brown,

Prepared by staff of the Legal, Finance, and Strategy Policy

Ceyla Pazarbasioglu, and Review Departments.

and Bernard Lauwers

\section{SUMMARY OF THE PROPOSED DECISIONS}

1. This supplement sets forth proposed decisions to adopt the reforms outlined in Fund Concessional Financial Support for Low Income Countries-Responding to the Pandemic (the "Paper") and further develops the staff's proposal regarding the creation of the Subsidy and Reserve Account and the Deposit and Investment Account in the Poverty Reduction and Growth Trust (PRGT). Specifically, the decisions (i) increase overall annual and cumulative access limits in the PRGT (145/435 percent of quota) and eliminate hard caps on access; (ii) amend the PRGT exceptional access criteria; (iii) extend the temporary increase of annual access limits under the PRGT (245 percent of quota) until end-December 2021; (iv) create two new accounts within the PRGT; (v) extend the deadline for the suspension of drawing under loan agreements for loan accounts in the event of liquidity needs of PRGT creditors from June 30, 2024 to June 30, 2029;

(vi) complete the review of PRGT interest rates; (vi) increase the limit for PRGT borrowing; and (vii) modify and consolidate the rules on blended access to resources under the PRGT and General Resources Account (GRA). With respect to the proposed new Subsidy Reserve Account and the Deposit Investment Account within the PRGT, this supplement further develops the proposal in the Paper with respect to the use of resources in the Deposit and Investment Account, mainly by giving contributors more flexibility in deciding on the use of investment earnings attributed to their investments and by allowing, with the consent of contributors, the Fund to decide on the use of investment income in the Deposit and Investment Account prior to the maturity of deposit and other investment agreements if this is deemed necessary in view of subsidy needs. 


\section{A. Decision I - Amendments to the Poverty Reduction and Growth Trust Instrument}

\section{This decision implements the staff proposals in the Paper as follows:}

- It establishes new overall annual and cumulative access limits under the PRGT of 145 percent of quota and 435 percent of quota (net of scheduled repayments), respectively, and eliminates the hard cap on exceptional access (Section II, Paragraph 2(a)(A)).

The new limits will apply to all new financing requests and to existing arrangements under the PRGT, with the exception that existing arrangements that were grandfathered under the Policy Safeguards for High Combined Credit Exposures under the PRGT/GRA ("PS-HCC") will remain subject to the PRGT EA thresholds and criteria in place at the time of the approval of these arrangements. ${ }^{1}$ This carve-out ensures adequate safeguards and even-handed treatment for exceptional access cases across all members with arrangements under the PRGT. In the event of an augmentation under such an arrangement, the grandfathering from the application of the PS HCC policy would end and both the PS-HCC policy and the new PRGT access rules would apply. ${ }^{2}$

- It extends the application of the temporarily increased PRGT annual access limit (increased since March 22, 2021 to 245 percent of quota through July 31, 2021)3 until end-December 2021. For financing in place or approved during this period, the temporarily increased limit will apply to any 12-month period that includes some part of the period between March 22, 2021 to December 31, 2021. For financing approved after December 31, 2021, the annual access limit would return to 145 percent of quota (Section II, Paragraph 2(a)(B)(ii)).

- It amends the criteria for exceptional access under the PRGT as described in Annex II of the Paper. The new criteria will apply to all new financing requests and to existing arrangements under the PRGT (except those grandfathered under the PS-HCC policy as discussed above); they will be assessed at each review, with the exception of criterion 3, which provides that a member is not eligible for exceptional access if it meets the income threshold for blending. This income criterion will only be assessed at the time of the approval of exceptional access (i.e., a request for an ECF or SCF arrangement or an RCF loan that involves exceptional access, an increase in access resulting in

\footnotetext{
1 See Policy Safeguards for Countries Seeking Access to Fund Financial Support that Would Lead to High Levels of Combined GRA-PRGT Exposures-Proposed Decision (footnote 3).

2 In practice, this carve-out will apply only to the existing ECF arrangement for Ethiopia (approved with additional blended financing under the EFF). It ensures that this arrangement remains subject to the safeguards of the PRGT exceptional access criteria as it was grandfathered under the PS-HCC policy. Any augmentation under the existing ECF arrangement or any new PRGT arrangement approved for Ethiopia would be subject to the new PRGT access limits and the new PRGT EA criteria, as is the case with all other PRGT arrangements.
}

3 See Temporary Extensions and Modifications of Access Limits in the Fund's Lending Facilities-Proposed Decisions and Short Extension of the Temporary Increases in PRGT Access Limits and the Review of the Interest Rate Structure Under the PRGT. 
new or augmented exceptional access, or a rephasing of an existing arrangement that results in exceptional access).

- It creates, within the PRGT, a new account, the Subsidy Reserve Account (SRA). As described in the Paper, the SRA is designed to receive grant contributions and transfers of resources derived from net investment earnings from the new Deposit and Investment Account (see below). ${ }^{4}$ In contrast to the other PRGT subsidy accounts, the SRA has a dual purpose. Firstly, the SRA would be able to subsidize PRGT lending after the resources held in the General Subsidy Account and the earmarked Subsidy Accounts are exhausted. ${ }^{5}$ Secondly, the SRA would also provide, as a second-line backstop, additional reserve coverage and security to PRGT creditors by authorizing the use of its resources to meet obligations to lenders to the PRGT loan accounts (e.g., in case of arrears to the PRGT) as they come due in circumstances where the Reserve Account had been depleted. ${ }^{6,7}$

- It creates, within the PRGT, a second new account, the Deposit and Investment Account (DIA). The purpose of the DIA is to create a vehicle for longer-term borrowing from contributors, the proceeds of which would be invested to generate net investment earnings in excess of the interest payable, if any, to the contributor. For purposes of the DIA, the Managing Director is authorized to enter, on behalf of the PRGT, into bilateral deposit agreements and other investment agreements with contributors. The proceeds of the borrowed resources will be invested in accordance with guidelines adopted by the Trustee. The resources derived from net investment earnings attributable to contributors will normally be transferred to the SRA at the final maturity of the related agreement; provided, however, that the Managing Director is also authorized to agree with individual contributors on transfers prior to the final maturity of the agreement. It is further proposed, to enhance flexibility for potential contributors, that a contributor to the DIA also be given the option to request that its share of resources derived from net investment earnings be transferred to the General Subsidy Account instead of the SRA. The resources in the DIA are held separately from the other accounts of the PRGT; consistent with existing practice, PRGT assets, including those in the DIA, can be invested jointly under mandates that provide for a clear

\footnotetext{
${ }^{4}$ As with other subsidy accounts, the Executive Board may, in exceptional circumstances, borrow resources for subsidy purposes. See Section IV, paragraph 3 of the PRGT Instrument.

${ }^{5}$ In this context, like resources in the other subsidy accounts, SRA resources are authorized to pay for the difference between the interest "due" from PRGT borrowers and the PRGT's interest payment due to PRGT creditors. These resources may not be used to cover PRGT borrowers' overdue interest payments or interest payments due to the creditors but which are not yet due from borrowers (e.g., because of interest payment mismatch); however such interest payments will be covered from the Reserve Account, and from the SRA in accordance with its purpose to provide backup to the Reserve Account, as described below.

${ }^{6}$ Specifically, in the event that receipts of loan repayments or interest payments from borrowers, together with authorized subsidy resources, are insufficient to cover the payments to creditors as they become due and payable (i.e., in the cases of (i) arrears to the PRGT by borrowers or (ii) differences in timing between scheduled principal repayments or interest payments to the creditors and principal repayments or interest payments under PRGT loans to the PRGT, where the Reserve Account resources are fully drawn, the SRA resources would then be used to cover these payments to creditors.
}

${ }^{7}$ Notwithstanding its dual purpose, the Subsidy Reserve Account is included among the subsidy accounts in the PRGT Instrument. 
attribution of the relative share of the invested assets to the various accounts of the PRGT. ${ }^{8}$ To ensure the reserve asset quality of resources contributed to the DIA, an encashment regime is provided for whereby a contributor may request, upon a representation of a balance of payments need, the early repayment of the principal amount of the borrowed resources. The encashment would be funded from resources in the DIA attributed to the contributor. A contributor exercising its encashment rights would be required to reconstitute the value of the principal amount as soon as possible once its balance of payments position improves. Repayment of the principal amount under a deposit or investment agreement with a contributor under all circumstances (including at maturity, encashment, or termination of the account) will be made exclusively from resources attributed to the deposit or other investment of that principal amount, and the net investment earnings thereon, net of cumulative interest previously paid to the contributor. ${ }^{9}$

- The provisions regarding the SRA and DIA are included in Section IX of the PRGT Instrument as provisions that can only be amended with the consent of affected contributors (see below).

- It updates the numbering of, and related cross-references to, Section IV of the PRGT Instrument to reflect the creation of the new DIA by renumbering the existing Section IV as Section IV.A, and allowing for the insertion of the DIA as Section IV.B of the PRGT Instrument.

- It extends the deadline in Section II, paragraph 4(c) of the PRGT Instrument from June 30, 2024 to June 30, 2029. This refers to the deadline under which a PRGT creditor with a borrowing agreement concluded after May 31, 2014 may request a suspension of drawings under its borrowing agreement in case of a liquidity need.

For information of Executive Directors a marked up copy of the PRGT Instrument showing the amendments is attached in the Annex.

\section{B. Decision II - Review of Interest Rate Structure}

\section{This decision completes the review of the PRGT interest rate structure and keeps the interest rate at zero percent for all PRGT credit outstanding. Under the PRGT Instrument, a}

\footnotetext{
${ }^{8}$ Under the current record keeping arrangements, detailed attribution is made of the share of each account in the investments. Moreover, FIN maintains a share allocation record of individual contributors and income earned on their investment and their share of resources in an account. This will allow the calculation of the current value of each contributor's principal amount in the DIA.

${ }^{9}$ In the event of accumulated losses in the DIA at final maturity (e.g., when cumulative net investment returns were lower than cumulative interest paid to the contributor), these would be attributed to contributor's principal amount, and accordingly no transfers of investment earnings for the contributor to the SRA would take place. As noted in the staff paper, investment agreements entail a certain degree of investment risk-particularly over shorter horizons. Incorporating some flexibility in the maturity schedule for the investment agreement could help manage investment risk by linking the maturity to the attainment of the pledged subsidy contribution. Similarly, accumulated losses at the time of encashment or termination of the DIA, would reduce the principal amount to be repaid to the contributor.
} 


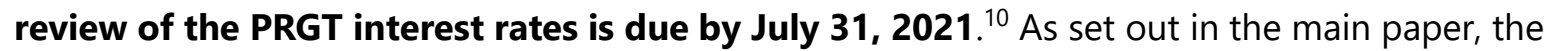
operation of the PRGT interest rate mechanism indicates that, based on the average SDR interest rate observed over the most recent 12-month period, the current zero percent interest rate applicable to credit outstanding under the ECF and SCF should be maintained through end-July 2023. Credit outstanding under the RCF remains at zero percent, in line with the Executive Board's decision in 2015.

\section{Decision III - Increase of PRGT Borrowing Limit}

4. This decision increases the PRGT Borrowing Limit. As set out in the Paper, stage one of the proposed funding strategy aims to mobilize an additional SDR 12.6 billion in PRGT loan resources. In this context, the decision authorizes the Managing Director to confirm, following consultations with creditors, that she does not intend to enter into borrowing agreements for the loan accounts if cumulative commitments under such agreements would exceed SDR 68.0 billion without further consultation with PRGT creditors regarding justification for such borrowing and the adequacy of the Reserve account (PRGT Borrowing limit).

\section{Decision IV - Blended Access to Financing under the GRA and PRGT}

\section{This decision amends the criteria for presumed blended access to PRGT and GRA} resources as set forth in the Paper and consolidates the rules on blending in a single Board decision. The rules on blending have been set out in in a series of summings up. The proposed decision simplifies and consolidates these rules into a single Executive Board decision for greater clarity and ease of access, as follows:

- "Presumption" of Blending: The decision sets forth the framework for when PRGT-eligible countries are "presumed" to access part of their Fund financing needs from the GRA. The concept of presumption means that PRGT-eligible members that meet the criteria for blending set forth in the decision and that request financing from the PRGT are required to meet part of their Fund financing needs from the GRA. ${ }^{11}$ On the other hand, PRGT-eligible members that do not meet the criteria for blending may access PRGT resources exclusively. Moreover, while PRGT-eligible members may always access the GRA in the same way as other members, given the financial benefits from borrowing on concessional terms, staff advises members that meet the blending presumption to seek financing through a blend of PRGT and GRA resources.

- Blending Criteria: The decision sets forth the new criteria for blending described in paragraphs 3843 of the Paper. With respect to the income criterion, a member meets this criterion (paragraph

\footnotetext{
10 See Short Extension of the Temporary Increases in PRGT Access Limits and the Review of the Interest Rate Structure Under the PRGT.

${ }^{11}$ As set forth in Review of Facilities for Low-Income Countries-Proposals for Implementation, for members who have resources in their first credit tranche available, implementing a blend of credit tranche and PRGT resources would entail the following modalities: The 1:2 blend of PRGT and credit tranche resources would still apply, but for the GRA resources phasing and performance criteria would only apply to purchases above the first credit tranche.
} 
1(a)) when its GNI per capita has exceeded the IDA operational cutoff by at least 5 percent for two consecutive years. This criterion shall apply immediately, looking back two years from the date of this decision (i.e., a member whose income exceeded the IDA cutoff in 2019 and 2020 by at least five percent meets the income criterion for blending). Even when a member meets the income criterion, it is not presumed to blend if it faces debt vulnerabilities that limit its access to international financial markets as specified in the proposed decision. Presumed blenders shall access a blend of PRGT and GRA resources in a ratio of one to two of PRGT resources to GRA resources. ${ }^{12}$

\section{E. Decision V - PRG Trust Reimbursement for FY 2022-2026}

\section{This decision suspends reimbursement of the GRA for the cost of administering the PRGT}

for FY 2022-2026. As set out in the Paper, staff proposes to suspend reimbursement of the GRA for the costs of administering the PRGT for the next five fiscal years. This temporary suspension of reimbursement is one of the recognized contingency measures under the PRGT's three-pillar framework, and permitted under the Fund's new income model endorsed in 2008. The proposed suspension of reimbursement would retain these resources in the PRGT's Reserve Account. ${ }^{13}$

\section{F. Majorities and Consent Requirements}

\section{The proposed decisions may be adopted by a majority of the votes cast and, with respect} to the changes to the PRGT Instrument, do not require the consent of current contributors to the PRGT's loan and subsidy accounts. The proposed changes to the PRGT Instrument do not create new uses for Special Disbursement Account (SDA) resources in the PRGT Reserve Account, so the SDA requirement for an 85 percent majority of the total voting power does not apply. The creation of the new SRA and DIA requires amendments to a number of so-called "protected provisions" listed in Section IX of the PRGT instrument. ${ }^{14}$ While this provision states that these provisions cannot be amended, it has consistently been interpreted that the Fund (as Trustee) may amend these provisions but that such amendments would require the consent of contributors to the extent that their interests are affected by the amendments, and protected provisions have been amended on many occasions in the past. ${ }^{15}$ In the view of staff, the proposed creation of the SRA and the DIA does not affect the interests of current subsidy and loan account contributors. With respect to the SRA, the proposed amendment only creates a new subsidy account whose resources are to be used once the subsidy resources in the other accounts have been exhausted. It therefore does not affect the interests of

\footnotetext{
12 Such blended access shall be subject to a cap on access to PRGT resources of 145 percent of quota per arrangement and subject to the overall limits on access to the PRGT.

13 See Developing a New Income Model for the Fund-Proposed Decisions.

${ }^{14}$ The creation of the new SRA and DIA would require amendments to the following "protected provisions": Section I, paragraph 2; Section III, paragraphs 4 and 5; Section IV, paragraphs 4 and 6, and Section IX.

${ }^{15}$ For a more extensive discussion of protected provisions and consent requirements, see The Multilateral Debt Relief Initiative (G-8 Proposal) and Its Implications for the Fund-Further Considerations-Supplemental Information (pages 1114).
} 
current contributors regarding the use of their contributions to the existing subsidy accounts. Moreover, SRA also provides added protection to loan account lenders in the event the Reserve Account resources were depleted, strengthening the protection for their existing loan commitments. For its part, the DIA creates a new source of funding for the SRA or the General Subsidy Account and does not affect the use of existing subsidy contributions in those accounts. As the amendments, therefore, do not affect the interests of current contributors, their consent is not required for the proposed changes to protected provisions. ${ }^{16}$

\footnotetext{
${ }^{16}$ For prior cases of changes to protected provisions that also did not require consent from contributors, see Modalities of a Gold Pledge for Use of ESAF Trust Resources under the Rights Approach and Selected Operational Issues in ESAF Arrangements.
} 


\section{Proposed Decisions}

The following decisions, which may be adopted by a majority of the votes cast, are proposed for adoption by the Executive Board:

Decision I. Amendments to the PRGT Instrument for Overall Normal Access Limits, Temporary Increase in Annual Access Limit, Exceptional Access Criteria and Creation of the Subsidy Reserve Account and Deposit and Investment Account

The Instrument to Establish the Poverty Reduction and Growth Trust ("PRGT Instrument"), Annex to Decision No. 8759-(87/176) ESAF, adopted December 18, 1987, as amended, along with its Appendices, shall be further amended as follows:

1. Section I, paragraph 2 of the PRGT Instrument shall be amended to read as follows:

"Paragraph 2. Accounts of the Trust

The operations and transactions of the Trust shall be conducted through a General Loan Account, an ECF Loan Account, a SCF Loan Account, and a RCF Loan Account (the latter four accounts collectively referred to herein as the "Loan Accounts"), a Reserve Account, a General Subsidy Account, an ECF Subsidy Account, a SCF Subsidy Account, a RCF Subsidy Account, an ESF Subsidy Account, and a Subsidy Reserve Account (the latter six accounts collectively referred to herein as the "Subsidy Accounts"), and a Deposit and Investment Account. The resources of the Trust shall be held separately in these Accounts."

CInternational Monetary Fund. Not for Redistribution 
2. Section II, Paragraph 2(a)(A) of the PRGT Instrument shall be replaced with the following:

"(a)(A) Except as specified in sub-paragraph (B) below, the overall access of each eligible member to the resources of the Trust under all facilities of the Trust as specified in Section I, Paragraph 1(a) shall be subject to (i) an annual limit of 145 percent of quota; and (ii) a cumulative limit of 435 percent of quota, net of scheduled repayments. The Trustee may approve access in excess of these limits if all of the following criteria are satisfied:

(1) The member is experiencing or has the potential to experience exceptional balance of payments pressures on the current account or capital account, resulting in a need for resources under the Trust that cannot be met within the normal limits.

(2) Risks to the sustainability of public debt are adequately contained, which shall be evidenced by, and subject to, the standards set forth below:

I. A rigorous and systematic analysis indicates that there is a high probability that the member's public debt is sustainable in the medium term. This is generally considered to be met for countries that are assessed under the Bank-Fund Debt Sustainability Framework for Low-Income Countries (the "LIC-DSF") to be at low or moderate overall risk of public debt distress; or II. Where the member's public debt is assessed to be sustainable but not with high probability (which includes cases where the member's overall risk of public debt distress is assessed to be high or in debt distress), or where the member's debt is assessed to be unsustainable ex ante, access to resources in excess of the normal limits will only be made available if the combination of the member's policies and financing from sources other than the Fund, which may include debt restructuring, restores public debt 
sustainability with high probability (generally considered to be met for countries that are assessed under the LIC-DSF to be at low or moderate overall risk of public debt distress) (i) within 36 months from Board approval in the case of a new arrangement under this Trust or a loan under the RCF, or within the period of the new arrangement, whichever is longer, or (ii) within the remaining period of an arrangement, in cases where the Board approves a request for an augmentation or a rephasing of access under the arrangement;

(3) The member does not meet the income criterion for presumed blending, as set forth in paragraph 1(a) of Decision No. [new decision on blending], at the time of making a request for resources under this Trust in excess of the access limits set forth in paragraph 2(a) $(\mathrm{A})$ above; and

(4) The policy program of the member provides a reasonably strong prospect of success, including not only the member's adjustment plans but also its institutional and political capacity to deliver that adjustment."

3. Section II, Paragraph 2(a)(B) (i) to (iii) shall be replaced with the following: "(a)(B)(i) During the period from March 22, 2021 to December 31, 2021 (the "Applicable Period"), the annual access limit shall be 245 percent of quota for financing approved through December 31, 2021 (the "Eligible Financing"). For the computation of the annual access under the above specified "Eligible Financing", the annual access limit of 245 percent 
of quota shall apply for any 12-month period that includes any part of the "Applicable Period".

(a)(B)(ii) Notwithstanding the increase in access limits set forth in Paragraphs 2(a)(A) and 2(a)(B)(i) above, a member's access to PRGT resources approved under an arrangement in place prior to September 9, 2020 that was exempted from the application of Policy Safeguards for High Combined GRA and PRGT Credit set forth in Decision No. 16873-(20/91) will remain subject to observance of the access limits and criteria for exceptional access to the PRGT that were in effect at the time of approval of such arrangement; if access under such an arrangement is augmented, the provisions in paragraphs $2(a)(A)$ and $2(a)(B)(i)$ shall apply to such an arrangement."

4. The references in Section II, paragraphs 4(a) and 4(b) to "Section IV, paragraph 5" shall be replaced with references to "Section IV.A, paragraph 5".

5. The references in Section III, paragraphs 1(b)(ii), 1(c)(iii), 1(d)(ii) and 1(e)(ii) of the PRGT Instrument to "Section V, paragraph 3 of this Instrument" shall be replaced with a reference to "Section IV.A, paragraph 4(g) and Section V, paragraph 3 of this Instrument".

6. In Section III, paragraph 4(b) of the PRGT Instrument, the reference to "Section IV" shall be replaced with a reference to "Section IV.A".

7. In Section III, paragraph 4(c), first sentence, "June 30, 2024" shall be replaced with "June 30, 2029."

8. In Section III, paragraph 5(a) of the PRGT Instrument, the reference to "Section IV" shall be replaced with a reference to "Section IV.A", the words "Subsidy Reserve Account and" shall be inserted before the words "Reserve Account" and the words "Section IV.A and" shall be inserted before the words "Section V". 
9. Section IV of the PRGT Instrument shall be renumbered as Section IV.A.

10. A new paragraph 1(f) shall be inserted into Section IV.A of the PRGT Instrument to read as follows:

"(f) The resources held in the Subsidy Reserve Account shall consist of:

(i) the proceeds of donations made to the Trust for the Subsidy Reserve Account;

(ii) the proceeds of loans made to the Trust for the Subsidy Reserve Account;

(iii) transfers from the Deposit and Investment Account in accordance with

Section IV.B, paragraph 3 of this Instrument;

(iv) net earnings from investment of resources held in that Account;

(v) payments of overdue principal or interest or interest thereon under Trust loans, and payments of interest under Trust loans to the extent that payment has been made to a creditor from the Subsidy Reserve Account; and

(vi) repayments of the principal under Trust loans, to the extent that resources in the Subsidy Reserve Account have been used to make payments to a creditor due to a difference in timing between scheduled principal repayments to the creditor and principal repayments under Trust loans."

11. New paragraphs $4(\mathrm{f})$ and $4(\mathrm{~g})$ shall be inserted into Section IV.A of the PRGT Instrument to read as follows:

"( $f)$ The Trustee shall draw upon the resources available in the Subsidy Reserve Account to:

(i) pay the difference, with respect to each interest period, between the interest due by the borrowers and the interest due on resources borrowed for loans under the 
facilities of the Trust specified in Section I, Paragraph 1 of the Instrument, provided that resources available in the Subsidy Reserve Account shall be drawn only if there are no other resources available in the relevant Subsidy Accounts for these purposes; or

(ii) to make payments of principal and interest on its borrowing for Trust loans, to the extent that the amounts available from receipts of repayments and interest from borrowers under Trust loans, together with the authorized subsidy under Section IV.A, paragraph 4, are insufficient to cover the payments to creditors as they become due and payable, provided that resources available in the Subsidy Reserve Account shall be drawn upon for these purposes only if there are no other resources immediately available in the Reserve Account.

(g) Any repayment of principal under Trust loans, to the extent that repayment to a creditor has been made from the Subsidy Reserve Account due to differences in timing between scheduled principal repayments to the creditor and principal repayments under Trust loans, any payments of overdue principal or interest or interest thereon under Trust loans, and any payments of interest under Trust loans to the extent that payment has been made to a creditor from the Subsidy Reserve Account, shall be made to the Subsidy Reserve Account."

12. In Section IV.A. of the PRGT Instrument, the following sentence shall be added at the end of paragraph 6(b)(i): "Any resources attributable to transfers from the Deposit and Investment Account shall be transferred to that Account."

13. In Section IV.A of the PRGT Instrument, paragraph 6(b)(vi) shall be renumbered as paragraph 6(vii) and a new paragraph $6(\mathrm{~b})(\mathrm{vi})$ shall be inserted to read as follows: 
"(vi) Any resources remaining in the Subsidy Reserve Account shall be used in a manner consistent with paragraph 4(f) of this Section to reduce to the fullest extent possible the interest rate paid by borrowers in accordance with Section II, paragraphs 4(a), (b), and (c) on loans from the PRGT, by means of payments to such borrowers. Any resources remaining after that subsidization and not attributable to the Deposit and Investment Account shall be transferred to the General Subsidy Account, provided that a contributor may request that its share in any remaining resources be returned to it. Any resources attributable to transfers from the Deposit and Investment Account shall be transferred to that Account."

14. A new Section IV.B shall be inserted into the PRGT Instrument to read as follows:

"Section IV.B Deposit and Investment Account

\section{Paragraph 1. Purpose and Resources}

The purpose of the Deposit and Investment Account is to provide a separate vehicle under which the Trust can borrow resources to generate net investment earnings for the benefit of the Subsidy Reserve Account or, at the request of a contributor, the General Subsidy Account. The resources held in the Deposit and Investment Account shall consist of the proceeds from deposit and other investment agreements with contributors and the net earnings on the investment proceeds. 
Paragraph 2: Borrowing for the Deposit and Investment Account

(a) The Trustee may enter into deposit and other investment agreements for the benefit of the Deposit and Investment Account with the aim of generating net investment earnings from the investment of the resources borrowed. For this purpose, the Managing Director of the Trustee is authorized to enter into deposit and other investment agreements and agree to their terms and conditions with contributors to the Deposit and Investment Account. The borrowed resources shall be invested in accordance with guidelines adopted by the Trustee.

(b) The agreements may provide for the right of a contributor to request the early repayment of the principal amount under its deposit or investment agreement upon representation of a balance of payments need. The contributor shall reconstitute any withdrawn amount as its balance of payments and reserve position improves.

Paragraph 3: Use of Resources

(a) Resources in the Deposit and Investment Account derived from net investment earnings shall be transferred to the Subsidy Reserve Account at the final maturity of the deposit and investment agreement such resources are attributable to; provided that, with the consent of the contributor, the Managing Director is authorized to transfer to the Subsidy Reserve Account at an earlier time resources attributable to that contributor's deposit or investment agreement, to meet the subsidization needs of the Trust. 
(b) A contributor may prescribe that investment earnings in the Deposit and Investment Agreement attributable to that contributor's investment be directed to the General Subsidy Account instead of the Subsidy Reserve Account.

\section{Paragraph 4: Termination Arrangements}

Upon completion of the subsidy operations authorized by this Instrument, the Trustee shall wind down the affairs of the Deposit and Investment Account. Contributors shall be repaid the principal of their deposits or investments and any remaining investment earnings or losses attributed to it.

Paragraph 5: Repayment of the principal amount and payment of interest to a contributor Repayment of the principal amount and any payment of interest to a contributor on any borrowing for the Deposit and Investment Account, including repayment upon maturity, early repayment in accordance with Section IV.B, paragraph 2(b), or repayment in accordance Section IV.B., paragraph 4, shall be made exclusively from resources attributed to the deposit or other investment of this principal amount and the net investment earnings thereon, net of the cumulative interest previously paid to the contributor."

15. In Section $\mathrm{V}$, paragraph 2 (a), the reference to "Section IV" shall be replaced with a reference to "Section IV.A".

16. Section VIII, paragraph 2(a) shall be amended to read as follows:

"(a) Termination and liquidation of the Subsidy Accounts shall be made in accordance with the provisions of Section IV.A, paragraph 6. Termination and liquidation of the Deposit and 
Investment Account shall be made in accordance with the provisions of Section IV.B, paragraph 4."

17. In Section IX of the PRGT Instrument, the reference to "Section IV" shall be replaced with a reference to "Section IV.A" and the words "Section IV.B;" shall be inserted before the words "Section $\mathrm{V}^{\prime \prime}$.

\section{Decision II. Review of Interest Rate Structure}

1. In accordance with Section II, paragraph 4(b) of the Instrument to Establish the Poverty Reduction and Growth Trust (the "PRGT Instrument"), annexed to Decision No. 8759-(87/176) ESAF, adopted December 18, 1987, as amended, the Fund, as Trustee of the Poverty Reduction and Growth Trust (the "Trustee"), has reviewed the interest rates for loans under the Extended Credit Facility ("ECF") and the Standby Credit Facility ("SCF").

2. In Section II, paragraph 4(a) of the PRGT Instrument, the reference to "July 1, 2019" shall be replaced with a reference to "August 1, 2021".

3. In Section II, paragraph 4(b) of the PRGT Instrument, the reference to "July 31, 2021" shall be replaced with a reference to "July 31, 2023".

\section{Decision III. Amendment to PRGT Borrowing Limit}

The Managing Director, having consulted with all creditors of the Poverty Reduction and Growth Trust (PRGT), is authorized to confirm that she does not intend to enter into borrowing agreements for the Loan Accounts of the PRGT if the cumulative commitments under such agreements exceed 
SDR 68.0 billion, except after consultation with all PRGT creditors regarding the justification for such additional borrowing and the adequacy of the PRGT's Reserve Account in relation thereto.

\section{Decision IV. Blended Access to Financing under the PRGT and the GRA}

1. A member that is included in the list of members annexed to Decision No. 8240-(85/56) SAF, as amended (i.e., a member eligible for financing under the Poverty Reduction and Growth Trust (PRGT), hereinafter "member") is a "Presumed Blender" in accordance with the criteria set forth below:

a. Income: A member meets the income thresholds for presumed blending if its annual per capita gross national income (GNI) has exceeded the prevailing operational cutoff for assistance from the International Development Association (IDA) by at least 5 percent for two consecutive years (the "income threshold"). Once a member has met the income threshold, it shall be deemed to continue to meet the threshold unless its annual per capita GNI falls below 95 percent of the IDA operational cut-off.

b. Absence of debt vulnerabilities that limit market access: A member that meets the income threshold as defined in Paragraph 1.a shall be presumed to blend unless it faces debt vulnerabilities that limit its access to international financial markets. A member will be considered to face debt vulnerabilities that limit its access to international financial markets if it is (i) in debt distress or (ii) at high risk of debt distress and either (a) does not meet the criterion of capacity to access international financial markets on a durable and substantial basis for the purpose of graduation from the PRGT eligibility as set forth in Paragraph 1(C)(1)(ii) of Decision No. 14521- 
(10/3), adopted January 11, 2010, as amended (the "PRGT Eligibility Decision") or (b) is a "small country" or a "microstate", as such terms are defined in paragraph 1 (D) of the PRGT Eligibility Decision.

2. A request by a Presumed Blender for access to PRGT resources shall be approved only in a blend with access to resources in the General Resources Account (GRA). The mix of PRGT and GRA resources shall be provided in a ratio of one to two of PRGT resources to GRA resources, subject to a cap on access to PRGT resources of 145 percent of quota per arrangement and subject to the overall limits on access to the PRGT set out in Section II, Paragraph 2 of this Instrument.

\section{Decision V. PRG Trust Reimbursement for FY 2022-2026}

Notwithstanding paragraph 3 of Decision No. 8760-(87/176), adopted on December 18, 1987, for financial years FY2022 through FY2026, no reimbursement shall be made to the General Resources Account from the Reserve Account of the Poverty Reduction and Growth Trust ("PRGT") for the cost of administering the PRGT. 


\title{
Annex. Fund Concessional Financial Support for Low Income Countries-Responding to the Pandemic-Proposed Decisions- Redlined Version
}

\author{
ANNEX \\ Instrument to Establish the Poverty Reduction and Growth Trust
}

Introductory Section

To help fulfill its purposes, the International Monetary Fund (hereinafter called the "Fund") has adopted this Instrument establishing the Poverty Reduction and Growth Trust (hereinafter called the "Trust"), which shall be administered by the Fund as Trustee (hereinafter called the "Trustee"). The Trust shall be governed by and administered in accordance with the provisions of this Instrument.

\section{Section I. General Provisions}

Paragraph 1. Purposes

The Trust shall assist in fulfilling the purposes of the Fund by -providing:

(a) loans on concessional terms (hereinafter called "Trust loans") to low-income developing members that qualify for assistance under this Instrument, in order to:

(i) support programs under the Extended Credit Facility (hereinafter called the "ECF") that enable members with a protracted balance of payments problem to make significant progress toward stable and sustainable macroeconomic positions consistent with strong and durable poverty reduction and growth;

(ii) support programs under the Standby Credit Facility (hereinafter called the "SCF") that enable members with actual or potential short-term balance of payments needs to achieve, maintain or restore stable and sustainable macroeconomic positions consistent with strong and durable poverty reduction and growth; 
(iii) support policies under the Rapid Credit Facility (hereinafter called the "RCF") of members facing urgent balance of payments needs so as to enable them to make progress towards achieving or restoring stable and sustainable macroeconomic positions consistent with strong and durable poverty reduction and growth; and (iv) for a transitional period, support programs under the Exogenous Shocks Facility that help members to resolve their balance of payments difficulties whose primary source is a sudden and exogenous shock in a manner consistent with strong and durable poverty reduction and growth; and

(b) grants, for a transitional period, to subsidize post-conflict and/or natural disaster emergency assistance purchases under Decision No. 12341-(00/117) made by low-income developing members as of January 7, 2010, through transfers to the Post-Conflict and Natural Disaster Emergency Assistance Subsidy Account for PRGT Eligible members annexed to Decision No. 12481-(01/45) ("the ENDA/EPCA Subsidy Account").

Paragraph 2. Accounts of the Trust

The operations and transactions of the Trust shall be conducted through a General Loan Account, an ECF Loan Account, a SCF Loan Account, and a RCF Loan Account (the latter four accounts collectively referred to herein as the "Loan Accounts"), a Reserve Account, a General Subsidy Account, an ECF Subsidy Account, a SCF Subsidy Account, a RCF Subsidy Account, and an ESF Subsidy Account, and a Subsidy Reserve Account (the latter five six accounts collectively referred to herein as the "Subsidy Accounts"), and a Deposit and Investment Account. The resources of the Trust shall be held separately in these Accounts.

\section{Paragraph 3. Unit of Account}

The SDR shall be the unit of account for commitments, loans, and all other operations and transactions of the Trust, provided that commitments of resources to the Subsidy Accounts may be made in currency.

Paragraph 4. Media of Payment of Contributions and Exchange of Resources

(a) Resources provided under borrowing agreements or donated to the Trust shall be received in a freely usable currency, subject to the provisions of (c) below, and provided that resources may be received by the Subsidy Accounts in other currencies.

(b) Payments by the Trust to creditors or donors shall be made in U.S. dollars or such other media as may be agreed between the Trustee and such creditors or donors. 
(c) Resources provided under borrowing agreements or donated to the Trust may also be made available in or exchanged for SDRs in accordance with such arrangements as may be made by the Trust for the holding and use of SDRs.

(d) The Trustee may exchange any of the resources of the Trust, provided that any balance of a currency held in the Trust may be exchanged only with the consent of the issuers of such currencies.

Section II. Trust Loans

Paragraph 1. Eligibility and Conditions for Assistance

(a) The members on the list annexed to Decision No. 8240-(86/56) SAF, as amended, shall be eligible for assistance from the Trust.

(b) Assistance under the ECF

(1) Assistance under the ECF shall be committed and made available to a qualifying member under a single arrangement of no less than three years and up to five years (hereinafter called an "ECF arrangement") in support of a macroeconomic and structural adjustment program presented by the member. It would be expected that ECF arrangements would normally be approved for a period of three years, although arrangements for up to five years may also be approved, where appropriate, and if the member so requests. The member shall also present a detailed statement of the policies and measures it intends to pursue for the first twelve months of the arrangement, and indicate how the program advances the member's poverty reduction and growth objectives, in line with the objectives and policies of the program. The ECF arrangement will prescribe the total amount of resources committed to the member, the amount to be made available during the first year of the arrangement, the phasing of disbursements during that year, and the overall amounts to be made available during the subsequent years of the arrangement. Disbursements shall be phased at regular intervals no more than six months apart (one upon approval and at normally regular intervals thereafter) with performance criteria applicable specifically to each disbursement and appropriate monitoring of key financial variables in the form of quantitative benchmarks and structural benchmarks for critical structural reforms. Structural benchmarks may be targeted for implementation either by a specific date or by the time of a specific review under the ECF arrangement. The ECF arrangement shall also provide for reviews by the Trustee of the member's program scheduled at intervals that are the same as those applicable to 
disbursements to evaluate the macroeconomic and structural reform policies of the member and the implementation of its program and reach new understandings if necessary. The determination of the phasing of, and the conditions applying to, disbursements after the first year of the ECF arrangement will be made by the Trustee in the context of reviews of the program with the member. At each review, the member will present a detailed statement describing progress made under the program, the policies it will follow during the next 12 months or up to the remaining period of the arrangement to further the realization of the objectives of the program, and how the program advances the country's poverty reduction and growth objectives, with such modifications as may be necessary to assist it to achieve its objectives in changing circumstances.

(2) Before approving an ECF arrangement, the Trustee shall be satisfied that the member has a protracted balance of payments problem and is making an effort to strengthen substantially and in a sustainable manner its balance of payments position under a policy program that supports significant progress toward a stable and sustainable macroeconomic position consistent with strong and durable poverty reduction and growth.

(3)(i) Subject to subparagraph (ii) below, the Trustee shall not complete the second or any subsequent review under an ECF Financial Services arrangement unless it finds that: $(A)$ the member concerned has a poverty reduction strategy that has been developed and made publicly available normally within the previous 5 years but no more than 6 years, and covers the period leading up to and covering the date of the completion of the relevant review; and (B) the poverty reduction strategy has been issued to the Executive Board and has been the subject of a staff analysis in the staff report on a request for an ECF arrangement or a review under an ECF arrangement. A Poverty reduction strategy issued to the Executive Board on or after May 24, 2019 shall be named Poverty Reduction and Growth Strategy (PRGS) and a poverty reduction strategy that has been issued to the Executive Board as an Economic Development Document shall be deemed a PRGS. A PRGS shall comprise any of the following: (a) a document developed by a member country on its national development plan or strategy that is already in existence and publicly available, and documents its poverty reduction strategy; or (b) a document newly prepared by a member country documenting its poverty reduction strategy. A PRGS shall be accompanied by a cover letter from the member country concerned to the Managing Director, and shall be issued to the Executive Board with the cover letter. As such, the cover letter shall be deemed to constitute part of the PRGS.

(ii) In cases where a member has limited institutional capacity for meeting the PRGS requirement specified in subparagraph (i) above, the member may request approval by the 
Executive Board of an extension of the deadline for issuance of the PRGS up until the fourth review under the ECF arrangement. Any request for an extension shall be made no later than the time of the request for completion of the second review. A member may request approval of a further extension of the deadline for issuance of the PRGS up until the sixth review under the ECF arrangement, provided that: $(A)$ the member can provide adequate justifications based on persistent limited institutional capacity for meeting the PRGS requirement and other urgent priorities; and (B) the member's arrangement has a duration of at least four years, or an extension of the arrangement to at least four years is requested. Any request for such additional extension of the deadline for issuance of the PRGS shall be made no later than the time of the request for completion of the review corresponding to the extended deadline for the PRGS requirement.

(iii) For purposes of this Instrument, subject to the terms of Section II, paragraphs 1(b)(3)(i)-(ii) above, the terms I-PRSP, PRSP, PRSP preparation status report and APR shall have the meaning given to each of them in Section I, paragraph 1 of the PRG-HIPC Trust Instrument (Annex to Decision No. 11436-(97/10), adopted February 4, 1997, as amended).

(4) A member may cancel an ECF arrangement at any time by notifying the Fund of such cancellation. An ECF arrangement for a member approved after the date of adoption of this decision will automatically terminate before its term if no program review under the arrangement has been completed over a period of eighteen months. The Trustee, at the authorities' request, may decide to delay the termination of the arrangement by up to three months in cases where the reaching of understandings between the authorities and the Trustee on targets and measures to put the ECF-supported program back on track within the term of the arrangement, appears imminent. The ECF arrangement will automatically terminate at the end of the extended period unless a program review under the arrangement is completed within this period. After the expiration of an ECF arrangement for a member, the cancellation of the ECF arrangement by the member, or the automatic termination of the ECF arrangement, the Trustee may approve additional ECF arrangements for an eligible member in accordance with this Instrument.

(c) Assistance under the SCF

(1) Assistance under the SCF shall be committed and made available to a qualifying member under an arrangement (hereinafter called an "SCF arrangement") in support of a macroeconomic and structural adjustment program presented by the member. The period for an SCF 
arrangement shall range from one to three years. The member shall present a detailed statement of the policies and measures it intends to pursue during the first year of the arrangement, and how the program advances the member's poverty reduction and growth objectives. In addition, the member will make an explicit statement, where applicable, about its intention to treat the SCF arrangement as precautionary. The SCF arrangement will prescribe the total amount of resources committed to the member and the phasing of disbursements during the period of the arrangement; provided that in cases where the period of a SCF arrangement exceeds one year, the arrangement may prescribe the amount to be made available during the first year of the arrangement and the phasing of disbursements during that year. Disbursements shall be phased at regular intervals no more than six months apart (one upon approval and at approximately regular intervals thereafter) with performance criteria applicable specifically to each disbursement and appropriate monitoring of key financial variables in the form of quantitative benchmarks and structural benchmarks for critical structural reforms. The SCF arrangement shall also provide for reviews by the Trustee of the member's program scheduled at intervals that are the same as those applicable to disbursements to evaluate the macroeconomic and structural reform policies of the member and the implementation of its program and reach new understandings if necessary. In cases where the period of a SCF arrangement exceeds one year, the determination of the phasing of, and the conditions applying to, disbursements during the period of the arrangement following the first year may be made by the Trustee in the context of reviews of the program with the member. At the time of each review, the member will present a detailed statement describing progress made under the program, the policies it will follow during the next twelve months or up to the remaining period of the arrangement to further the realization of the objectives of the program, and how the program advances the country's poverty reduction and growth objectives, with such modifications as may be necessary to assist it to achieve its objectives in changing circumstances. The member may request at any time any previously scheduled and undrawn disbursement under an SCF arrangement, provided that the most recently scheduled review under the arrangement prior to the request has been completed. After the expiration of an SCF arrangement for a member, or the cancellation of the SCF arrangement by the member, or the automatic termination of the SCF arrangement, the Trustee may approve additional SCF arrangements for that member in accordance with the Instrument provided that, normally, no SCF arrangement shall be approved that could result in a member having had SCF arrangements in place for more than three years out of any six-year period, assessed on a rolling basis. In applying this limitation, the Trustee shall not include previously approved SCF arrangements that have expired with no disbursement having taken place or new SCF arrangements whose 
approval the member has requested and for which the Trustee, at the time of consideration of the request, assesses that the member does not have an actual balance of payments need.

(2) Before approving a SCF arrangement, the Trustee shall be satisfied (a) that the member does not have a protracted balance of payments problem, and has an actual or potential short-term balance of payment need that is expected (or in the case of a potential balance of payments need, would be expected) to be resolved within two years and in any event not later than three years; (b) that the member's balance of payments difficulties are not predominantly caused by a withdrawal of financial support by donors; and (c) that the member is implementing, or is committed to implement, policies aimed at resolving the balance of payments difficulties it is encountering or could encounter, and at achieving, maintaining or restoring a stable and sustainable macroeconomic position consistent with strong and durable poverty reduction.

(3) Notwithstanding subparagraph 2 above, no SCF arrangement shall be approved before January 1,2010 , based solely on the existence of a potential balance of payments need.

(4) The Trustee shall not complete the second or any subsequent review under an SCF arrangement with an initial duration exceeding two years unless it finds that: $(A)$ the member concerned has a poverty reduction strategy that has been developed and made publicly available normally within the previous 5 years but no more than 6 years, and covers the period leading up to and covering the date of the completion of the relevant review; and (B) the poverty reduction strategy has been issued to the Executive Board and has been the subject of a staff analysis in the staff report on a request for an SCF arrangement or a review under an SCF arrangement. A poverty reduction strategy issued to the Executive Board on or after May 24, 2019 shall be named Poverty Reduction and Growth Strategy Financial Services (PRGS) and shall comprise any of the following: (a) a document developed by a member country on its national development plan or strategy that is already in existence and publicly available, and documents its poverty reduction strategy; or (b) a document newly prepared by a member country documenting its poverty reduction strategy. A PRGS shall be accompanied by a cover letter from the member country concerned to the Managing Director, and shall be issued to the Executive Board with the cover letter. As such, the cover letter shall be deemed to constitute part of the PRGS.

(5) A member may cancel an SCF arrangement at any time by notifying the Fund of such cancellation. An SCF arrangement for a member approved after the date of adoption of this decision, which has an initial duration of more than 24 months or is extended to more than 24 
months, will automatically terminate before its term if no program review under the arrangement has been completed over a period of eighteen months. The Trustee, at the authorities' request, may decide to delay the termination of the arrangement by up to three months in cases where the reaching of understandings between the authorities and the Trustee on targets and measures to put the SCF-supported program back on track within the term of the arrangement, appears imminent. The SCF arrangement will automatically terminate at the end of the extended period unless a program review under the arrangement is completed within this period.

\section{(d) Assistance under the RCF}

(1) Assistance under the RCF shall be made available to a qualifying member through outright loan disbursements. A member requesting assistance under the RCF shall describe in a letter the general policies it plans to pursue to address its balance of payment difficulties, how its policies advance its poverty reduction and growth objectives, and its intention not to introduce measures or policies that would compound its balance of payments difficulties. The member shall also commit to undergoing a safeguard assessment, provide staff with access to its central bank's most recently completed external audit reports and authorize its external auditors to hold discussions with staff. The Trustee will approve support under the RCF only where it is satisfied that the member will cooperate with the Trustee in an effort to find, where appropriate, solutions for its balance of payments difficulties. In exceptional cases, the Managing Director may request that the member implement upfront measures before recommending that the Trustee approve a disbursement under the RCF.

(2) Before approving a disbursement under the RCF, the Trustee shall be satisfied (a) that the member is experiencing an urgent balance of payments need characterized by a financing gap that, if not addressed, would result in an immediate and severe economic disruption; (b) that the member's balance of payments difficulties are not predominantly caused by a withdrawal of financial support by donors; and (c) normally, that the member either (i) has a balance of payments need that is expected to be resolved within one year with no major policy adjustments being necessary, or (ii) lacks capacity to implement an upper credit tranche-quality economic program owing to its limited policy implementation capacity or the urgent nature of its balance of payments need. If a member has received a disbursement under the RCF within the preceding three years, then any additional disbursements under the RCF may be approved only where the Trustee is satisfied that: (i) the member's balance of payments need was caused primarily by a sudden and exogenous shock, or (ii) the member has established a track record of adequate macroeconomic policies for a period of normally about six-months prior to the request; provided that $(A)$ effective as 
of January 1,2022 , a member may not receive more than two disbursements under the RCF during any 12-month period and (B) any disbursements between July 13, 2020 and December 31, 2021 shall not count towards the limit set forth in (A) above.

\section{(e) General Provisions}

(1) A member may not obtain assistance from the Trust under the ECF, SCF or ESF at the same time. So long as the requirements under the Instrument for approval of such assistance have been met, a member may obtain assistance under the RCF when it has an ECF, ESF, or SCF arrangement in place, if (a) disbursements under the relevant arrangement are delayed due to delays in program implementation, the nonobservance of conditions attached to such disbursements or delays in reaching new understandings when necessary, and (b) the member's balance of payments need giving rise to the request for assistance under the RCF is caused primarily by a sudden and exogenous shock.

(2) Commitments under arrangements under this Instrument may be made for the period through December 31, 2024.

(3) The Managing Director shall not recommend for approval, and the Trustee shall not approve, a request for a disbursement under the RCF or an arrangement under this Instrument whenever the member has an overdue financial obligation to the Fund in the General Resources Account, the Special Disbursement Account, or the SDR Department, or to the Fund as Trustee, or while the member is failing to meet a repurchase expectation to the Fund pursuant to Decision No. 7842-(84/165) on the Guidelines on Corrective Action, or is failing to meet a repayment expectation pursuant to Section II, paragraph 3(c) or the provisions of Appendix I to this Instrument.

(4) The Trustee shall not complete a review under an arrangement under this Instrument unless and until all other conditions for the disbursement of the corresponding loan have been met or waived.

Paragraph 2. Amount of Assistance

(a)(A) Except as specified in sub-paragraph (B) below, the overall access of each eligible member to the resources of the Trust under all facilities of the Trust as specified in Section I, Paragraph 1(a) shall be subject to (i) an annual limit of 100 percent of quota; and (ii) a cumulative limit of 300 percent of quota, net of scheduled repayments (hereinafter the "normal annual access limit" and the "normal 
cumulative access limit", respectively). The Fund may approve access in excess of these limits in cases where the member is experiencing an exceptionally large balance of payments need, has a comparatively strong adjustment program and ability to repay the Fund, does not have sustained past access to international financial markets, and has income at or below the prevailing operational eutoff for assistance from the International Development Association (IDA); provided that access shall in no case exceed (i) a maximum annual limit of 133.33 percent of quota, and (ii) a maximum cumulative limit of 400 percent of quota, net of scheduled repayments (hereinafter the "exceptional annual access limit" and the "exceptional cumulative access limit" respectively). For the purpose of this sub-paragraph, a member is deemed to have sustained past access to international financial markets if, in addition to having income above 80 percent of the IDA operational cutoff, the public debtor has issued or guaranteed external bonds or has received disbursements under external commercial loans contracted or guaranteed by the public debtor, as defined in Executive Board Decision No. 14521-(10/3), as amended, during at least two of the past five years in a cumulative amount equivalent to at least 25 percent of the member's quota.

(a)(A) Except as specified in sub-paragraph (B) below, the overall access of each eligible member to the resources of the Trust under all facilities of the Trust as specified in Section I, Paragraph 1(a) shall be subject to (i) an annual limit of 145 percent of quota; and (ii) a cumulative limit of 435 percent of quota, net of scheduled repayments. The Trustee may approve access in excess of these limits if all of the following criteria are satisfied:

(1) The member is experiencing or has the potential to experience exceptional balance of payments pressures on the current account or capital account, resulting in a need for resources under the Trust that cannot be met within the normal limits.

(2) Risks to the sustainability of public debt are adequately contained, which shall be evidenced by, and subject to, the standards set forth below:

I. A rigorous and systematic analysis indicates that there is a high probability that the member's public debt is sustainable in the medium term. This is generally considered to be met for countries that are assessed under the Bank-Fund Debt Sustainability Framework for Low-Income Countries (the "LIC-DSF") to be at low or moderate overall risk of public debt distress; or

II. Where the member's public debt is assessed to be sustainable but not with high probability (which includes cases where the member's overall risk of public debt distress is assessed to be high or in debt distress), or where the member's debt is assessed to be unsustainable ex ante, access to resources in excess of the normal limits will only be made available if the combination of the member's policies and financing from sources other than the Fund, which may include debt restructuring, 
restores public debt sustainability with high probability (generally considered to be met for countries that are assessed under the LIC-DSF to be at low or moderate overall risk of public debt distress) (i) within 36 months from Board approval in the case of a new arrangement under this Trust or a loan under the RCF, or within the period of the new arrangement, whichever is longer, or (ii) within the remaining period of an arrangement, in cases where the Board approves a request for an augmentation or a rephasing of access under the arrangement;

(3) The member does not meet the income criterion for presumed blending, as set forth in paragraph 1(a) of Decision No. [new decision on blending], at the time of making a request for resources under this Trust in excess of the access limits set forth in paragraph 2(a)(A) above; and

(4) The policy program of the member provides a reasonably strong prospect of success, including not only the member's adjustment plans but also its institutional and political capacity to deliver that adjustment.

(B) (i) During the period from July 13, 2020 to March 21, 2021 (the "Applicable Period"), the normal annual access limit and the exceptional annual access limit specified in sub-paragraph (A) above shall be 150 percent of quota and 183.33 percent of quota respectively, provided that these limits shall apply to requests for new arrangements or RCFs and to requests for augmentation of rephasing of access, approved through March 21, 2021 (hereinafter the "Eligible Financing") and provided further that for the computation of the annual access under the above specified "Eligible Financing", the annual access limits of 150 percent of quota and 183.33 percent of quota shall apply for any 12-month period that includes any part of the "Applicable Period."

(ii) During the period from March 22, 2021 to July 31, 2021 (the "Applicable Period"), the overall access of a member to the resources of the Trust under all facilities shall be subject to (a) a normal annual access limit of 245 percent of quota and an exceptional annual access limit of 278.33 percent of quota, and (b) a normal cumulative access limit of 435 percent of quota, net of scheduled repayments, and an exceptional cumulative access limit of 535 percent of quota, net of scheduled repayments, provided that these limits in (a) and (b) above shall apply when a member requests new PRGT resources (i.e., a new arrangement or a new RCF loan, or an augmentation of access under an existing arrangement) and any such request is approved through July 31, 2021 (the "Eligible Financing"). In the absence of approval of such Eligible Financing, a member's overall access to the resources of the PRGT shall be subject to the access limits specified in Section II, Paragraph 2(a)(A), provided that for the period from July 13, 2020 to March 21, 2021, the annual limits shall be as specified in Paragraph 2(a)B)(i) above. For the computation of the annual access under the above specified "Eligible Financing", the annual access limits of 245 percent of quota and 278.33 percent of quota shall apply for any 12-month period that includes any part of the "Applicable Period". 
(iii) New arrangements approved between March 22, 2021 and July 31, 2021 and existing arrangements with additional access approved during the same period, that involve cumulative access above 300 percent of quota, net of scheduled repayments, or annual access above 100 percent of quota (or above 150 percent of quota for any 12 -month period that includes the period from July 13, 2020 to March 21, 2021), will remain subject to the annual and cumulative access limits specified in (a) and (b) of Section II, Paragraph 2(a)(B)(ii) for the entire duration of the arrangement, including when the duration of such arrangement is subsequently extended, unless on or after August 1, 2021, the Fund approves additional access to PRGT resources through an augmentation of access under the arrangement or through a new outright loan under the RCF.

(a)(B)(i) During the period from March 22, 2021 to December 31, 2021 (the "Applicable Period"), the annual access limit shall be 245 percent of quota for financing approved through December 31, 2021 (the "Eligible Financing"). For the computation of the annual access under the above specified "Eligible Financing", the annual access limit of 245 percent of quota shall apply for any 12-month period that includes any part of the "Applicable Period".

(a)(B)(ii) Notwithstanding the increase in access limits set forth in Paragraphs 2(a)(A) and 2(a)(B)(i) above, a member's access to PRGT resources approved under an arrangement in place prior to September 9, 2020 that was exempted from the application of Policy Safeguards for High Combined GRA and PRGT Credit set forth in Decision No. 16873-(20/91) will remain subject to observance of the access limits and criteria for exceptional access to the PRGT that were in effect at the time of approval of such arrangement; if access under such an arrangement is augmented, the provisions in paragraphs 2(a)(A) and $2(\mathrm{a})(\mathrm{B})(\mathrm{i})$ shall apply to such an arrangement.

(b) Subject to the provisions in subparagraphs (i) to (iv) below, the access of each eligible member under the RCF shall be subject to an annual limit of 50 percent of quota, and a cumulative limit of 100 percent of quota, net of scheduled repayments, including where the assistance is requested to address an urgent balance of payments need resulting primarily from a sudden and exogenous shock and the member's existing and prospective policies are sufficiently strong to address the exogenous shock:

(i) each disbursement shall not exceed 25 percent of quota except where the member requests assistance under the RCF to address an urgent balance of payments need resulting primarily from a sudden and exogenous shock (including a large natural disaster under (ii) below);

(ii) the annual and cumulative access limits under the RCF shall be 80 percent of quota and 133.33 percent of quota, net of scheduled repayments, respectively, where (a) the member requests assistance under the RCF to address an urgent balance of payments need resulting from a natural disaster that occasions damage assessed to be equivalent to or to exceed 20 percent of the member's gross domestic product (GDP) and (b) the member's existing and prospective policies are sufficiently strong to address the natural disaster shock. For the period 
from June 21, 2021 to December 31, 2021, these annual and cumulative access limits shall be 130 percent of quota and 183.33 percent of quota, net of scheduled repayments, respectively;

(iii) for the period from April 6, 2020 to December 31, 2021, a member's request for assistance under the RCF to address an urgent balance of payments need resulting primarily from a sudden and exogenous shock shall be subject to an annual access limit of 100 percent of quota and a cumulative access limit of 150 percent of quota, net of scheduled repayments; and

(iv) outstanding credit by a member under the rapid-access component of the ESF or outstanding purchases from the General Resources Account under emergency post conflict/natural disaster assistance covered by Decision No. 12341-(00/117), shall count towards the annual and cumulative limits applicable to access under the RCF. With effect from July 1 , 2015, any purchases from the General Resources Account under the Rapid Financing Instrument shall count towards the annual and cumulative limits applicable to access under the RCF.

(d) These access limits shall be subject to review from time to time by the Trustee.

(e) To the extent that a member has notified the Trustee that it does not intend to make use of the resources available from the Trust, the member shall not be included in the calculations of the access limits on Trust loans.

(f) The access for each member that qualifies for assistance from the Trust under the ECF, SCF, RCF or ESF shall be determined on the basis of an assessment by the Trustee of the actual or potential balance of payments need of the member, the strength of its adjustment program and capacity to repay the Fund, the amount of the member's outstanding use of credit extended by the Fund, and its record in using Fund credit in the past. The access for each member that qualifies for assistance under the RCF and ESF shall also take into account the size and likely persistence of the shock (where applicable, in the case of the RCF).

(g) The amount of resources committed to a qualifying member under an ECF, SCF or ESF arrangement may be increased at the time of any review contemplated under the arrangement, to help meet a larger balance of payments need or in the case of an ECF or SCF arrangement, to support a strengthening of the program. The amount committed to a member under an ECF arrangement shall not be reduced because of developments in its balance of payments, unless such developments are substantially more favorable than envisaged at the time of approval of the arrangement and the improvement for the member derives in particular from improvements in the external environment. 
(h) The amount of resources committed to a qualifying member under an ECF or SCF arrangement may also be increased by the Trustee in an ad-hoc review between scheduled reviews under the arrangement to address an increase in the underlying balance of payments problems of the qualifying member where the problem is so acute that the augmentation cannot await the next scheduled review under the arrangement. The Trustee, however, shall not approve requests for augmentation at an ad hoc review if the scheduled review associated with the most recent availability date preceding the augmentation request has not been completed. In support of a request for augmentation between scheduled reviews under an ECF or SCF arrangement, the member will describe in a letter of intent the nature and size of its balance of payment difficulties, and any information relevant to program implementation, including exogenous developments. Before approving such augmentation, the Trustee shall be satisfied that the program remains on track to achieve its objectives at the time of the augmentation, based on the information provided by the member, and, in particular, that the member is in compliance with any continuous performance criteria or that a waiver of nonobservance is justified and that all prior actions have been met. Requests for augmentation of access that do not exceed 15 percent of quota would be considered for approval on a lapse-of-time basis as provided for in Decision/A/13207, as amended. Following its approval by the Trustee, the augmentation of access under the arrangement will not exceed the amount immediately needed by the member in light of its balance of payments difficulties and will become available to the member in a single disbursement, which the member may request at any time until the availability date of the next scheduled disbursement under the ECF or SCF arrangement. A program review following an augmentation of access under the arrangement between scheduled reviews would be expected to include a comprehensive review of policies under the program. In order to allow the Trustee to undertake such a comprehensive assessment of the member's policies, this review may not be completed on a lapse of time basis.

(i) Any commitment shall be subject to the availability of resources to the Trust.

Paragraph 3. Disbursements

(a) Any disbursement shall be subject to the availability of the resources to the Trust.

(b) Disbursements under an arrangement under this Instrument must precede the expiration of the arrangement period. If phased amounts under an arrangement do not become available as scheduled due to delays in program implementation, nonobservance of conditions attached to such disbursements or delays in reaching new understandings when necessary, the Trustee may rephase those amounts over the remaining period of the arrangement. The Trustee may also 
extend the original period of (i) an ECF arrangement to allow for the disbursement of rephased amounts or to provide additional resources in light of projected developments in the member's balance of payments position, subject to appropriate conditions consistent with the terms of assistance under the ECF, provided that the total period of the arrangement shall not exceed five years overall, and (ii) an SCF or ESF arrangement for up to the overall maximum two -year period referred to in Section II, paragraph 1 (c)(1) and Appendix III, respectively, to allow for the disbursement of rephased amounts or to provide additional resources subject to appropriate conditions consistent with the terms of assistance under the ESF or SCF.

(c) When requesting a disbursement under the SCF, RCF or ESF, the member shall represent that it has a need because of its balance of payments or its reserve position or developments in its reserves. The Trustee shall not challenge this representation of need prior to providing the member with the requested disbursement. If, after a disbursement is made, the Trustee determines that the disbursement took place in the absence of a need, the Trustee may decide that the member shall be expected to repay an amount equivalent to the disbursement, together with any interest accrued thereon, normally within a period of 30 days from the date of the Executive Board decision establishing that the member is expected to make an early repayment. If the member fails to meet a repayment expectation within the period established by the Trustee, (i) the Managing Director shall promptly submit a report to the Executive Board together with a proposal on how to deal with the matter, and (ii) interest shall be charged on the amount subject to the repayment expectation at the rate applicable to overdue amounts under paragraph 4 of this Section.

(d) Following a member's qualification for a disbursement, the disbursement shall be made on the soonest value date for which the necessary notifications and payment instructions can be issued by the Trustee.

(e) No disbursement to a member shall be made after the expiration of the period referred to in Section III, paragraph 3.

(f) In cases of misreporting and noncomplying disbursements of Trust loans, the provisions of Appendix I, which is incorporated at the end of this Instrument, shall apply.

(g) Disbursements under an arrangement to a qualifying member shall be suspended in all the cases specified in Paragraph 1(e)(3) of this Section. 
(h) The Trustee's approval of a loan disbursement under the RCF after March 22, 2021 shall automatically expire after 60 days following the date of such approval (the "automatic expiration date") if the Trustee has not received the member's authenticated instructions to request the disbursement of the approved RCF loan. The Trustee, at the member's request made prior to the automatic expiration date, may decide to delay such expiration date for an additional period not exceeding 60 days from the automatic expiration date.

Paragraph 4. Terms of Loans

(a) Effective July 1, 2019 August 1, 2021, and subject to the provisions of Section IV.A, paragraph 5 , interest on the outstanding balance of Trust loans shall be charged the rate of zero percent per annum on loans under the ECF, the SCF, the ESF, and the RCF.

(b) The interest rates for loans outstanding under the ECF and the SCF as specified under paragraph (a) shall be subject to periodic reviews to take account of developments in world interest rates, with such first review to be completed by fuly 31, 2021 July 31, 2023, and subsequent reviews every two years thereafter. In the context of such reviews, and subject to the provisions of Section IV.A, paragraph 5, the interest rate on the outstanding balances of loans under the ECF and SCF shall normally be determined by the Trustee as follows:

(i) If the SDR interest rate (average rate over the most recently observed 12-month period) is less than 2 percent, the interest rate shall be established or maintained, as the case may be, at zero percent per annum for ECF and SCF loans;

(ii) If the SDR interest rate (average rate over the most recently observed 12 -month period) is between 2 percent and 5 percent, the interest rate shall be established or maintained, as the case may be, at 0.25 percent per annum for ECF and SCF loans;

(iii) If the SDR interest rate (average rate over the most recently observed 12-month period) is greater than 5 percent, the interest rate shall be established or maintained, as the case may be, at 0.5 percent per annum for ECF and SCF loans. (c) Notwithstanding the provisions of paragraph (a) or any interest rate determined in terms of the provisions of paragraph (b), interest at a rate equal to the SDR interest rate shall be charged on the amounts of any overdue interest on or overdue repayments of Trust loans.

(c) Notwithstanding the provisions of paragraph (a) or any interest rate determined in terms of the provisions of paragraph (b), interest at a rate equal to the SDR interest rate shall be charged on the amounts of any overdue interest on or overdue repayments of Trust loans. 
(d) Trust loans shall be disbursed in a freely usable currency as decided by the Trustee. They shall be repaid, and interest paid, in U.S. dollars or other freely usable currency as decided by the Trustee. The Managing Director is authorized to make arrangements under which, at the request of a member, SDRs may be used for disbursements to the member or for payment of interest or repayments of loans by the member to the Trust.

(e) The Trustee may not reschedule the repayment of loans from the Trust.

(f) Trust loans under the ECF, RCF and ESF shall be repaid in ten equal semi-annual installments beginning not later than five and a half years from the date of each disbursement and completed at the end of the tenth year after that date. Trust loans under the SCF shall be repaid in nine equal semi-annual installments beginning not later than four years from the date of each disbursement and completed at the end of the eighth year after that date.

Paragraph 5. Availability Fee

A charge in the amount of 0.15 percent per annum shall be payable on the full amount of disbursements available during each six-month period under an SCF arrangement, or any shorter period that is remaining under an SCF arrangement, to the extent that such available disbursements were not drawn by the member. The charge shall be paid to the SCF Subsidy Account five days after the end of each relevant period. Payment of the availability fee shall normally be made in SDRs but can also be made in a freely usable currency as decided by the Trustee. The Managing Director shall make the necessary arrangements for the use of SDRs for payment of the availability fee.

\section{Paragraph 6. Modifications}

Any modification of these provisions will affect only loans made after the effective date of the modification, provided that modification of the interest rate shall apply to interest accruing after the effective date of the modification.

Section III. Borrowing for the Loan Account

Paragraph 1. Resources

(a) For purposes of this Section III, the term "borrowing agreements" shall comprise loan and note purchase agreements, and the term "Trust borrowing" shall comprise loans made to the 
Trust and notes issued by the Trust, including loans made and notes issued for the purposes set forth in Section III, paragraph 4(b) of this Instrument.

(b) The resources held in the General Loan Account shall consist of:

(i) the proceeds of Trust borrowing for the General Loan Account; and

(ii) payments of principal and interest on Trust loans funded with drawings under borrowing agreements to the General Loan Account, subject to the provisions of Section IV.A, paragraph 4(g) and Section V, paragraph 3 of this Instrument.

(c) The resources held in the ECF Loan Account shall consist of:

(i) the proceeds of loans made to the Trust for the Loan Account of the Trust as of January 7, 2010, unless a lender notifies the Trustee by January 22, 2010, that it wishes to transfer the proceeds of its share in the amounts not yet committed under PRGF and ESF arrangements to another Loan Account.

(ii) the proceeds of Trust borrowing for the ECF Loan Account; and

(iii) payments of principal and interest on Trust loans funded with drawings under borrowing agreements to the ECF Loan Account, subject to the provisions of Section IV.A, paragraph 4(g) and Section $\mathrm{V}$, paragraph 3 of this Instrument.

(d) The resources held in the SCF Loan Account shall consist of:

(i) the proceeds of Trust borrowing for the SCF Loan Account; and

(ii) payments of principal and interest on Trust loans funded with drawings under borrowing agreements to the SCF Loan Account, subject to the provisions of Section IV.A, paragraph 4(g) and Section $\mathrm{V}$, paragraph 3 of this Instrument.

(e) The resources held in the RCF Loan Account shall consist of:

(i) the proceeds of Trust borrowing for the RCF Loan Account; and

(ii) payments of principal and interest on Trust loans funded with drawings under borrowing agreements to the RCF Loan Account, subject to the provisions of Section IV.A, paragraph 4(g) and Section $\mathrm{V}$, paragraph 3 of this Instrument.

Paragraph 2. Borrowing Authority 
The Trustee may borrow resources for the Loan Accounts on such terms and conditions as may be agreed between the Trustee and the respective creditors, subject to the provisions of this Instrument. For this purpose the Managing Director of the Trustee is authorized to enter into borrowing agreements and agree to their terms and conditions with creditors to the Loan Accounts of the Trust.

Paragraph 3. Commitments

Commitments for drawings under borrowing agreements to the Loan Accounts of the Trust that were entered into before November 30, 1993, shall extend through December 31, 1997, and under borrowing agreements that are entered into after November 30, 1993, shall extend through December 31, 1999. The drawdown period under borrowing agreements to the Loan Accounts of the Trust entered into or amended after September 19, 2001, shall normally extend through December 31, 2018. The drawdown period under borrowing agreements to the Loan Accounts of the Trust entered into or amended after May 31, 2014, shall normally extend through December 31, 2029. The drawdown period may be extended by mutual agreement between the Trustee and the creditor. The Managing Director is authorized to conclude such agreements on behalf of the Trustee.

\section{Paragraph 4. Drawings under Borrowing Agreements}

(a) The Trustee may draw under borrowing agreements to the General Loan Account for purposes of loan disbursements under any of the facilities of the Trust, provided that it shall draw first (i) under borrowing agreements to the ECF Loan Account for purposes of ECF and ESF loan disbursements, (ii) under borrowing agreements to the SCF Loan Account for purposes of SCF loan disbursements, and (iii) under borrowing agreements to the RCF Loan Account for purposes of RCF loan disbursements, and provided further that before calling on commitments made under new borrowing agreements entered into, or augmented under existing borrowing agreements amended, after May 31, 2014, for disbursements under a facility of the Trust, the Trustee shall aim to first draw resources available for that facility under borrowing agreements entered into before that date, including from the General Loan Account if, and to the extent that, commitments of loan resources for all facilities are considered adequate by the Managing Director. Drawings on the commitments of individual creditors over time shall be made so as to maintain broad proportionality of these drawings relative to commitments to each Loan Account, provided that commitments under borrowing agreements entered into or augmented after May 31, 2014, shall only be taken into account after borrowing agreements entered into 
before that date have been fully drawn. Drawings under paragraph 4(b) below will not be taken into account for purposes of the proportionality requirement set forth in this paragraph 4(a).

(b) Notwithstanding subparagraph (a) above, the Trustee may draw under one or more borrowing agreements to any Loan Account of the Trust to fund the early repayment of outstanding Trust borrowing under another borrowing agreement to any Loan Account of the Trust ("encashment"), where (i) the terms of all such borrowing agreements permit the Trustee to make drawings to fund such early repayments, and (ii) the creditor requesting early repayment represents that its balance of payments and reserve position (the balance of payments and reserve position of the relevant member if the creditor is the central bank or other official institution of a member) justify the early repayment, and the Trustee, having given this representation the overwhelming benefit of any doubt, agrees. As from the effective date of such early repayment, the creditor or creditors whose borrowing agreements have been drawn to fund the early repayment shall have the same rights to repayment as the creditor receiving the early repayment had with respect to the encashed claim, including all rights to payments of principal and interest pursuant to paragraph 5 of this Section III. For purposes of Section IV.A of this Instrument, drawings under this paragraph 4(b) shall be considered resources borrowed for the Trust loans for which the disbursements related to the encashed claims were made.

Borrowing agreements allowing for encashment shall provide for the same effective maturity dates for drawings under this paragraph 4(b) as apply to encashed claims. Drawings on the commitments of individual creditors under this paragraph 4(b) shall be made with the aim of maintaining broad proportionality of these drawings relative to the commitments of these creditors.

(c) Calls on commitments under borrowing agreements shall be suspended temporarily if, at any time prior to June 30,1997, in case of a commitment under a borrowing agreement entered into before November 30,1993, or prior to June 30,1999, in case of a commitment under a borrowing agreement entered into after November 30, 1993, or prior to June 30, 2018, in case of a commitment under a borrowing agreement entered into after August 31, 2001, or prior to tune 30, 2024 June 30, 2029, in case of a commitment under a loan agreement entered into after May 31, 2014, the creditor represents to the Trustee that it has a liquidity need for such suspension and the Trustee, having given this representation the overwhelming benefit of any doubt, agrees. The suspension shall not exceed three months, provided that it may be extended for further periods of three months by agreement between the creditor and the Trustee. No extension shall be agreed which, in the judgment of the Trustee, would prevent drawing of the full amount of the commitment. 
(d) Following any suspension of calls with respect to the commitment of a creditor, calls will be made on that commitment thereafter so as to restore as soon as practicable the proportionality of drawings contemplated pursuant to this paragraph 4.

Paragraph 5. Payments of Principal and Interest

(a) The Trust shall make payments of principal and interest on its borrowing for the Loan Accounts from the payments into these accounts of principal and interest made by borrowers under Trust loans. Payments of the authorized subsidy shall be made from the Subsidy Accounts in accordance with Section IV.A of this Instrument, and, as required, payments shall be made from the Subsidy Reserve Account and Reserve Account in accordance with Section IV.A and Section V of this Instrument.

(b) The Trust shall pay interest on outstanding borrowing for Trust loans promptly after June 30 and December 31 of each year, unless the particular modalities of a borrowing agreement make it necessary for the Trustee to agree with the creditor on interest payments at other times; provided however that interest on outstanding drawings under borrowing agreements that provide for disbursements in SDRs will normally be paid promptly after April 30, July 31, October 31, and January 31 of each year.

Section IV.A Subsidy Accounts

Paragraph 1. Resources

(a) The resources held in the General Subsidy Account shall consist of:

(i) the proceeds of donations made to the Trust for the General Subsidy Account;

(ii) the proceeds of loans made to the Trust for the General Subsidy Account;

(iii) transfers from the Special Disbursement Account in accordance with Section F of Decision No. 14354-(09/79);

(iv) transfers from the Reserve Account in accordance with Section V, Paragraph 5(b)(ii) of this Instrument.

(v) net earnings from investment of resources held in that Account.

(b) The resources held in the ECF Subsidy Account shall consist of: 
(i) the proceeds of donations made to the Trust for the PRGF-ESF Subsidy Account and the PRGF Subsidy Account as of January 7, 2010, unless a donor notifies the Trustee that it wishes to transfer the proceeds of its outstanding donation to another Subsidy Account by January 22, 2010;

(ii) the proceeds of loans made to the Trust for the PRGF-ESF Subsidy Account and the PRGF Subsidy Account as of January 7, 2010, unless a lender notifies the Trustee that it wishes to transfer the proceeds of its outstanding loan to another Subsidy Account by January 22, 2010;

(iii) the proceeds of donations made to the Trust for the ECF Subsidy Account;

(iv) the proceeds of loans made to the Trust for the ECF Subsidy Account;

(v) transfers from the Special Disbursement Account in accordance with Decision No. 10531 $(93 / 170)$;

(vi) transfers from the Special Disbursement Account in accordance with paragraph 5(c) of Decision No. 13588-(05/99) MDRI;

(vii) transfers from the Trust for Special Poverty Reduction and Growth Operations for the Heavily Indebted Poor Countries and Interim ECF Subsidy Operations (PRG-HIPC Trust), in accordance with Section III bis of the Instrument establishing that Trust; and

(viii) net earnings from investment of resources held in that Account.

(c) The resources held in the SCF Subsidy Account shall consist of:

(i) the proceeds of donations made to the Trust for the SCF Subsidy Account;

(ii) the proceeds of loans made to the Trust for the SCF Subsidy Account;

(iii) proceeds from availability fees in accordance with Section II, paragraph 5 of this Instrument; and

(iv) net earnings from investment of resources held in that Account.

(d) The resources held in the RCF Subsidy Account shall consist of:

(i) the proceeds of donations made to the Trust for the RCF Subsidy Account;

(ii) the proceeds of loans made to the Trust for the RCF Subsidy Account; and 
(iii) net earnings from investment of resources held in that Account.

(e) The resources held in the ESF Subsidy Account shall consist of:

(i) the proceeds of donations made to the Trust for the ESF Subsidy Account as of January 7, 2010, unless a donor notifies the Trustee that it wishes to transfer the proceeds of its outstanding donation to another Subsidy Account by January 22, 2010;

(ii) the proceeds of loans made to the Trust for the ESF Subsidy Account as of January 7, 2010, unless a lender notifies the Trustee that it wishes to transfer the proceeds of its outstanding loan to another Subsidy Account by January 22, 2010; and

(iii) net earnings from investment of resources held in that Account.

(f) The resources held in the Subsidy Reserve Account shall consist of:

(i) the proceeds of donations made to the Trust for the Subsidy Reserve Account;

(ii) the proceeds of loans made to the Trust for the Subsidy Reserve Account;

(iii) transfers from the Deposit and Investment Account in accordance with Section IV.B, paragraph 3 of this Instrument;

(iv) net earnings from investment of resources held in that Account;

(v) payments of overdue principal or interest or interest thereon under Trust loans, and payments of interest under Trust loans to the extent that payment has been made to a creditor from the Subsidy Reserve Account; and

(vi) repayments of the principal under Trust loans, to the extent that resources in the Subsidy Reserve Account have been used to make payments to a creditor due to a difference in timing between scheduled principal repayments to the creditor and principal repayments under Trust loans.

\section{Paragraph 2. Donations}

The Trustee may accept donations of resources for any of the Subsidy Accounts on such terms and conditions as may be agreed between the Trustee and the respective donors, subject to the provisions of this Instrument. To the extent possible, annual contributions should be made 
before April 30 of each year. For this purpose the Managing Director of the Trustee is authorized to accept donations of resources and agree to their terms and conditions with donors to the Subsidy Accounts of the Trust.

\section{Paragraph 3. Borrowing}

The Trustee may, in exceptional circumstances, borrow resources for any of the Subsidy Accounts from official lenders on such terms and conditions as may be agreed between the Trustee and the lenders, in order:

(a) to prefinance an amount that is firmly committed to be donated to the Trust for the relevant Subsidy Account; repayment of principal and any payments of interest on such borrowing shall be contingent upon the receipt by the relevant Subsidy Account of the donation that has been prefinanced; and

(b) that the relevant Subsidy Account may benefit from net investment earnings on the proceeds of a loan extended at a concessional interest rate; repayment of principal and any payment of interest on such borrowing shall be made exclusively from the proceeds of liquidation of the investment and the earnings thereon. For this purpose the Managing Director of the Trustee is authorized to enter into borrowing agreements and agree to their terms and conditions with lenders to the Subsidy Accounts of the Trust.

\section{Paragraph 4. Authorized Use of Subsidy Accounts}

(a) The Trustee shall draw upon the resources available in the General Subsidy Account to pay the difference, with respect to each interest period, between the interest due by the borrowers and the interest due on resources borrowed for loans under the facilities of the Trust specified in Section I, Paragraph 1 of the Instrument, provided that resources available in the General Subsidy Account shall be drawn upon for these purposes only if there are no other resources immediately available in the ECF Subsidy Account, SCF Subsidy Account, RCF Subsidy Account or ESF Subsidy Account, as the case may be, for these purposes. For purposes of the preceding sentence, resources in the PRG-HIPC Trust that are transferable to the ECF Subsidy Account shall not be considered resources immediately available in the ECF Subsidy Account. The Trustee may also draw upon resources available in the General Subsidy Account for transfer to the ENDA/EPCA Subsidy Account, if there are no other resources immediately available in the ENDA/EPCA Subsidy Account for purposes of the subsidies of post-conflict and/or natural disaster emergency assistance purchases provided by that Account. Any such transfers shall be limited to the amounts needed for subsidy payments. 
(b) The Trustee shall draw upon the resources available in the ECF Subsidy Account to pay the difference, with respect to each interest period, between the interest due by the borrowers and the interest due on resources borrowed for loans under the ECF and ESF, provided that resources in the ESF Subsidy Account shall be drawn first, with respect to the interest on ESF loans, before resources in the ECF Subsidy Account are drawn to subsidize ESF loans.

(c) The Trustee shall draw upon the resources available in the SCF Subsidy Account to pay the difference, with respect to each interest period, between the interest due by the borrowers and the interest due on resources borrowed for loans under the SCF.

(d) The Trustee shall draw upon the resources available in the RCF Subsidy Account to pay the difference, with respect to each interest period, between the interest due by the borrowers and the interest due on resources borrowed for loans under the RCF.

(e) The Trustee shall draw upon the resources available in the ESF Subsidy Account to pay the difference, with respect to each interest period, between the interest due by the borrowers and the interest due on resources borrowed for loans under the ESF.

(f) The Trustee shall draw upon the resources available in the Subsidy Reserve Account to:

(i) pay the difference, with respect to each interest period, between the interest due by the borrowers and the interest due on resources borrowed for loans under the facilities of the Trust specified in Section I, Paragraph 1 of the Instrument, provided that resources available in the Subsidy Reserve Account shall be drawn only if there are no other resources available in the relevant Subsidy Accounts for these purposes; or

(ii) to make payments of principal and interest on its borrowing for Trust loans, to the extent that the amounts available from receipts of repayments and interest from borrowers under Trust loans, together with the authorized subsidy under Section IV.A, paragraph 4, are insufficient to cover the payments to creditors as they become due and payable, provided that resources available in the Subsidy Reserve Account shall be drawn upon for these purposes only if there are no other resources immediately available in the Reserve Account.

(g) Any repayment of principal under Trust loans, to the extent that repayment to a creditor has been made from the Subsidy Reserve Account due to differences in timing between scheduled principal repayments to the creditor and principal repayments under Trust loans, any payments 
of overdue principal or interest or interest thereon under Trust loans, and any payments of interest under Trust loans to the extent that payment has been made to a creditor from the Subsidy Reserve Account, shall be made to the Subsidy Reserve Account.

\section{Paragraph 5. Calculation of Subsidy}

(a) The amount of the subsidy shall be determined by the Trustee in the light of (i) the objective of ensuring that the facilities of the Trust are highly concessional facilities and, to the extent possible, of reducing the rate of interest charged on Trust loans in accordance with Section II, paragraphs 4(a), (b), and (c), as well as the objective of subsidizing, as needed, the rate of charge on purchases from the General Resources Account ("GRA") in accordance with the terms of the ENDA/EPCA Subsidy Account; (ii) the rate of interest on resources available to the Loan Accounts and the rate of charge on GRA purchases covered by the ENDA/EPCA Subsidy Account; and (iii) the availability and prospective availability of resources to the Subsidy Accounts of the Trust and the ENDA/EPCA Subsidy Account.

(b) The Trustee shall keep the operation of the Subsidy Accounts under review. If at any time it determines that resources available or committed are likely to be insufficient to reduce the rate of interest on Trust loans in accordance with Section II, paragraphs 4(a), (b), and (c) throughout the operation of the Trust, and to fund needed transfers to the ENDA/EPCA Subsidy Account to subsidize the rate of charge on GRA purchases in accordance with the terms of that Account, then the Trustee shall seek such additional resources as may be necessary to achieve this objective.

(c) Should adequate additional resources not be forthcoming to reduce the rate of interest on Trust loans in accordance with Section II, paragraphs 4(a), (b), and (c), or to fund needed transfers to the ENDA/EPCA Subsidy Account to subsidize the rate of charge on GRA purchases in accordance with the terms of that Account, then the Trustee shall recalculate the subsidy with a view to reducing those interest rates to the lowest feasible rates and funding those transfers to the maximum extent that could be applied throughout the remaining life of the Trust. The rate of interest charged on all outstanding loans by the Trust under the relevant facility shall be adjusted accordingly in the succeeding interest periods, and the level of transfers to the ENDA/EPCA Subsidy Account shall be calculated to achieve the new level of subsidization. Borrowers shall be notified promptly of such adjustments. Further recalculations and adjustments shall be made in subsequent interest periods, as necessary in light of relevant developments, including the rate of interest on resources available to the Loan Accounts, the rate of charge on purchases covered by 
the ENDA/EPCA Subsidy Account and the availability of resources to the Subsidy Accounts and the ENDA/EPCA Subsidy Account.

(d) If the interest due to creditors for an interest period has exceeded the interest due by borrowers under the relevant facility, together with the authorized subsidy under paragraph 4 of this Section for that period, and payment to creditors of that difference has been made from the Reserve Account in accordance with Section $V$, paragraph 2, then an amount equivalent to that difference shall be added to the interest due by the relevant borrowers for the succeeding interest period. Payment of that amount shall be made to the Reserve Account in accordance with Section $V$, paragraph 3. The additional interest due shall not be taken into account in the calculation of the authorized subsidy for that same interest period.

\section{Paragraph 6. Termination arrangements}

(a) The ESF Subsidy Account shall be terminated after its resources as of January 7, 2010 have been used for subsidy operations in accordance with paragraphs 4(b) and 4(e) of this Section or transferred to other Subsidy Account in accordance with paragraph 1(e) of this Section.

(b) Upon completion of the subsidy operations authorized by this Instrument, the Fund shall wind up the affairs of the Subsidy Accounts. The Fund may also wind up the affairs of any Subsidy Account other than the General Subsidy Account prior to the completion of the overall subsidy operations authorized by this Instrument, if the Fund deems this to be appropriate. In case of termination of a Subsidy Account in accordance with this subparagraph, the remaining resources shall be used as follows:

(i) Any resources remaining in the General Subsidy Account shall be used in a manner consistent with paragraph 4(a) of this Section (i) to reduce to the fullest extent possible the interest rate paid by borrowers in accordance with Section II, paragraphs 4(a), (b), and (c) on loans from the PRGT, by means of payments to such borrowers, and (ii) to fund transfers to the ENDA/EPCA Subsidy Account needed to subsidize the rate of charge on any remaining outstanding GRA purchases in accordance with the terms of the ENDA/EPCA Subsidy Account. Any resources remaining after that subsidization and transfer shall be distributed to the Fund, donors, and creditors that have contributed to the General Subsidy Account, in proportion to their contributions, including donors and creditors of resources transferred from other Subsidy Accounts upon their termination. The resources representing the Fund's share in such distribution shall be transferred to the Special Disbursement Account. Any resources 
attributable to transfers from the Deposit and Investment Account shall be transferred to that account.

(ii) Any resources remaining in the ECF Subsidy Account shall be used to reduce to the fullest extent possible the interest rate paid by borrowers on ECF and ESF loans in accordance with Section II, paragraphs 4(a), (b), and (c), by means of payments to such borrowers. Any resources remaining after that subsidization shall be transferred to the General Subsidy Account, provided that a contributor may request that its share in any remaining resources be returned to it.

(iii) Any resources remaining in the SCF Subsidy Account shall be used to reduce to the fullest extent possible the interest rate paid by borrowers on SCF loans in accordance with Section II, paragraphs 4(a), (b), and (c), by means of payments to such borrowers. Any resou rces remaining after that subsidization shall be transferred to the General Subsidy Account, provided that a contributor may request that its share in any remaining resources be returned to it.

(iv) Any resources remaining in the RCF Subsidy Account shall be used to reduce to the fullest extent possible the interest rate paid by borrowers on RCF loans in accordance with Section II, paragraphs 4(a), (b), and (c), by means of payments to such borrowers. Any resources remaining after that subsidization shall be transferred to the General Subsidy Account, provided that a contributor may request that its share in any remaining resources be returned to it.

(v) Any resources remaining in the ESF Subsidy Account shall be used to reduce to the fullest extent possible, in accordance with Section II, paragraphs 4(a), (b), and (c), the interest rate paid by borrowers on ESF loans, by means of payments to such borrowers. Any resources remaining after that subsidization shall be transferred to the General Subsidy Account, provided that a contributor may request that its share in any remaining resources be returned to it.

(vi) Any resources remaining in the Subsidy Reserve Account shall be used in a manner consistent with paragraph 4(f) of this Section to reduce to the fullest extent possible the interest rate paid by borrowers in accordance with Section II, paragraphs 4(a), (b), and (c) on loans from the PRGT, by means of payments to such borrowers. Any resources remaining after that subsidization and not attributable to the Deposit and Investment Account shall be transferred to the General Subsidy Account, provided that a contributor may request that its share in any remaining resources be returned to it. Any resources attributable to transfers from the Deposit and Investment Account shall be transferred to that Account. 
(vii) For the purposes of the distributions provided for in this paragraph 6, account will be taken of donations, the net earnings from investment of the proceeds of concessional loans extended to the Subsidy Accounts under paragraph 3(b) above, and the subsidy element of concessional loans extended to the Trust under Section III; the subsidy element associated with such loans shall be calculated as the difference, if positive, between the SDR rate of interest and the interest on such loans, applied to the amount of the loans during the period they were outstanding.

Section IV.B Deposit and Investment Account

Paragraph 1. Purpose and Resources

The purpose of the Deposit and Investment Account is to provide a separate vehicle under which the Trust can borrow resources to generate net investment earnings for the benefit of the Subsidy Reserve Account or, at the request of a contributor, the General Subsidy Account. The resources held in the Deposit and Investment Account shall consist of the proceeds from deposit and other investment agreements with contributors and the net earnings on the investment proceeds.

Paragraph 2: Borrowing for the Deposit and Investment Account

(a) The Trustee may enter into deposit and other investment agreements for the benefit of the Deposit and Investment Account with the aim of generating net investment earnings from the investment of the resources borrowed. For this purpose, the Managing Director of the Trustee is authorized to enter into deposit and other investment agreements and agree to their terms and conditions with contributors to the Deposit and Investment Account. The borrowed resources shall be invested in accordance with guidelines adopted by the Trustee.

(b) The agreements may provide for the right of a contributor to request the early repayment of the principal amount under its deposit or investment agreement upon representation of a balance of payments need. The contributor shall reconstitute any withdrawn amount as its balance of payments and reserve position improves.

Paragraph 3: Use of Resources

(a) Resources in the Deposit and Investment Account derived from net investment earnings shall be transferred to the Subsidy Reserve Account at the final maturity of the deposit and 
investment agreement such resources are attributable to; provided that, with the consent of the contributor, the Managing Director is authorized to transfer to the Subsidy Reserve Account at an earlier time resources attributable to that contributor's deposit or investment agreement, to meet the subsidization needs of the Trust.

(b) A contributor may prescribe that investment earnings in the Deposit and Investment Agreement attributable to that contributor's investment be directed to the General Subsidy Account instead of the Subsidy Reserve Account.

Paragraph 4: Termination Arrangements

Upon completion of the subsidy operations authorized by this Instrument, the Trustee shall wind down the affairs of the Deposit and Investment Account. Contributors shall be repaid the principal of their deposits or investments and any remaining investment earnings or losses attributed to it.

Paragraph 5: Repayment of the principal amount and payment of interest to a contributor Repayment of the principal amount and any payment of interest to a contributor on any borrowing for the Deposit and Investment Account, including repayment upon maturity, early repayment in accordance with Section IV.B, paragraph 2(b), or repayment in accordance Section IV.B., paragraph 4, shall be made exclusively from resources attributed to the deposit or other investment of this principal amount and the net investment earnings thereon, net of the cumulative interest previously paid to the contributor.

\section{Section V. Reserve Account}

Paragraph 1. Resources

The resources held in the Reserve Account shall consist of:

(a) transfers by the Fund from the Special Disbursement Account in accordance with Decision No. 8760-(87/176), adopted December 18, 1987, as amended by Decision No. 10531-(93/170), adopted December 15, 1993;

(b) net earnings from investment of resources held in the Reserve Account;

(c) net earnings from investment of any resources held in the Loan Accounts pending the use of these resources in operations; 
(d) payments of overdue principal or interest or interest thereon under Trust loans, and payments of interest under Trust loans to the extent that payment has been made to a creditor from the Reserve Account;

(e) transfers by the Fund from the Special Disbursement Account in accordance with Decision No. 10286-(93/23) ESAF, adopted February 22, 1993; and

(f) repayments of the principal under Trust loans, to the extent that resources in the Reserve Account have been used to make payments to a creditor due to a difference in timing between scheduled principal repayments to the creditor and principal repayments under Trust loans.

Paragraph 2. Use of resources

(a) The resources held in the Reserve Account shall be used by the Trustee to make payments of principal and interest on its borrowing for Trust loans, to the extent that the amounts available from receipts of repayments and interest from borrowers under Trust loans, together with the authorized subsidy under Section IV.A, paragraph 4, are insufficient to cover the payments to creditors as they become due and payable.

(b) The Trustee may decide to use income from the investment of the resources in the Reserve Account for subsidy purposes by transferring such income to the General Subsidy Account if the Trustee determines that additional subsidy resources are required for the subsidization of outstanding PRGT lending or new lending commitments. The amount of any transfers shall be decided by the Trustee following consultations with all creditors to the Loan Accounts on the adequacy of the Reserve Account to protect claims of the creditors to the PRGT Loan Accounts.

\section{Paragraph 3. Payments to the Reserve Account}

Any repayment of principal under Trust loans, to the extent that repayment to a creditor has been made from the Reserve Account due to differences in timing between scheduled principal repayments to the creditor and principal repayments under Trust loans, any payments of overdue principal or interest or interest thereon under Trust loans, and any payments of interest under Trust loans to the extent that payment has been made to a creditor from the Reserve Account, shall be made to the Reserve Account.

Paragraph 4. Review of resources 
If resources in the Reserve Account are, or are determined by the Trustee likely to become, insufficient to meet the obligations of the Trust that may be discharged from the Reserve Account as they become due and payable, the Trustee shall review the situation in a timely manner.

\section{Paragraph 5. Reduction of resources and liquidation}

(a) Whenever the Trustee determines that amounts in the Reserve Account of the Trust exceed the amount that may be needed to cover the total liabilities of the Trust to creditors that are authorized to be discharged by the Reserve Account, the Trustee shall retransfer such excess amount to the Fund's Special Disbursement Account.

(b) Notwithstanding (a) above, the equivalent of up to SDR 250 million may be transferred from the Reserve Account to the Special Disbursement Account to be used to provide Trust Grants or Trust loans, as defined in the Instrument to Establish a Trust for Special PRG Operations for the Heavily Indebted Poor Countries and Interim ECF Subsidy Operations. These transfers will be made only when and to the extent that the Trustee of the Trust established by that Instrument determines that there are no other resources immediately available for this purpose.

(c) Upon liquidation of the Trust, all amounts in the Reserve Account remaining after discharge of liabilities authorized to be discharged by the Reserve Account shall be transferred to the Special Disbursement Account.

Section VI. Transfer of Claims

Paragraph 1. Transfers by creditors

(a) Any creditor shall have the right to transfer at any time all or part of any claim to any member of the Fund, to the central bank or other fiscal agency designated by any member for purposes of Article V, Section 1 ("other fiscal agency"), or to any official entity that has been prescribed as a holder of SDRs pursuant to Article XVII, Section 3 of the Fund's Articles of Agreement.

(b) The transferee shall, as a condition of the transfer, notify the Trustee prior to the transfer that it accepts all the obligations of the transferor relating to the transferred claim with respect to renewal and new drawings, and shall acquire all the rights of the transferor with respect to repayment of and interest on the transferred claim, except that any right to encashment pursuant to Section III, paragraph 4(b) of this Instrument shall be acquired only if the transferee 
is a member or the central bank or other fiscal agency of a member and, at the time of transfer, the balance of payments and reserve position of the member is considered sufficiently strong in the opinion of the Fund for its currency to be usable in transfers under the Fund's Financial Transactions Plan.

Paragraph 2. Transfers among electing creditors

(a) Any creditor to one of the Loan Accounts ("electing creditors") may inform the Trustee that it stands ready, upon request by the Trustee, to purchase claims on the Trust from any other electing creditor, provided that the holdings of claims so acquired shall at no time exceed the amount communicated to the Trustee and subject to the other provisions of this section. A list of electing creditors and the amounts communicated by them shall be established separately by the Trustee. This list may be extended and the amounts therein increased in accordance with communications received subsequently.

(b) An electing creditor shall have the right to transfer temporarily to other electing creditors part or all of any claim arising from its loans to the Trust or note purchases under Section III, if the electing creditor represents to the Trustee that it has a liquidity need to make such transfer and the Trustee, having given this representation the overwhelming benefit of any doubt, agrees.

(c) The Trustee shall allocate each transfer by an electing creditor under this provision to all other electing creditors in proportion to the amounts by which the respective maximum holdings listed in the attachment exceed actual holdings of claims acquired under this provision; provided, however, that no allocation shall be made to an electing creditor if it represents to the Trustee that it has a liquidity need for exclusion from an allocation and the Trustee agrees, in which case allocations to the remaining electing creditors shall be adjusted accordingly.

(d) The purchaser of any claim transferred under this provision shall assume, as a condition of the transfer, any obligation of the transferor, relating to the transferred claim, with respect to the renewal of drawing on Trust borrowing and to new drawings in the event a renewal, having been requested, is not agreed by the transferor.

(e) Transfers of claims under this provision shall be made in exchange for freely usable currency and shall be reversed in the same media within three months, provided that such transfers may be renewed, by agreement between the transferor and the Trustee, for further periods of three 
months up to a total of one year. Notwithstanding the above, the transferor shall reverse a transfer under this provision not later than the date on which the transferred claim is due to be repaid by the Trust.

(f) Interest on claims transferred under this Section shall be paid by the Trust to the transferor in accordance with the provisions of the transferor's borrowing agreement with the Trust. The transferor shall pay interest to the transferee(s) on the amount transferred, so long as the transfer remains outstanding, at a daily rate equal to that set out in Rule T-1 of the Fund's Rules and Regulations; such interest shall be payable three months after the date of a transfer or of its renewal, or on the date the transfer is reversed, whichever is earlier.

Section VII. Administration of the Trust

Paragraph 1. Trustee

(a) The Trust shall be administered by the Fund as Trustee. Decisions and other actions taken by the Fund as Trustee shall be identified as taken in that capacity.

(b) Subject to the provisions of this Instrument, the Fund in administering the Trust shall apply the same rules as apply to the operation of the General Resources Account of the Fund.

(c) The Trustee, acting through its Managing Director, is authorized:

(i) to make all arrangements, including establishment of accounts in the name of the International Monetary Fund, which shall be accounts of the Fund as Trustee, with such depositories of the Fund as the Trustee deems necessary; and

(ii) to take all other administrative measures that the Trustee deems necessary to implement the provisions of this Instrument.

Paragraph 2. Separation of assets and accounts, audit and reports

(a) The Resources of the Trust shall be kept separate from the property and assets of all other accounts of the Fund, including other administered accounts, and shall be used only for the purposes of the Trust in accordance with this Instrument.

(b) The property and assets held in the other accounts of the Fund shall not be used to discharge liabilities or to meet losses arising out of the administration of the Trust. The resources of the Trust shall not be used to discharge liabilities or to meet losses arising out of the administration of the other accounts of the Fund. 
(c) The Fund shall maintain separate financial records and prepare separate financial statements for the Trust.

(d) The external audit firm selected under Section 20 of the Fund's By-Laws shall audit the financial transactions and records of the Trust. The audit shall relate to the financial year of the Fund.

(e) The Fund shall report on the resources and operations of the Trust in the Annual Report of the Executive Board to the Board of Governors and shall include in that Annual Report the report of the external audit firm on the Trust.

Paragraph 3. Investment of resources

(a) Any balances held by the Trust and not immediately needed in operations shall be invested. Investments shall be made as determined by the Trustee in accordance with guidelines adopted by the Trustee from time to time.

Section VIII. Period of Operation and Liquidation

Paragraph 1. Period of operation

The Trust established by this Instrument shall remain in effect for as long as is necessary, in the judgment of the Fund, to conduct and to wind up the business of the Trust.

Paragraph 2. Liquidation of the Trust

(a) Termination and liquidation of the Subsidy Accounts shall be made in accordance with the provisions of Section IV.A, paragraph 6. Termination and liquidation of the Deposit and Investment Account shall be made in accordance with the provisions of Section IV.B, paragraph 4.

(b) All other resources, if any, shall be used to discharge any liabilities of the Trust, other than those incurred under Section IV.A, and any remainder shall be transferred to the Special Disbursement Account of the Fund.

Section IX. Amendment of the Instrument 
The Fund may amend the provisions of the Instrument, except this Section and Section I, paragraphs 1 and 2; Section III, paragraphs 4 and 5; Section IV.A, paragraphs 4 and 6; Section IV.B; Section V; Section VI; Section VII, paragraph 2(a) and (b); and Section VIII, paragraph 2(b).

\section{APPENDIX I}

Misreporting and Noncomplying Disbursements Under Poverty Reduction and Growth Facility and Poverty Reduction and Growth Trust Facilities-Provisions on Corrective Action

a. A noncomplying disbursement occurs when (i) the Trustee makes a disbursement to a member in accordance with the Instrument on the basis of a finding by the Trustee or the Managing Director that all applicable conditions established for that disbursement under the terms of the decisions on the disbursement have been observed, and (ii) that finding later proves to be incorrect. For the purposes of these provisions, a condition established under the terms of a decision on a disbursement means a condition specified in the arrangement for the relevant disbursement; in a decision approving the arrangement or approving an outright disbursement; in a decision approving an augmentation of access under an ECF or SCF arrangement during an ad-hoc review, or in a decision completing a scheduled review, or granting a waiver of applicability or for the nonobservance of a performance criterion under the arrangement.

b. Whenever evidence comes to the attention of the staff of the Trustee indicating that a member may have received a noncomplying disbursement, the Managing Director shall promptly inform the member concerned.

c. If, after consultation with the member, the Managing Director determines that the member did receive a noncomplying disbursement, the Managing Director shall promptly notify the member and submit a report to the Executive Board together with recommendations.

d. In any case where the noncomplying disbursement was made no more than four years prior to the date on which the Managing Director informed the member, as provided for in paragraph (b), the Executive Board may decide either (i) that the member will be called upon to make an early repayment, or (ii) that the nonobservance will be waived.

e. If the decision of the Executive Board is to call upon the member to make an early repayment as provided for in paragraph (d)(i), the member will be expected to repay an amount equivalent to the noncomplying disbursement, together with any interest accrued thereon, normally within a period of 30 days from the date of the Executive Board decision. 
f. A waiver under paragraph (d)(ii) will normally be granted only if the deviation from the relevant performance criterion or other condition was minor or temporary, or if, subsequent to the disbursement, the member had adopted additional measures appropriate to achieve the objectives supported by the relevant decision on the disbursement.

g. If a member fails to meet a repayment expectation under these guidelines within the period established by the Executive Board, (i) the Managing Director shall promptly submit a report to the Executive Board together with a proposal on how to deal with the matter, and (ii) interest shall be charged on the amount subject to the repayment expectation at the rate applicable to overdue amounts under Section II, Paragraph 4 of the Instrument.

h. For the purposes of this decision:

(i) whenever the Managing Director considers there is evidence indicating that a member may have received a noncomplying disbursement, but the nonobservance of the relevant performance criterion or other specified condition was de minimis in nature, as defined in paragraph 1 of Decision No. 13849, the communication referred to in paragraph (b) may be made by a representative of the relevant Area Department;

(ii) if the Managing Director determines that a member has received a noncomplying disbursement and considers that the nonobservance of the relevant performance criterion or other specified condition was de minimis in nature, as defined in paragraph 1 of Decision No. 13849, the notification referred to in paragraph (c) may be made by a representative of the relevant Area Department, and the report of the Managing Director contemplated in paragraph (c) shall, wherever possible, be included in a staff report on the relevant member that deals with issues other than the noncomplying disbursement and shall include a recommendation that the related nonobservance be considered to be de minimis in nature, and that a waiver for nonobservance be granted. In those rare cases when such a staff report cannot be issued to the Board promptly after the Managing Director concludes that a noncomplying disbursement has been made, the Managing Director shall consult Executive Directors and, if deemed appropriate by the Managing Director, a stand-alone report on the noncomplying disbursement will be prepared for consideration by the Executive Board, normally on a lapse-of-time basis; and

(iii) whenever the Executive Board finds that a noncomplying disbursement has been made but that the nonobservance of the relevant performance criterion or other specified condition 
was de minimis in nature as defined in paragraph 1 of Decision No. 13849, a waiver for nonobservance shall be granted by the Executive Board.

\section{APPENDIX II}

Procedures for Addressing Overdue Financial Obligations to the Poverty Reduction and Growth Trust

The following procedures aim at preventing the emergence or accumulation of overdue financial obligations to the Poverty Reduction and Growth Trust (the "Trust") and at eliminating existing overdue obligations. These procedures will be implemented whenever a member has failed to make a repayment of principal or payment of interest to the Trust ("financial obligation").

1. Whenever a member fails to settle a financial obligation on time, the staff will immediately send a cable urging the member to make the payment promptly; this communication will be followed up through the office of the Executive Director concerned. At this stage, the member's access to the Fund's resources, including Poverty Reduction and Growth Trust and HIPC resources, will have been suspended.

2. When a financial obligation has been outstanding for two weeks, management will send a communication to the Governor for that member stressing the seriousness of the failure to meet obligations to the Trust and urging full and prompt settlement.

3. The Managing Director will notify the Executive Board normally one month after a financial obligation has become overdue, and will inform the Executive Board of the nature and level of the arrears and the steps being taken to secure payment.

4. When a member's longest overdue financial obligation has been outstanding for six weeks, the Managing Director will inform the member concerned that, unless all overdue obligations are settled, a report concerning the arrears to the Trust will be issued to the Executive Board within two weeks. The Managing Director will in each case recommend to the Executive Board whether a written communication should be sent to a selected set of Fund Governors, or to all Fund Governors. If it were considered that it should be sent to a selected set of Fund Governors, an informal meeting of Executive Directors will be held to consider the thrust of the communication. Alternatively, if it were considered that the communication should be sent to all Fund Governors, a formal Board meeting will be held to consider a draft text and preferred timing. 
5. A report by the Managing Director to the Executive Board will be issued two months after a financial obligation has become overdue, and will be given substantive consideration by the Executive Board one month later. The report will request that the Executive Board limit the member's use of Trust resources. A brief factual statement noting the existence and amount of arrears outstanding for more than three months will be posted on the member's country-specific page on the Fund's external website. This statement will also indicate that the member's access to the Fund's resources, including Poverty Reduction and Growth Trust and HIPC resources, has been and will remain suspended for as long as such arrears remain outstanding. A press release will be issued following the Executive Board decision to limit the member's use of the Trust resources. A similar press release will be issued following a decision to lift such limitation. Periods between subsequent reviews of reports on the member's arrears by the Executive Board will normally not exceed six months. The Managing Director may recommend advancing the Executive Board's consideration of the reports regarding overdue obligations. The Managing Director may also recommend postponing for up to one-year periods the Executive Board's consideration of a report regarding a member's overdue obligations in exceptional circumstances where the Managing Director judges that there is no basis for an earlier evaluation of the member's cooperation with the Fund.

6. The Annual Report and the financial statements will identify those members with overdue obligations to the Trust outstanding for more than six months.

\section{Removal from the list of PRGT-eligible countries}

7. When a member's longest overdue financial obligation has been outstanding for six months, the Executive Board will review the situation of the member and may remove the member from the list of PRGT eligible countries. Any reinstatement of the member on the list of PRGT eligible countries will require a new decision of the Executive Board. The Fund shall issue a press release upon the decision to remove a member from the list of PRGT eligible countries. A similar press release shall be issued upon reinstatement of the member on the list. The information contained in such press releases, where pertinent, shall be included in the Annual Report for the year concerned.

\section{Declaration of noncooperation with the Trust}

8. A declaration of noncooperation with the Trust may be issued by the Executive Board whenever a member's longest overdue financial obligation has been outstanding for twelve months. The 
decision as to whether to issue such a declaration would be based on an assessment of the member's performance in the settlement of its arrears to the Trust and of its efforts, in consultation with the Fund, to follow appropriate policies for the settlement of its arrears. Three related tests would be germane to this decision regarding (i) the member's performance in meeting its financial obligations to the Trust, taking account of exogenous factors that may have affected the member's performance; (ii) whether the member had made payments to creditors other than the Fund while continuing to be in arrears to the Trust; and (iii) the preparedness of the member to adopt comprehensive adjustment policies. The Executive Board may at any time terminate the declaration of noncooperation in view of the member's progress in the implementation of adjustment policies and its cooperation with the Fund in the discharge of its financial obligations. Upon a declaration of noncooperation, the Fund could also decide to suspend the provision of technical assistance. The Managing Director may also limit technical assistance provided to a member, if in his judgment that assistance was not contributing adequately to the resolution of the problems associated with overdues to the Trust. The Fund shall issue a press release upon the declaration of noncooperation and upon the termination of the declaration. The information contained in such press releases shall be included in the Annual Report(s) for the year(s) concerned. 


\section{INTERNATIONAL MONETARY FUND}

July 12,2021

FUND CONCESSIONAL FINANCIAL SUPPORT FOR LOW INCOME COUNTRIES-RESPONDING TO THE PANDEMICADDITIONAL BACKGROUND INFORMATION

Approved By

Seán Nolan and

Christian Mumssen
Prepared by the Strategy, Policy, and Review Department and the Finance Department.

This supplement contains additional information that may be useful to Directors in considering the staff proposals outlined in "Fund Concessional Financial Support for Low-Income Countries-Responding to the Pandemic." One note examines how the additional borrowing space made available to countries by the temporary increases in PRGT access limits approved in July 2020 and March 2021 has been used. A second note compares the recent and expected evolution of IMF lending to low income countries (LICs) during 2017-22 with staff estimates and projections of financial support to LICs from other international financial institutions over the same period. 


\section{Use of Additional Borrowing Space Following Temporary Increases in}

\section{PRGT Access Limits}

This note examines the use of the additional borrowing space provided by the temporary increases in PRGT access limits introduced in July 2020 and March 2021. To recap:

- The normal annual/cumulative access limits under the PRGT were set at 100/300 percent of quota in May 2019.

- On July 13, 2020, the normal annual access limit (NAAL) to PRGT resources was increased on a temporary basis to 150 percent of quota, with a view to providing additional borrowing space for countries that had sought emergency financing since the onset of the pandemic.

- On March 22, 2021, the NAAL was increased further to 245 percent of quota while the normal cumulative access limit (NCAL) was increased to 435 percent of quota, with both increases initially set to expire at end-June 2021, later extended to end-July 2021.

From July 13, 2020 through end-June 2021, the Executive Board approved six requests for new PRGT arrangements, three requests for augmentation of access under existing PRGT arrangements, and thirteen requests for support under the Rapid Credit Facility (RCF). Details on the access levels approved for these 22 requests are outlined in Table 1.

- Maximum annual access exceeded the pre-pandemic NAAL of 100 percent of quota in four of the six requests for new arrangements, albeit by no more than 20 percent of quota in three of the four cases (Afghanistan, Madagascar and Kenya). ${ }^{1}$ In the fourth case (Sudan), the large initial disbursement was linked to the clearance of arrears to the Fund in the context of the HIPC and beyond HIPC/MDRI debt relief.

- Maximum annual access exceeded 100 percent of quota in one of the three cases involving an augmentation of access under an existing arrangement. An augmentation of the ECF arrangement with Mauritania in September 2020, in an amount equivalent to 15.7 percent of quota, brought annual access under the PRGT to 115.7 percent of quota. Mauritania's access to the RCF in April 2020 had been limited to 74.3 percent of quota, given the NAAL of 100 percent of quota in place at the time.

- Maximum annual access exceeded $\mathbf{1 0 0}$ percent of quota as a result of RCF requests in five of the thirteen cases (Chad, Madagascar, Malawi, Cameroon and Benin), by a maximum of 23 percent of quota: all five countries had pre-pandemic UCT arrangements.

\footnotetext{
${ }^{1}$ In each of the three cases, annual access under the program exceeded 100 percent because of prior drawings under the RCF.
} 
In sum, use of the additional borrowing space created by the temporary increase in PRGT access limits has been modest in scale and aligned with the objectives of this policy change: ${ }^{2}$

(i) three countries that had received emergency financing in the early stages of the pandemic were able to move ahead with new arrangements with somewhat higher levels of initial access; and (ii) six countries that had borrowed under pre-pandemic arrangements were provided with additional access to address the pandemic, five via the RCF and one via an augmentation. An unplanned benefit was the ability to provide Sudan with a large disbursement of concessional resources to facilitate the arrears clearance operation.

\begin{tabular}{|c|c|c|c|c|c|}
\hline Table & RGT Program & $\begin{array}{l}\text { Jmentatic } \\
\text { (As of }\end{array}$ & $\begin{array}{l}\text { and EF Reque } \\
\text { d-June 2021) }\end{array}$ & Approved & ce July 2020 \\
\hline Country & Arrangement Type & Approval Date & $\begin{array}{l}\text { Total Amount Approved } \\
\text { under PRGT }{ }^{1 /} \\
\text { (percent of quota) }\end{array}$ & $\begin{array}{l}\text { Cumulative access } \\
\text { under PRGT }{ }^{2 /} \\
\text { (percent of quota) }\end{array}$ & $\begin{array}{l}\text { Maximum annual access } \\
\text { under PRGT } \\
\text { (percent of quota) }\end{array}$ \\
\hline \multicolumn{6}{|c|}{ Program requests (6) } \\
\hline Afghanistan & ECF & $11 / 6 / 2020$ & 80 & 139 & 107 \\
\hline Madagascar & ECF & $3 / 29 / 2021$ & 90 & 281 & 120 \\
\hline Kenya & ECF-EFF & $4 / 2 / 2021$ & 75 & 175 & 114 \\
\hline Senegal & SBA-SCF & 6/7/2021 & 47 & 80 & 26 \\
\hline Uganda & ECF & $6 / 28 / 2021$ & 200 & 300 & 75 \\
\hline Sudan & ECF & $6 / 28 / 2021$ & 275 & 275 & 167 \\
\hline \multicolumn{6}{|c|}{ Augmentation requests (3) } \\
\hline São Tomé and Príncipe & ECF & $7 / 27 / 2020$ & 100 & 185 & 97 \\
\hline Mauritania & ECF & 9/2/2020 & 106 & 189 & 116 \\
\hline Gambia, The & ECF & $1 / 15 / 2021$ & 88 & 137 & 81 \\
\hline \multicolumn{6}{|c|}{ RCF requests with program in place (1) } \\
\hline Sierra Leone & RCF (concurrent with ECF) & $3 / 15 / 2021$ & 17 & 207 & 82 \\
\hline \multicolumn{6}{|c|}{ RCF requests without program in place (12) } \\
\hline Chad & RCF & $7 / 22 / 2020$ & 35 & 295 & 115 \\
\hline Lesotho & RFI-RCF & $7 / 29 / 2020$ & 17 & 32 & 17 \\
\hline Madagascar & RCF & $7 / 30 / 2020$ & 50 & 281 & 113 \\
\hline Malawi & RCF & $10 / 2 / 2020$ & 52 & 211 & 123 \\
\hline Cameroon & RCF & $10 / 21 / 2020$ & 40 & 255 & 120 \\
\hline South Sudan & RCF & $11 / 11 / 2020$ & 15 & 65 & 15 \\
\hline Nicaragua & RFI-RCF & $11 / 20 / 2020$ & 17 & 17 & 17 \\
\hline Benin & RFI-RCF & $12 / 21 / 2020$ & 33 & 197 & 108 \\
\hline Myanmar & RFI-RCF & $1 / 12 / 2021$ & 17 & 33 & 33 \\
\hline Guinea-Bissau & RCF & $1 / 25 / 2021$ & 50 & 118 & 50 \\
\hline Tonga & RCF & $1 / 25 / 2021$ & 50 & 50 & 50 \\
\hline South Sudan & RCF & $3 / 30 / 2021$ & 50 & 65 & 65 \\
\hline \multicolumn{6}{|c|}{$\begin{array}{l}\text { 1/ For augmentation requests, augmentations are included in total amount approved. } \\
\text { 2/ As of end-June } 2021 . \\
\text { Note: Countries with annual/cumulative access levels in excess of } 100 / 300 \text { percent of quota are marked in blue; countries with } \\
\text { annual/cumulative access levels in excess of } 150 / 300 \text { percent of quota are marked in green. }\end{array}$} \\
\hline
\end{tabular}

\footnotetext{
2 See "Temporary Modification to the Fund's Annual Access Limits" (June 30, 2020), paragraph 3 for a discussion of these objectives.
} 


\section{IMF Financial Support for LICs in a Comparative Context, 2017-2022}

This note compares the evolution of IMF lending to LICs during 2017-2022 with trends in financial support to LICs provided by other international financial institutions (IFIs), focusing on the World Bank, the African Development Bank (AfDB), and the Asian Development Bank (AsDB). Projections for 2021-22 are those of IMF staff, informed by published financial information and projections from the other institutions. Projections for the AfDB and the AsDB, in particular, may have been revised significantly from earlier documents and should be viewed as illustrative. That said, the projections show the broad trends in financial commitments from the four IFIs as a group and in the Fund's share of total commitments.

\section{Data presented are on the financing commitments made by each institution during the} relevant calendar year. Commitments can differ substantially from disbursements in any given year-both because project loans approved during the year (as with Fund arrangements) will disburse over several years into the future, and because project loans and Fund arrangements approved in previous years will be disbursing in the current year. A step increase in financing commitments made in year T will usually take some years to be fully reflected in loan disbursements, both for the MDBs and the Fund.

The normal lag between financial commitments and disbursements did not apply to Fund financial support to LICs in 2020, because the bulk of that support was provided via the Fund's emergency financing (EF) instruments. Board approval of EF requests usually lead to full disbursement of the loan amounts within a few days; also, in the early months of the pandemic, measures to accelerate the processing times of EF requests were implemented to facilitate the prompt provision of financial assistance.

\section{Trends in financial support to LICs during 2017-2022 are illustrated in Figures A2.1 and A2.2. ${ }^{3}$}

Data for World Bank financial commitments on a calendar year basis are obtained by a simple splicing of fiscal year data. ${ }^{4}$ The main takeaways from these estimates are:

- Fund financing commitments to LICs surged in 2020, accounting for almost one-quarter of total financing to LICs from the four IFIs, up from an annual average of 8 percent of total financing during 2017-2019.

- The annual level of Fund financing commitments is expected to ease somewhat by 2022, accounting for about 18 percent of total projected IFI financing. ${ }^{5}$

\footnotetext{
3 Projections of Fund commitments in 2021-2022 are aligned with the Baseline projections discussed in the main text; the numbers include financing provided under both the PRGT and the GRA.

4 The World Bank's fiscal year runs from July 1 through June 30. The calendar year estimate presented here for 2019 equals half the amount committed in FY2019 (ending in June 2019) plus half the amount committed in FY2020.

${ }^{5}$ Underestimation of likely commitments by the AsDB and the AfDB in 2021-22 would imply that the Fund's share of total commitments is overstated.
} 
- The Fund share of total IFI disbursements during 2020 was likely significantly higher than the estimated 24 percent share of IFI commitments, given the central role of fast-disbursing emergency financing in Fund support during this year. With the projected shift back to multiyear arrangements in 2021-22, the Fund share of disbursements will be lower than its share of new commitments in these years, since most of the Fund financing commitments made in 2020 were disbursed immediately.

- The combined level of financing for LICs from all four IFIs is expected to reach some $\$ 56$ billion in 2021-a very sharp increase from the levels of support provided during the pre-pandemic years. Financing is projected to fall slightly in 2022, but could be significantly higher with enhanced shareholder support for IFI concessional lending and grant finance.

Figure 1. IFIs' Support to LICs (USD billion) ${ }^{1 / 2 / 3 /}$

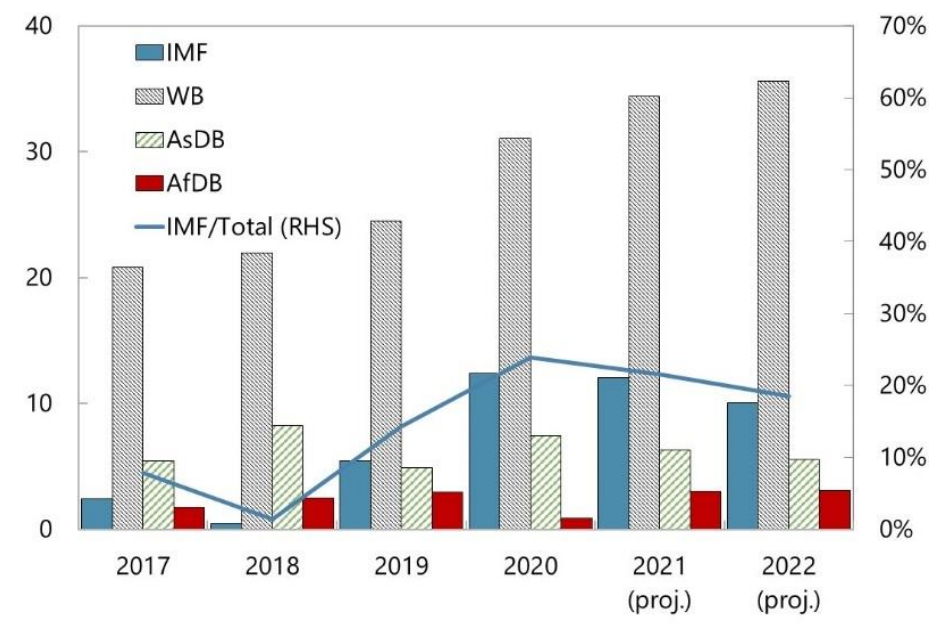

Sources: WB, ADB, AfDB, and IMF staff calculations

${ }^{1 / E l i g i b i l i t y ~ f o r ~ c o n c e s s i o n a l ~ f i n a n c i a l ~ a s s i s t a n c e ~ v a r i e s ~ a c r o s s ~ t h e ~ i n s t u t i o n s . ~ T o ~ f a c i l i t a t e ~ c o m p a r i s o n, ~ t h e ~ s p e c i f i c a t i o n ~ o f ~ L I C S ~}$ used here is as follows: IMF-all PRGT-eligible countries; WB-all IDA-eligible countries, excluding Pakistan and Nigeria; AsDBall countries currently eligible for concessional loans or grants, excluding Pakistan; AfDB—all countries eligible for African Development Fund (ADF) resources.

2/ Figures/projections are for calendar years: WB financing in S2 2022 is assumed to be 10 percent higher than in S2 2021.

3/ 2021-2022 figures are IMF staff projections. Projections for the IMF include PRGT and GRA commitments, and projections for the World Bank include both IDA and IBRD loan commitments. 
Figure 2. IFls' Support to LICs (USD billion) ${ }^{1 / 2 /}$

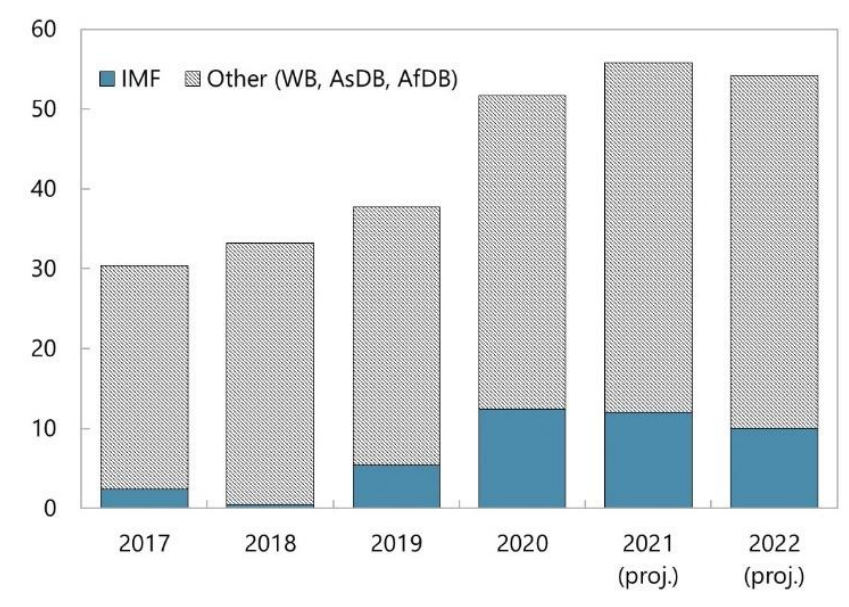

Sources: WB, AsDB, AfDB, and IMF staff calculations

1/ For country groups, see footnote 1 in Figure 2.

2/ 2021-2022 figures are IMF staff projections. Projections for the IMF include PRGT and GRA commitments, and projections for the World Bank include both IDA and IBRD loan commitments. 